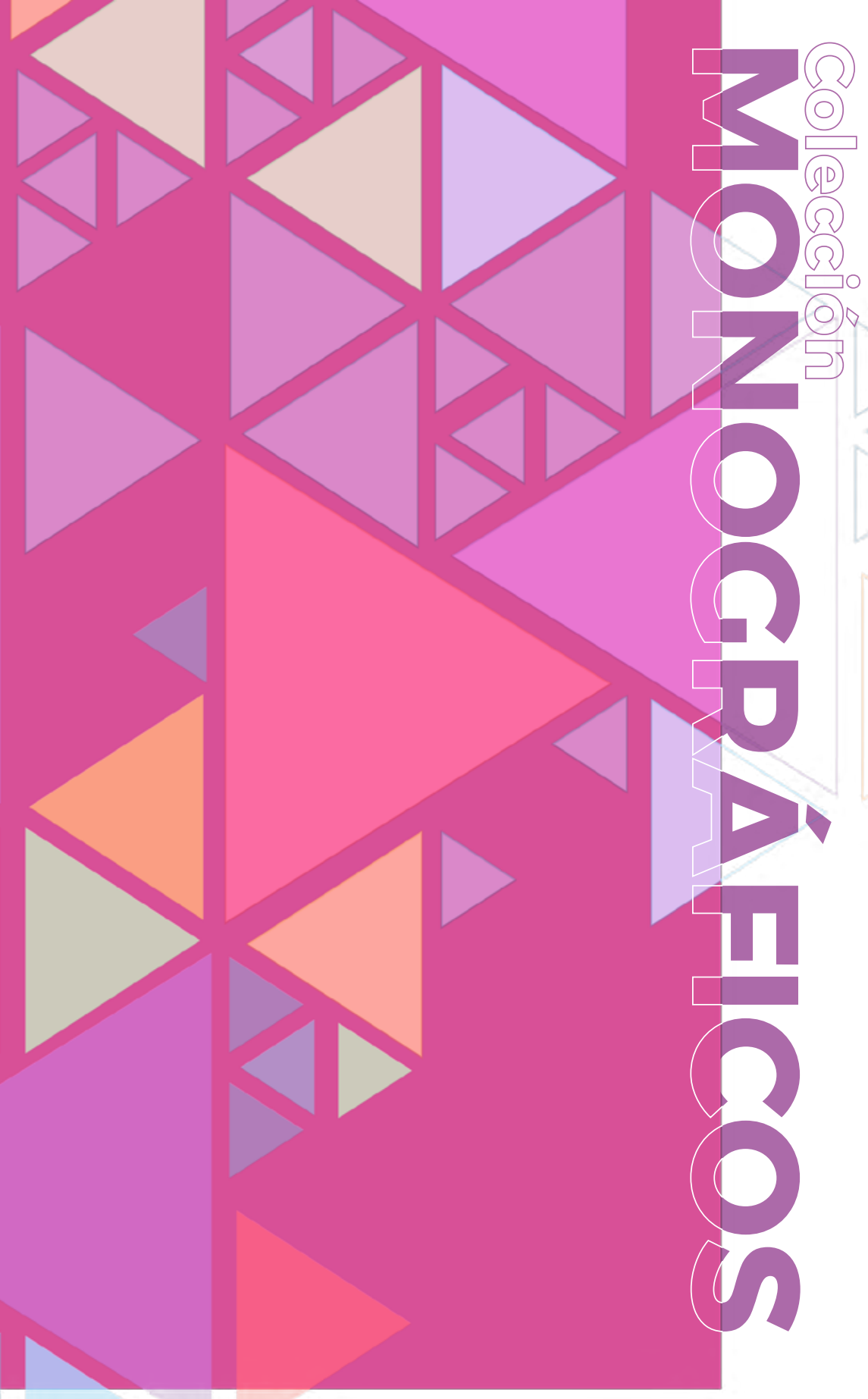

Responsabilidad social empresarial:

Prácticas y perspectivas de la gestión organizacional en el contexto ecuatoriano

Mariana Del Rocío Verdezoto Reinoso Compiladora

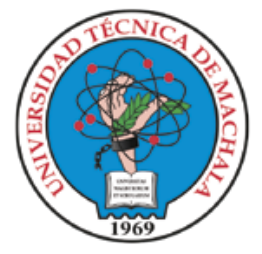


Ediciones UTMACH

147 pág: $21 \times 29,7 \mathrm{~cm}$

Colección Monográficos

Título: Responsabilidad social empresarial: prácticas y perspectivas de la gestión organizacional en el contexto ecuatoriano - Mariana

Del Rocío Verdezoto Reinoso (Compiladora)

Primera edición 2020

ISBN: 978-9942-24-140-5

CDD 338,9

1. Desarrollo y crecimeinto económico,

2. Empresa y gestión

--Temas relacionados

Publicación PDF 
Responsabilidad social empresarial: prácticas y perspectivas de la gestión organizacional en el contexto ecuatoriano

Mariana Del Rocío Verdezoto Reinoso

COMPILADORA

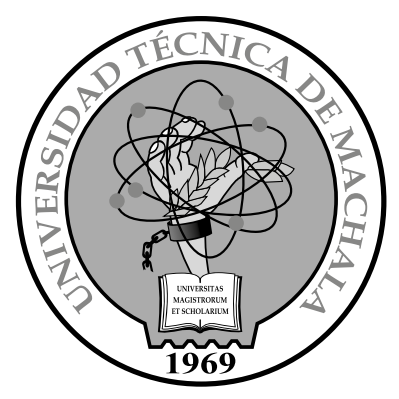


Autoridades

César Quezada Abad - Rector Amarilis Borja Herrera - Vicerrector Académico Jhonny Pérez Rodríguez - Vicerrector Administrativo

Luis Brito Gaona

Director de Investigación

(c) Ediciones UTMACH Colección Monográficos

Título original:

Responsabilidad social empresarial: prácticas y perspectivas de la gestión organizacional en el contexto ecuatoriano

ISBN: 978-9942-24-140-5

(c) Mariana Del Rocío Verdezoto Reinoso

(Compiladora)

(c) Autores de capítulos

DOI: http://doi.org/10.48190/9789942241405

Primera edición 2020

Karina Lozano Zambrano Jefe editor / Diseño y edición editorial

Fernanda Tusa Jumbo - Corrector de estilos Jorge Maza-Cordova - Asesor tecnológico

Karla Ibañez y Cyndi Aguilar - Equipo de difusión

Este obra está bajo una licencia de Creative Commons Reconocimiento No Comercial.

Esta licencia permite a otros entremezclar, ajustar y construir a partir de su obra con fines no comerciales, siempre y cuando le reconozcan la autoría y sus nuevas creaciones estén bajo una licencia con los mismos términos. 


\section{Contenido}

Pág Acciones de responsabilidad social en

11 la Universidad Técnica de

Responsabilidad social en el sector público del Ecuador

Pág

31

Pág Ámbito jurídico normativo de la responsabilidad social empresarial

51 (RSE) en el sector bananero del

Ecuador

Costeo de actividades por responsabilidad social empresarial en el sector bananero

\section{Pág}

97

El emprendimiento como eje económico de las familias en la ciudad de Loja

Responsabilidad Social Empresarial y el emprendimiento comunitario femenino en el sector turístico de Santa Elena - Ecuador 


\section{Introducción}

Sin duda alguna la Responsabilidad Social Empresarial (RSE), ha logrado una transcendencia desde su aparición, y hoy en día, se puede vislumbrar su prevalencia en el tiempo de modo indefinido, debido a su posicionamiento en diversos contextos de las sociedades en el mundo como empresas, instituciones, organizaciones sin fines de lucro, universidades, entre otros.

Ecuador, por su parte está inmerso en esta tendencia que viene gestándose de manera globalizada y que cada vez se impone con más fortaleza. Es por ello que, el sistema económico ecuatoriano, en sus diversas formas de organización económica: pública, privada mixta, popular y solidaria, han promovido diversas acciones y buenas prácticas socialmente responsables en su gestión organizacional, abocados a lineamientos y directrices publicadas por organismos internacionales de la RSE, apoyados en consultorías especializadas, establecimientos de alianzas estratégicas, promulgación de disposiciones legales con criterios de responsabilidad social que preserven los recursos de la economía nacional, la consecución de los objetivos organizacionales y por ende el desarrollo del país.

Ante este escenario, la universidad como cerebro de una nación, es la principal protagonista al llamado de las necesidades sociales de su contexto. En este sentido, la Universidad Técnica de Machala, da respuesta a través del eje sustantivo de la investigación desempeñado por sus docentes investigadores en pro de una contribución al Plan Nacional de Desarrollo 2017 - 2021 en lo que concierne al Objetivo 3: Garantizar los derechos de la naturaleza para las actuales y futuras generaciones, específicamente con la Política 3.5; y, al Objetivo 5: Impulsar la productividad y competitividad para el crecimiento económico sostenible de manera redistributiva y solidaria, en cuanto a su Política 5.8.

Dentro de este marco, se concibe a la RSE desde un enfoque estratégico, que precisas dos perspectivas: como integración de negocio y sociedad en búsqueda de posicionamiento de mercado; $y$, desde la perspectiva fundamentada en la asignación de recursos, éstas ligadas a una ventaja competitiva: buena imagen y reputación, especialización y diferenciación de productos y servicios, tal como se puede apreciar en el contenido de los capítulos de esta obra colectiva, producto de la labor investigativa de un equipo de docentes, quienes han predispuesto el debido cuidado profesional, nivel y pertinencia de los contenidos, directrices, lineamientos y estructuras establecidos por la Colección Monográficos de la Editorial UTMACH.

De acuerdo con esta óptica, el presente monográfico tiene como propósito mostrar las prácticas y perspectivas de Responsabilidad Social Empresarial desde los 
contextos organizacionales: académico, productivo, de prestación de servicios, tanto en ámbito público como en el privado en diversas localidades de Ecuador, a través de los resultados de investigación de cada uno de los autores de los capítulos constituyentes de esta obra. La información se presenta en estructura de artículo científico, que, aunque permite al lector la facilidad de entender y articular el contenido de cada uno de sus capítulos de manera independiente, a la vez, instituyen una complementariedad de un corpus global relativo a la RSE.

De esta manera, tomando en consideración lo antes expuesto, cada uno de los capítulos del presente monográfico es un aporte investigativo para el lector, mismo que se ha sistematizado en el ámbito público en los capítulos I y II; finalmente, a partir del capítulo III al capítulo VI, prosigue la RSE en el contexto privado, lo cual está dado por los siguientes aspectos:

En el capítulo I: Acciones de Responsabilidad Social en la Universidad Técnica de Machala: percepción de docentes, se exhibe los resultados de investigación sobre la percepción que tienen los docentes de la Universidad Técnica de Machala sobre acciones de Responsabilidad Social, los mismos que de acuerdo a los informantes del estudio infieren el predominio del desconocimiento de concepciones elementales de Responsabilidad Social Universitaria, RSU; así a mismo, consideran que la implementación de la RSU contribuiría a la mejora del sistema académico; y, se pone de manifiesto la recomendación de la instauración de estamentos de RSU con el compromiso de partes interesadas en el logro de objetivos institucionales a largo plazo.

El capítulo II: Responsabilidad social en el sector público del Ecuador, expone el análisis de las prácticas de Responsabilidad Social aplicadas al sector público, frente a sus principales categorías, aportando a través de su objeto de estudio, Ministerio del Interior de Ecuador, derivaciones concluyentes tales como, la necesidad de prácticas socialmente responsables desde su política y objetivos institucionales; carencia de normativas legales específicas para su regulación; y, la concepción de Responsabilidad Social, prácticas de transparencia y rendición de cuentas se encuentran ligados al cumplimiento relacionados con aspectos económico - legal impositivos y medioambientales agnados a los impactos en el desarrollo territorial; este último, como innovación pública mediante la Responsabilidad Social, tributaría al desarrollo de la sociedad y el Estado.

En el capítulo III: Ámbito jurídico normativo de la Responsabilidad Social Empresarial (RSE) en el sector bananero de Ecuador, se presenta un análisis de la 
incidencia del marco normativo jurídico respecto a los principios de la RSE en las áreas de los derechos humanos, ambientales y laborales del sector bananero del Ecuador, mismo que podría contribuir a los interesados a concientizar acerca de la relevancia de la aplicación de las normativas de RSE, así como la adecuación de la normativa interna a los beneficios que trae consigo una actuación social responsable en el logro de objetivos organizacionales.

En lo que corresponde al capítulo IV: Costeo de actividades por Responsabilidad Social Empresarial en el sector bananero, se analiza qué sistema de acumulación de costos contribuye de mejor manera al Sistema de Información Gerencial en la esfera de la Responsabilidad Social Empresarial, para la evaluación del impacto social - medioambiental que las actividades productivas representen para el entorno, la sostenibilidad y la ventaja competitiva de las empresas bananeras de la provincia de El Oro, para lo cual efectúa una caracterización de las actividades del proceso productivo e identifica la cadena de valor en las empresas bananeras y las actividades relativas a la RSE como una oportunidad para llevar a cabo un control ambiental, para la determinación de la ventaja competitiva a través de actividades esenciales y generadores de valor conducentes a la determinación de un sistema de Costeo Basado en Actividades para este tipo de organizaciones. Así también, se ha estimado a la RSE como herramienta en la ventaja competitiva en las empresas bananeras.

Por su parte, el capítulo V: El emprendimiento como eje económico de las familias en la ciudad de Loja, se enfoca a explicar la influencia del emprendimiento como eje económico en las familias en la ciudad de Loja, mediante la determinación del crecimiento de los emprendimientos y la comprensión de la influencia de éstos en las economías de las familias lojanas, para llegar a término que las empresas familiares son clave en el crecimiento económico a largo plazo a escala internacional, no obstante, traen consigo una escasa noción de innovación así como la necesidad de transición generacional eficiente que trae implícito como obstaculizador un nexo emocional. Por otra parte, indica el punto de interés de las investigaciones en torno a ellas, por las preeminencias manifiestas en el estudio, pese a encontrarse en un inicial proceso evolutivo. Además, señalan a Loja como tenedora importante de emprendedores, esto debido a la interrelación de entidades público - privadas para la formación de emprendedores y la articulación de ideas de negocios sostenibles.

Por último, el capítulo VI: Responsabilidad Social Empresarial y el emprendimiento comunitario femenino en el sector turístico de Santa Elena - Ecuador, el 
objetivo fue determinar la aplicabilidad de la responsabilidad social empresarial y la participación del género femenino en el desarrollo de los emprendimientos comunitarios turístico de Santa Elena - Ecuador, revelando destacadamente que la tendencia de los tres elementos de la RSE: alcance, impacto e indicadores, las conservan en sus gestiones, considerando a la sociedad o sector circundante, resalta las acciones alineadas al Producto/Servicio ecológico; continuado por compromisos con la comunidad y de responsabilidad con cliente interno/externo. Así también se expresa las necesidades de los turistas y emprendedoras comunitarias para la mejora en la prestación de servicios turísticos, que van desde adecuaciones ecológicas, establecimiento de alianzas estratégicas con recurso humano que posea fortaleza en el dominio del idioma inglés hasta la implementación de plataformas tecnológicas importantes para su progreso.

Cada sección incluye las respectivas referencias bibliográficas, documentos elegidos, revisados y analizados diligentemente por sus autores, para fundamentar de modo sólido el sustento teórico del estudio que han decido incursionar sobre la RSE.

Por último, es conveniente anotar que se pone sobre la palestra estudios que evidencian la necesidad de fortalecer la RSE en las organizaciones, los cuales se constituyen en aristas y objeto de futuras investigaciones, por lo que invito al lector a adentrarse en la presente obra a fin de disponer de un mayor entendimiento sobre RSE en la gestión de organizaciones en el contexto ecuatoriano. 



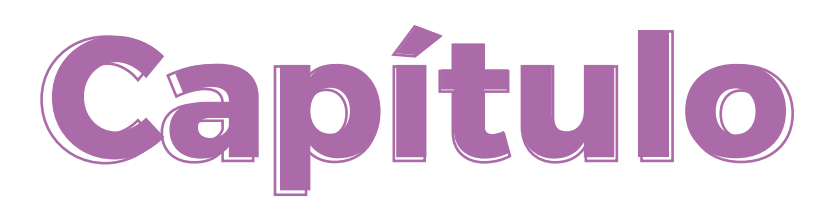

Acciones de responsabilidad social en la Universidad Técnica de Machala: percepción de docentes 
Acciones de responsabilidad social en la Universidad Técnica de Machala: percepción de docentes

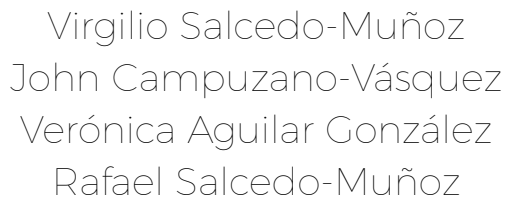

Autores 


\section{Acciones de responsabilidad social en la Universidad Técnica de Machala: percepción de docentes}

\section{Virgilio Salcedo-Muñoz}

Economista Agropecuario-Universidad Técnica de Machala; Ingeniero Comercial en Contabilidad y Auditoría- Universidad Técnica de Machala; Diplomado Superior en Sistemas de Pensiones y Seguridad Social-Universidad Autónoma de México; Diplomado superior en Tributación-Universidad de Guayaquil; Magister en Tributación y Finanzas Universidad de Guayaquil; Candidato a Doctor en Ciencias Económicas Universidad del Zulia Venezuela; Autor y Coautor de artículos indexados en revistas corriente principal y regional y de capítulos de libros; Profesor Titular Agregado 3 Universidad Técnica de Machala. Miembro del Grupo de Investigación en Desarrollo Económico Territorial (GIDET)

\section{John Campuzano-Vásquez}

Economista -Universidad Estatal de Guayaquil; Magister en Docencia Universitaria e Investigación, Magíster en Administración de Empresas - Universidad Técnica de Machala; Diplomado Superior en Gestión del Talento Humano -Universidad Técnica Particular de Loja; Candidato a Doctor en Ciencias Económicas Universidad del Zulia Venezuela; Autor y Coautor de artículos indexados en revistas corriente principal y regional y de capítulos de libros; Profesor Titular Agregado 3 Universidad Técnica de Machala. Director Miembro del Grupo de Investigación en Desarrollo Económico Territorial (GIDET)

Verónica Aguilar González

Licenciada en Contabilidad y Auditoría-Universidad Técnica de Machala; Ingeniera Comercial con Mención en Contabilidad y Auditoría-Universidad Técnica de Machala; Diplomado superior en Tributación-Universidad de Guayaquil; Magister en Tributación y Finanzas Universidad de Guayaquil; Autor y Coautor de artículos indexados en revistas corriente principal y regional y de capítulos de libros; Consultora Independiente.

Rafael Salcedo-Muñoz

Ingeniero Civil- Universidad Técnica de Machala; Autor y Coautor de artículos indexados en revistas corriente principal y regional y de capítulos de libros; Docente del Instituto Superior Tecnológico Ismael Perez Pazmiño; Consultor independiente.

DOI: http://doi.org/10.48190/9789942241405.1 


\section{Resumen}

El presente trabajo investiga la percepción que tienen los docentes de la Universidad Técnica de Machala sobre acciones de Responsabilidad Social, para ello se aplicó una encuesta con 20 preguntas en las cuales se indaga la presencia de iniciativas y programas enmarcados con la Responsabilidad Social Universitaria y como estas pueden afectar a docentes y demás usuarios internos y externos. La investigación es de tipo descriptivo, con enfoque metodológico cuantitativo. Los resultados arrojan que la universidad no tiene una estructura administrativa especializada en Responsabilidad Social Universitaria mediante la cual se desarrollen y ejecuten programas, acciones, proyectos o iniciativas que la muestren como una institución moderna y adecuada a los cambios estratégicos. Sin embargo, se destaca que de manera vertical se desarrollan ciertas acciones o actividades que están ligadas a ésta, lo que permite recomendar la creación legal de instancias formales y sostenibles de Responsabilidad Social Universitaria que comprometan a docentes y demás stakeholders en la consecución de objetivos institucionales de largo plazo vinculantes con el quehacer de todos los que hacen la comunidad universitaria de la provincia de El Oro.

Palabras claves: responsabilidad Social Universitaria, Docentes, Educación superior, Participación social, Acciones.

\section{Introducción}

El rol que desempeña la Universidad, debe superar a las clásicas funciones asignadas a la misma: gestión, docencia, investigación y extensión (Dominguez, 2009; Francois Vallaeys, De la Cruz, \& Sasia, 2009; Gaete Quezada, 2010; Moya, 2010). Así, además de la formación, la investigación y la transferencia de conocimiento y tecnología, las instituciones de educación superior deben asumir un compromiso, serio y constante, con la sociedad. En palabras de Benavides (como lo citó Aldeanueva, 2011), "el buen gobierno, la gestión sostenible, la defensa del medioambiente y las acciones sociales y solidarias conforman los valores que distinguen e identifican a las universidades socialmente responsables”. (p. 39).

Esta característica que potencia las funciones básicas de la academia es la Responsabilidad Social Universitaria (RSU), definida por Vallaeys (2008) como una obligación que toda institución o empresa debería tener y la cual debe ser practicada a diario; en esa misma línea y definición los autores Valarezo \& Túñez ( 2014) acotan que la RSU “dinamizará el funcionamiento interno de la organización, y facilitará el diálogo y la construcción de vínculos con otros actores sociales, para juntos articularse a un proyecto planificado de desarrollo sostenible de la sociedad" (p. 87). 
En ese sentido los autores Larrán \& Andrades (2015) mencionan que la RSU responde primordialmente a la necesidad de realizar una reflexión sobre la coherencia entre lo enunciado en la misión, los estatutos de la universidad y el quehacer diario. Además otro de los factores que identifican Gaete \& Bratos (2012) es que las investigaciones enmarcadas en la RSU deben consistir en visibilizar las experiencias académicas y de gestión, a través de las cuales la universidad hace presencia en territorios, trabajando en problemáticas concretas y relacionándose con comunidades y con diversos actores sociales.

Por otro lado Vallaeys (2006) complementa la conceptualización de RSU al indicar que:

"mediante ella se compenetra cada una de las partes orgánicas de la Universidad, incluyendo en una misma estrategia de gestión a la administración, la docencia, la investigación y todos los demás servicios universitarios vinculados con la comunidad fuera de la organización” (p.5).

La RSU está totalmente vinculada con las Instituciones de Educación Superior (IES), está cumple un rol crucial para el buen desarrollo y progreso de las sociedades. Es así que la Universidad Técnica de Machala (UTMach) puede potenciar su proyección académica, tomando en cuenta su función central que es la de formar estudiantes con visión académica holística integral, que fusione lo académico con lo social, ambiental y económico bajo una perspectiva humanística acorde a lo que promueve la RSU (Salcedo, Brito, \& Campuzano, 2015).

Bajo estos antecedentes se realiza la presente investigación, que se enfoca en determinar la percepción que tienen los docentes de este centro educativo sobre acciones de Responsabilidad Social promovidas desde UTMach.

\section{Bases Teóricas}

\section{Conceptualización de la RSU}

Es importante destacar el concepto de RSU, el cual desde la óptica de Salcedo, Nuñez, Campuzano, Saltos, \& Nuñez (2017) la definen como políticas y estrategias para proyectar y expandir las instituciones de educación superior, mediante programas y proyectos que busquen alcanzar la vinculación académica con la sociedad.

En relación con el objeto de estudio, es necesario analizar brevemente el concepto de Responsabilidad Social Empresarial para un mejor entendimiento del tema. En este contexto Vallaeys (2008) menciona que no es nada más que una estrategia corporativa en la cual se invierte una fracción importante de su presupuesto en acciones sociales y medioambientales, funcionando de igual manera para las instituciones de educación superior pero con una estrategia que apunta a su vinculación social y productiva. 
Así mismo la responsabilidad social en general, se da cuando una organización o institución que es consciente del compromiso, obligación y deber de contribuir con la sociedad para que viva dentro de principios de justicia, compromiso y equidad social, económica y ambiental. En investigaciones recientes Valleys (2019) destaca que la RSU es una nueva política de gestión universitaria que redefine la tradicional extensión y proyección social solidaria, introduciendo un enfoque global de los impactos administrativos y académicos en todos los procesos de la universidad.

Complementando, la RSU es una política de calidad ética del desempeño en la comunidad universitaria que se da a través de la gestión responsable de los impactos educativos, cognitivos, laborales, sociales y ambientales que la universidad produce, en una conversación participativa con la sociedad para poder así promover el desarrollo humano sustentable (Medina et al., 2017).

La RSU como estrategia que ayuda en los procesos administrativos, académicos y laborales en las universidades es una variante de la RSE (Vera J, 2015) que nace a inicios de la década de los cincuenta con Bowen (1953), la cual tiene el reconocimiento ético, político y social, cuyo objeto es buscar el bien común, cumpliendo así varias funciones de vital importancia en las universidades contribuyendo en la búsqueda del bienestar de cada uno de sus stakeholders sean estos internos o externos, por ese motivo algunas universidades han implementado este tipo de acciones.

Ampliando la visión del concepto de RSU, Sacco (2009) citando a Bacigalupo (2007, pág.1) propone la siguiente definición de RSU “enfoque ético del vínculo mutuo entre universidad y sociedad, compromiso moral irrenunciable que genera nuevo conocimiento relevante para solución de problemas sociales, y permite la aplicación directa del saber científico y tecnológico, así como una formación profesional más humanitaria”.

Para consolidar su concepto lo sintetiza en cinco pilares básicos, que se resumen en la siguiente figura.

Figura 1. Visión básica del concepto de RSU
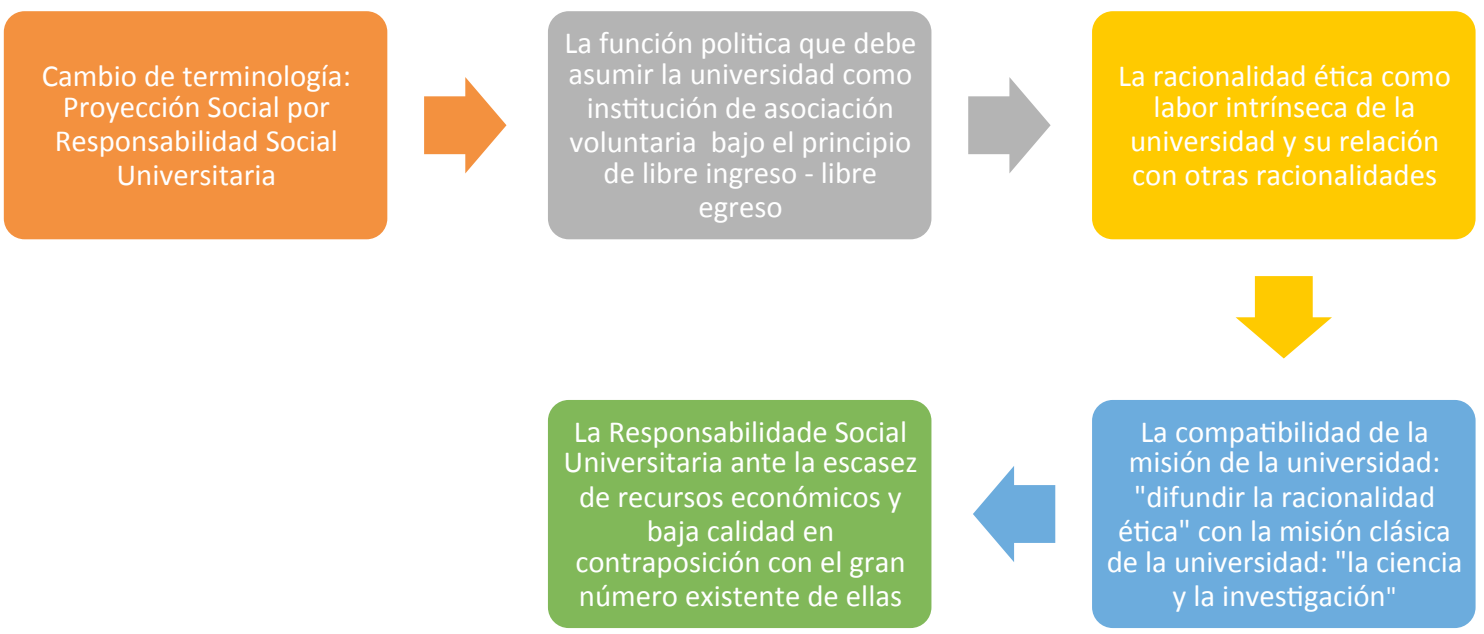

Nota: en base a (Sacco, 2009 citando a Eduardo Bacigaluo 2007) 


\section{Objetivos de la RSU}

La RSU busca formar estudiantes capacitados para comprometerse con sus acciones, dar soluciones a los problemas de su entorno, ser empáticos, justos, solidarios y éticos, promover la democracia y participación, que sepan escuchar e intercambiar ideas para promover el bienestar común bajo principios de democracia (Ramírez, Moctezuma, \& González, 2017).

La responsabilidad social forma parte de la misión de la universidad, por consiguiente Valle \& Pérez (2016) mencionan que las instituciones y empresas deberían cumplir y dar a notar su actuación responsable ante la sociedad, especialmente para las personas interesadas en el tema. La IES debe cumplir con el requisito de transparencia y diálogo con agentes públicos o grupos de interés.

Desde el punto de vista de Raza \& Loachamín (2015) la educación superior se ha reconocido desde siempre como un factor de movilidad social. La RSU se muestra como un reto, siendo así que los centros de educación superior se comprometan no solo a la formación de profesionales competentes, sino también a formar hombres y mujeres sensibles a las problemáticas de la comunidad, comprometidos con el progreso de la nación.

En cuanto a la educación superior pública la United Nations Educational Scientific and Cultura Organization (UNESCO) (2009) afirma que es responsable de comprender los problemas sociales en sus diferentes dimensiones y mejorar la capacidad de las personas para enfrentarlos; se encarga de contribuir al desarrollo sostenible y el bienestar de la población, y para esto deben contar con autonomía, que contribuirá con la excelencia, la tenacidad, la capacidad y la responsabilidad social.

En esta misma línea López, Zalthen, \& Cervantes (2016) indican que otro de los objetivos se plasma en las acciones de comunicación con sus grupos de interés tanto interno como externo pueden formar parte de la responsabilidad social para poder así alcanzar unos acercamientos e interacciones adecuadas. Es de suma importancia que las universidades del país instituyan dentro de sus políticas institucionales a la RSU como un modelo de gestión integral.

\section{Principios, estrategias y valores de la RSU}

Respecto a los principios de la RSU; De la Cuesta, De la Cruz, \& Rodríguez (2015) destacan que se fundamentan en 5 pasos: administrar efectiva y eficientemente los recursos; promover comportamientos éticos, inclusivos y de compromiso profesional para la comunidad; cooperar en la resolución de problemas en el entorno social; aplicar estrategias de gestión interna para satisfacer académicamente a la comunidad universitaria; insertar a la universidad avances tecnológicos, económicos, culturales y humanos.

Por otra parte, la investigación de Olarte \& Ríos, (2015) establece varios enfoques mediante los cuales se ejecuta responsabilidad social como los humanistas, pedagógico, ético, socio-curricular los mismos que proponen estrategias de apren- 
dizaje con eje central en la investigación. De este modo se trata de transformar las universidades, adaptándose a las necesidades de los estudiantes, promoviendo el bienestar por medio de la implementación de políticas y acciones de mejoramiento del clima organizacional.

No obstante, existen pocos enfoques cualitativos sobre la percepción de los docentes acerca de la RSU y el rol que cumplen para incorporar en el proceso educativo, es de vital importancia que los docentes se capaciten, promuevan la responsabilidad Social para una mejor convivencia con todos que conforman la Universidad (Gaete, 2016)

Mediante el presente gráfico se describe el proceso de RSU mediante cuatro pasos a implementarse en las Instituciones de Educación Superior que se fortalecen con acciones, estrategias, iniciativas y programas propuestos desde organismos públicos y privados de carácter nacional e internacional.

Figura 2. Proceso de responsabilidad social universitaria a implementarse

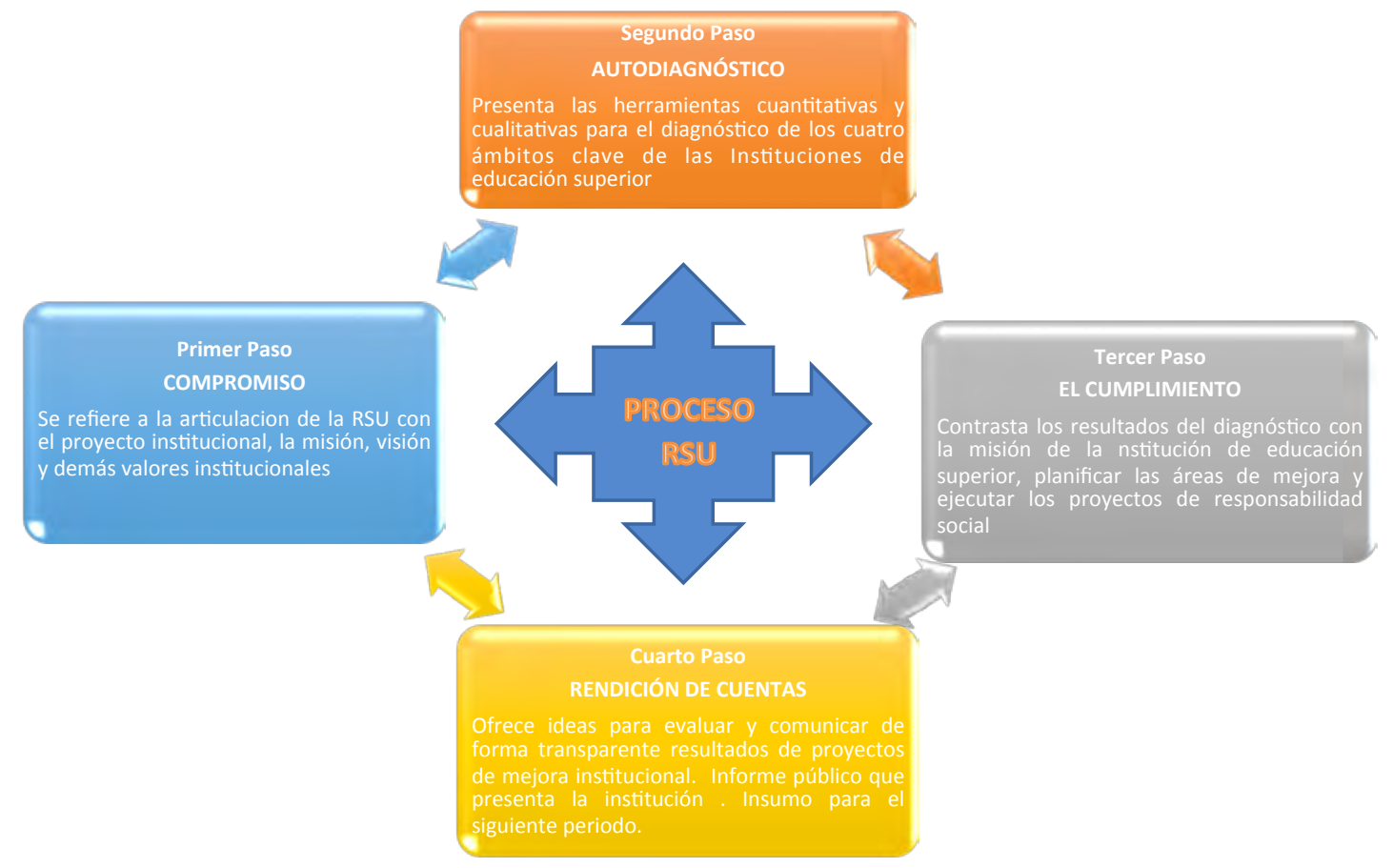

Nota: base en Londoño (2013) citando a Vallaeys, De la Cruz y Sasia (2009)

En el año 2002 se presentó en Chile el proyecto "Universidad Construye País" mediante alianza entre varias universidades, organismos gubernamentales y no gubernamentales con el propósito de expandir el concepto y empoderar la práctica de la RSU en las IES chilenas. En dicho documento se resaltó los cuatro pilares básicos de la universidad (Docencia, Investigación, Extensión y Gestión) los cuales deben "estar iluminados por los principios y valores que caracterizan la RSU” (Universidad: Construye Pais, 2002, p. 7). Esta relación de principios, valores y procesos claves se los interpreta en mejor medida en la figura 3. 
Figura 3. Relación principios y valores de la universidad socialmente responsable

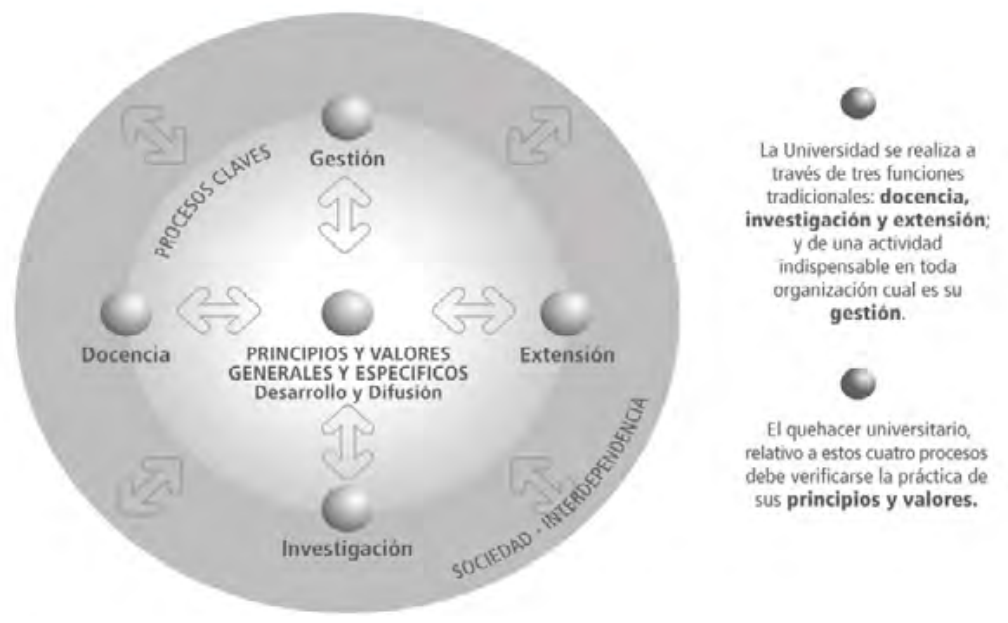

Nota: Tomado de (Universidad: Construye Pais, 2002)

En el proyecto de RSU de la universidad Chilena, desde la óptica de Vera (2015), los principios y valores de las universidades que aplican RSU, quedan agrupados en tres tópicos, que se los representa adaptados en el figura 4:

Figura 4. Principios y valores en IES aplicando RSU

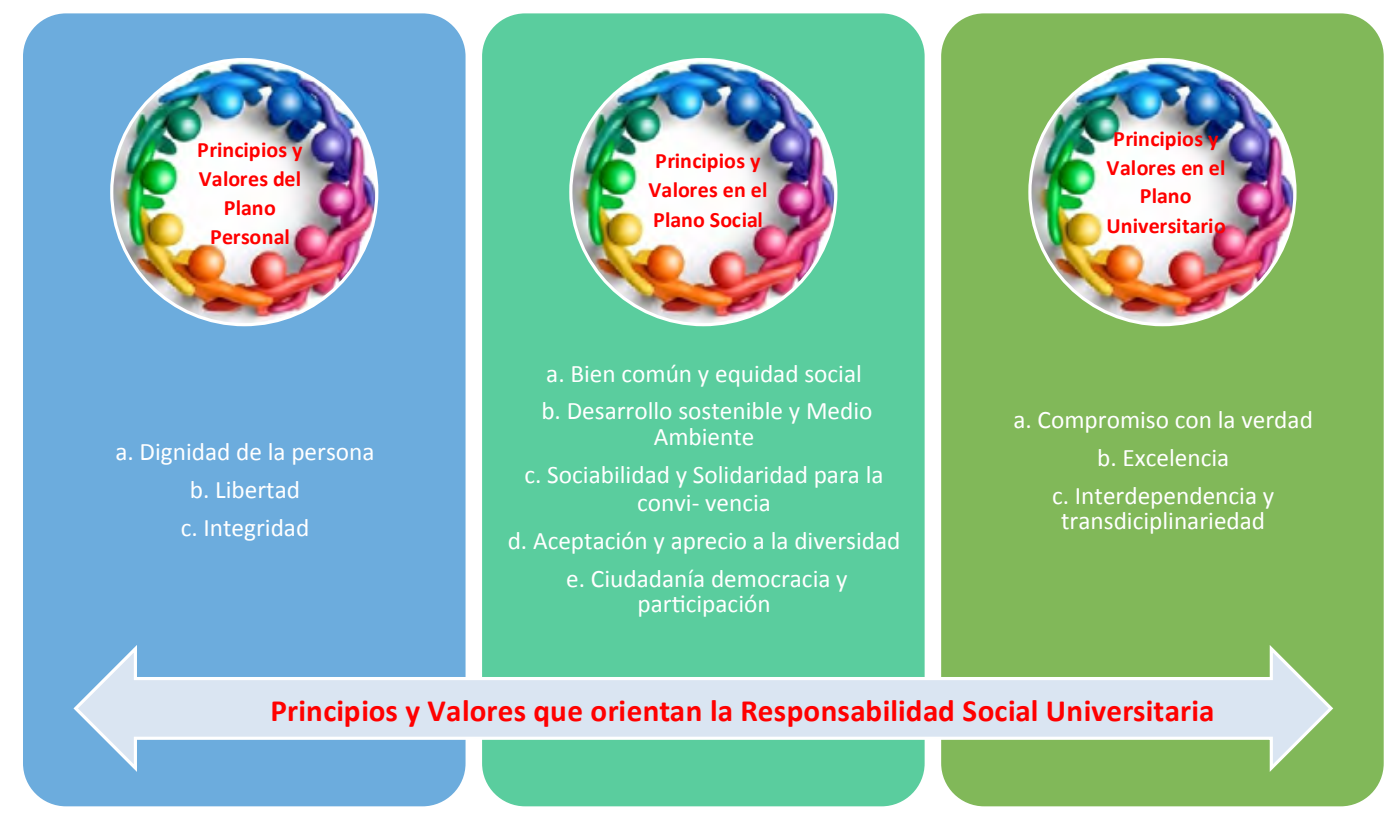

Nota: en base a: (Universidad: Construye Pais, 2002; Vera J, 2015) 


\section{Metodología}

La investigación se realizó recurriendo al método científico y deductivo; con un enfoque metodológico cuantitativo, de tipo básico, nivel descriptivo y diseño no experimental transversal. La técnica empleada fue la encuesta con 20 preguntas elaboradas en 5 bloques desde información básica, hasta información de conocimiento sobre acciones de RSU en la UTMach, la aplicación de la misma se hizo mediante muestreo aleatorio simple (César Bernal, 2016) en 60 docentes de la UTMach, quienes pertenecen a las 5 facultades existentes.

\section{Resultados}

La muestra obtenida corresponde a un segmento de la población de docentes de la UTMach. Se encuestó a 60 personas repartidas en 5 facultades equilibrando el balance entre hombres y mujeres. El estudio fue dirigido a múltiples sectores educativos con el fin de obtener resultados representativos de la problemática. Los hombres representan el 65\% de la muestra con un promedio de 12.01 años de docencia; las mujeres por su parte representan el $35 \%$ del total y su promedio de 7.31 años de docentes en la universidad. Es importante aclarar que de las 20 preguntas se seleccionaron las más representativas y que se correlacionan con las otras que no han sido declaradas en este trabajo.

\section{Conocimiento de Responsabilidad Social por parte de los docentes}

Luego de identificados los años de experiencia docente, sexo y la facultad de adscripción del profesor encuestado la siguiente pregunta busca determinar el conocimiento existente de parte de los docentes de las diferentes facultades de la UTMach

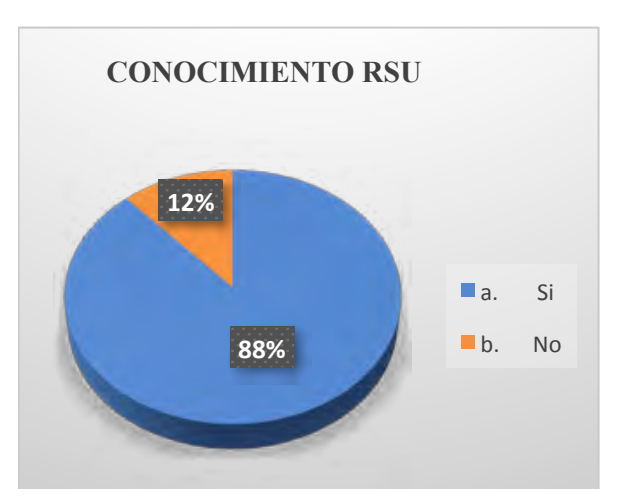

Nota: Encuesta aplicada a docentes 2019. sobre responsabilidad social de manera general.

Los resultados obtenidos mediante las encuestas aplicadas demuestran que el $88 \%$ de los encuestados tienen algún conocimiento sobre responsabilidad social, mientras que el $12 \%$ restante no conoce sobre este tema. Es decir, la mayoría de docentes que comparten sus conocimientos en la UTMach tienen conocimiento sobre lo que es y engloba la responsabilidad social

\section{Acciones RSU dadas en UTMach}

La siguiente pregunta analiza la frecuencia con la que presenta a sus docentes ciertas acciones o programas propios que se alinean dentro de la RSU que se ejecutan 
dentro de la institución, pese a que la universidad no posee un departamento o área a fin. Por lo que esta pregunta demuestra que el 23\% de los docentes refiere

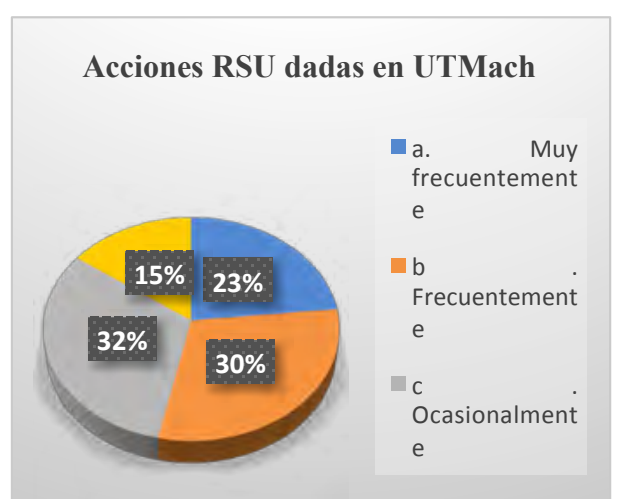

Nota: Encuesta aplicada a docentes 2019 que ha obtenido información sobre las acciones o programas vinculados a la RSU de forma muy frecuentemente, del mismo modo, el 30\% menciona que el tema es socializado de manera frecuente, el $32 \%$ ha escuchado sobre de manera ocasional, y finalmente el 15\% manifiesta que nunca ha escuchado de acciones, lineamientos, políticas o programas vinculados a la RSU en la UTMach.

\section{Implementación del departamento RSU en UTMach}

La siguiente pregunta abarca la importancia de la existencia de Responsabilidad Social en la universidad mediante programas, acciones, estrategias, lineamientos ejecutados desde un departamento propio, de manera que esta esté presente en

Implementacion de departamento de RSU

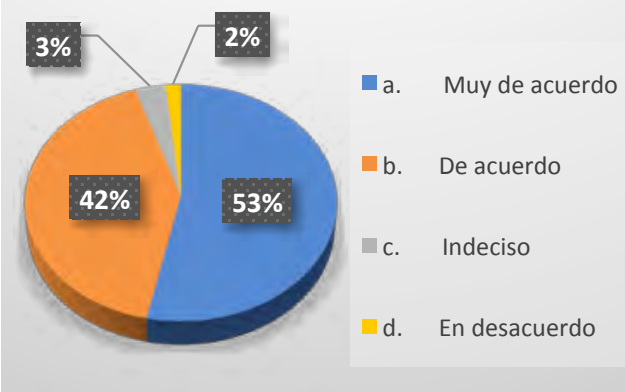

todos los estamentos del alma mater.

De este modo, el 53\% de los encuestados manifiesta que está muy de acuerdo que exista Responsabilidad Social en la UTMach, del mismo modo, el $42 \%$ revela que está de acuerdo, no obstante, el $3 \%$ se encuentra indeciso, y finalmente el $2 \%$ asegura estar en desacuerdo sobre la implementación de Responsabilidad Social.

\section{Mejora de procesos en la UTMach}

Con esta pregunta se busco determinar si al aplicar de manera formal u oficial la

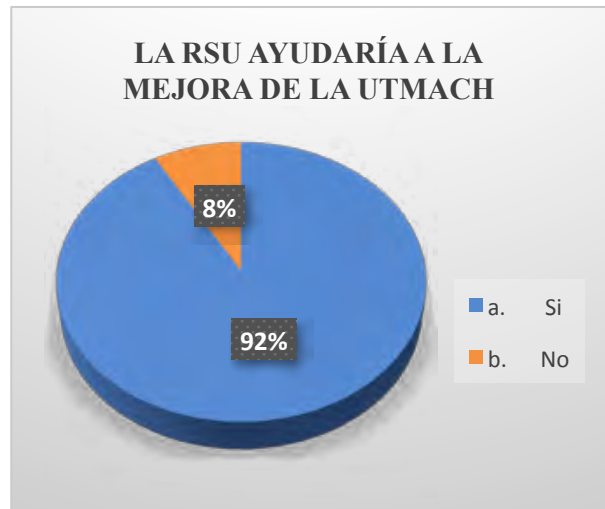

Nota: Encuesta aplicada a docentes 2019 RSU ayudaría en los procesos internos, en la docencia, en protocolos, así mismo si esto ayudaría a todos los stakeholders internos.

Los resultados obtenidos mediante las encuestas aplicadas demuestran que el 92\% de los encuestados piensan que la RSU mejoraría los procesos internos y externos de la UTMach, no obstante, el $8 \%$ de las personas medita que la RSU no sería de mucha ayuda. 


\section{Implementación de RSU ayuda a las políticas internas}

Mediante esta pregunta se consultó si los docentes de la UTMach creen que implementar RSU en el sistema educativo de las universidades ayudaría a la factibilidad

RSU ES PRIORIDAD EN LOS SISTEMAS EDUCATIVOS

$8 \%$

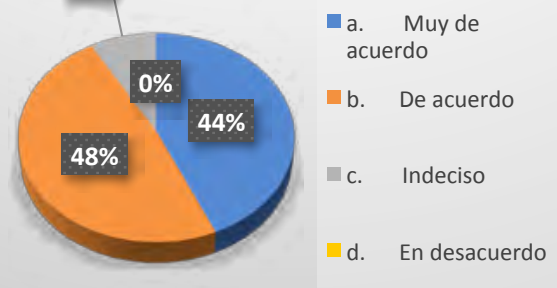

Nota: Encuesta aplicada a docentes 2019 de las políticas internas y externas en las instituciones de educación superior.

A partir de los datos obtenidos el 44 y $48 \%$ están de acuerdo que la RSU si ayudaría a mejorar las políticas internas y externas de la UTMach y de las universidades del país, mientras que el $8 \%$ de los encuestados está indeciso en si se debería aplicar la RSU en los procesos internos y externos de las universidades del país.

\section{Acciones de RSU ambientales desde la UTMach}

En cuanto a políticas o acciones que se realicen desde la UTMach de programas de formación especial entre docentes y estudiantes sobre el cuidado del medio ambiente.

Los resultados obtenidos en las encuestas por parte de los docentes manifiestan que el $9 \%$ de programas del cuidado del medio ambiente se los realiza todos los días, el $35 \%$ ocasionalmente, el $40 \%$ algunas veces, el 13\% casi nunca y para finalizar el 3\% dice que nunca se realizan estos programas.

Estas cifras concluyen que una cantidad mayor de profesores tienen conoci-

Acciones de RSU ambientales desde la UTMach.

\section{$13 \% \quad 3 \%$}

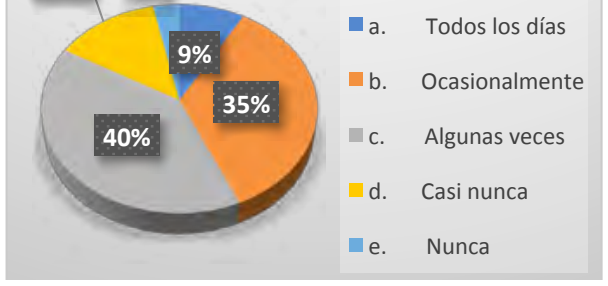
miento sobre si la UTMach realiza estos programas diariamente. Es importante destacar que una cantidad mínima que equivale al 3\% de la población de docentes universitarios de dicha institución dicen que nunca se realizan estos programas. Esta pregunta permite conocer que tan informado se encuentra el maestro en el ámbito del cuidado del medio ambiente por parte de la universidad.

Nota: Encuesta aplicada a docentes 2019

\section{Acciones de RSU a la solución de conflictos sociales}

Mediante esta pregunta se determina si los docentes de la UTMach creen que la RSU ayudaría a la solución de conflictos sociales dentro y fuera de los predios universitarios. 
El 18\% de docentes creen que la RSU impulsada desde la UTMach ayudaría a reducir los conflictos sociales, el $25 \%$ ocasionalmente, el $32 \%$ algunas veces, el $13 \%$ casi nunca y para finalizar el $12 \%$ creen que no ayudaría en lo absoluto

\section{Acciones de Gobierno Corporativo en la UTMach}

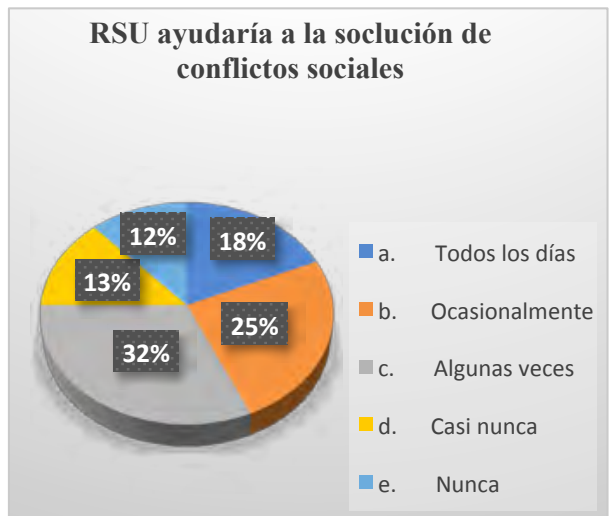

Nota: Encuesta aplicada a docentes 2019

La pregunta número 18 analiza, si el consejo de administración de la universidad anteriormente nombrada, realiza funciones de compensación, evaluación, auditoria y planeación a los docentes y personal administrativo, como parte del buen gobierno corporativo, pese a que no esté definida la RSU de manera firme en la institución.

El 28\% de los docentes indicaron que el consejo de administración de la UTMach si realiza funciones de evaluación, auditoria y planeación, el $27 \%$ manifiesta que casi siempre, el $30 \%$ indicaron que rara vez lo hacen, el $13 \%$ casi nunca y por último el $2 \%$ manifestaron que el consejo de administración nunca realiza funciones de evaluación, auditoria y planeación.
Gobierno Corporativo en la UTMach

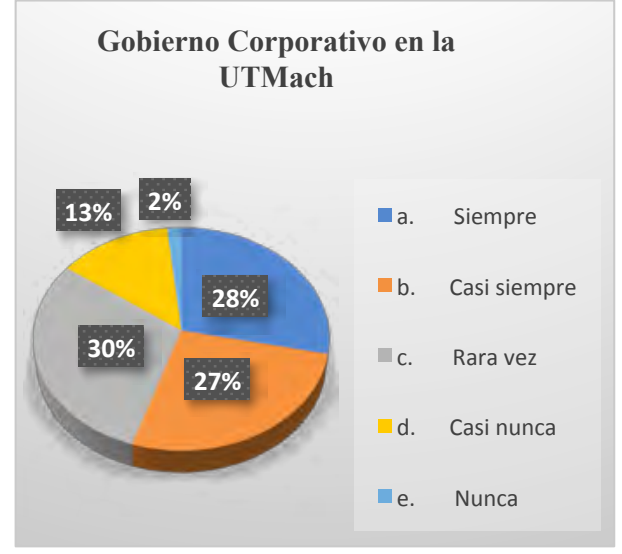

Nota: Encuesta aplicada a docentes 2019

\section{Participación Docente y Rendición de cuentas en Acciones de RSU}

La pregunta investiga si la UTMach favorece la participación de los docentes en actividades o acciones alineadas a la RSU .

EL 28\% de los docentes indicaron que la UTMach siempre favorece la parti-

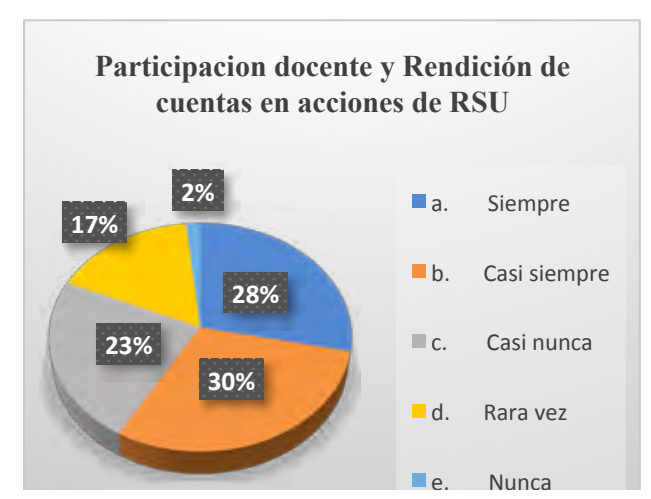

Nota: Encuesta aplicada a docentes 2019 cipación de ellos en actividades con el fin de representar a la universidad, el 30\% manifestaron que casi siempre los permite participar en actividades representativas, el $23 \%$ indicaron que casi nunca, el $17 \%$ manifestaron que rara vez y por último el $2 \%$ indicaron que la UTMach nunca favorece la participación de los docentes en actividades representativas. 


\section{Acciones de Integración entre los estamentos}

La pregunta indaga, si en la UTMach se elaboran acciones para el desarrollo de actividades de integración universitaria entre docentes, funcionarios y estudiantes para una buena convivencia entre sí.

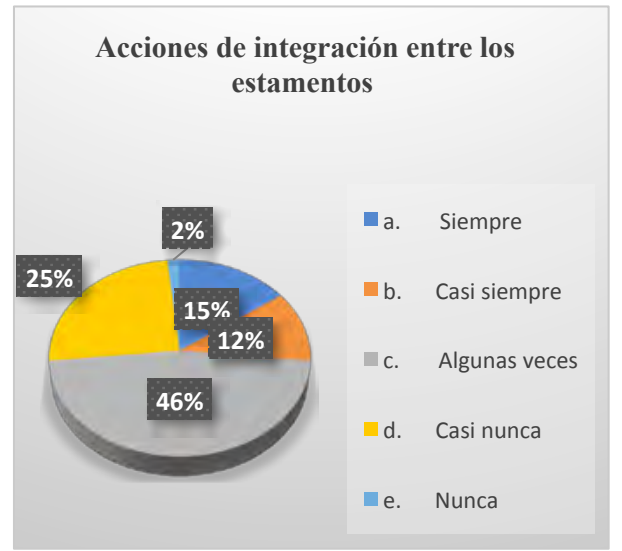

Nota: Encuesta aplicada a docentes 2019
El 15\% de los docentes indicaron que la UTMach siempre desarrolla acciones para el desarrollo de actividades de integración universitaria, el $12 \%$ de los docentes indicaron que casi siempre, el $46 \%$ manifestaron que la UTMach algunas veces elaboran métodos de desarrollo de actividades para el desarrollo de actividades de integración universitaria, el $25 \%$ indicaron que casi nunca y por el ultimo el $2 \%$ de los docentes indicaron que la UTMach nunca elabora métodos de integración.

\section{Conclusiones}

A partir del análisis y la contextualización del problema, se puede concluir que la mayoría de docentes si tienen conocimientos básicos de lo que es la Responsabilidad Social, sin embargo, son pocos los profesores que han escuchado en profundidad sobre RSU al interior de la universidad, por ende, desconocen o no saben identificar las acciones que son producto de una planificación sólida y sostenible de RSU.

Con respecto a los datos obtenidos se observa que el 92\% de docentes creen que la RSU si es implementada de manera formal en la universidad ayudaría a mejorar el sistema académico, pero solo el 53\% de ellos están de acuerdo con que la universidad lleve a cabo un plan de RSU, con lo que se crea una contradicción que puede ser explicada por la falta de información que se mencionó líneas atrás.

Finalmente se evidenció que la universidad no ha constituido en su estructura organizacional una dependencia que direccione, ejecute y evalúe acciones específicas en ese aspecto. Sin embargo, se destaca que de manera vertical se desarrollan ciertas acciones o actividades que están ligadas a ésta y que corresponden a la normativa nacional de instituciones de educación superior, como por ejemplo la unidad de Bienestar Estudiantil para ayudar a solventar situaciones económicas, psicológicas y académicas de estudiantes y docentes, en la que se desarrollan servicios y programas como becas para estudiantes de bajos recursos, convenios interinstitucionales en áreas de la salud, asistencia social a estudiantes y docente. No 
obstante estas son acciones aisladas, que no son parte de una planificación formal de largo plazo que vincule los objetivos instituciones con las demandas de la comunidad y demás miembros del ecosistema universitario, lo que permite recomendar la creación legal de instancias formales y sostenibles de RSU que comprometan a docentes y demás stakeholders en la consecución de objetivos institucionales de largo plazo vinculantes con el quehacer de todos los que hacen la comunidad universitaria de la provincia de El Oro. 


\section{Referencias}

Aldeanueva Fernández, I. (2011). Responsabilidad Social en la Universidad Centroamericana. SPICUM.

Asamblea Nacional del Ecuador. LOES, Registro Oficial $\$$ (2011). Ecuador.

Bowen, H. R. (1953). Social Responsibilities of the Businessman. Harper. Retrieved from https://books.google.com/books?id=q2Q9MQAACAAJ\&pgis=1

César Bernal. (2016). Bernal Cesar A - Metodologia De La Investigacion. (Pearson, Ed.) (Cuarta). Bogota: Pearson Educación.

De la Cuesta González, M., De la Cruz Ayuso, C., \& Rodríguez Fernández, J. M. (2015). Responsabilidad social universitaria. Dictamen Libre, (17), 81-91. https://doi.org/10.18041/2619-4244/dl.17.3083

Dominguez, M. J. (2009). Responsabilidad Social Universitaria. Synergies, 8(9), 37-67. Retrieved from http://www.netbiblo.com/openurl.asp?genre=issue\&id=doi:10.4272/978-84-9745-423-0

Espinoza Santeli, G., \& Guachamín Montoya, M. (2017). La responsabilidad social universitaria en Ecuador. Estudios de La Gestión. Revista Internacional de Administración, 1(1), 9-27. https://doi.org/10.32719/25506641.2017.1.1

Fassin, Y. (2011). A Dynamic Perspective in Freeman's Stakeholder Model. Journal of Business Ethics, (July), 1-11. https://doi.org/10.1007/s10551-011-0942-6

Freeman, E. (1984). Strategic management: a stakeholder approach. Boston: Pitman.

Freeman, E. (2004). The Stakeholder Approach Revisited. Pitman Publishing, 5(3), 228-241. https://doi.org/10.3763/jsfi.2010.0008

Freeman, E., \& McVea, J. (2001). A Stakeholder Approach to Strategic Management. SSRN Electronic Journal, 1(01), 276. https://doi.org/10.2139/ssrn.263511

Freeman, R. E., \& Evan, W. M. (n.d.). Corporate Governance: A Stakeholder Interpretation. The Journal of Behavioral Economica, 19(4), 337-359.

Gaete Quezada, R. (2016). Perception of college student leaders about University social responsability. Obets, 11(2), 461-485. https://doi.org/10.14198/ OBETS2016.11.2.04

Gaete Quezada, R. A. (2010). Departamento de sociología y trabajo social tesis doctoral : Responsabilidad Social Universitaria : una nueva mirada a la relación de la universidad con la sociedad desde la perspectiva de las Dirigida por : Un estudio de caso. España: Universidad de Valladolid .... Universidad de Valladolid. 
Gaete Quezada, R., \& Bratos Martín, M. (2012). A look to the university internationalization from the perspective of social responsibility: Young researchers discourses [Una mirada a la internacionalización universitaria desde la perspectiva de la responsabilidad social: Discursos de los jóvenes inves. Estudios Pedagogicos, 38(1), 255-272. https://doi.org/10.4067/S0718-07052012000100015

Larrán, J., \& Andrades, F. (2015). Análisis de la responsabilidad social universitaria desde diferentes enfoques teóricos. Revista Iberoamericana de Educacion Superior, 6(15), 91-107. https://doi.org/10.1016/S2007-2872(15)30005-6

López Noriega, M. D., Zalthen Hernández, L., \& Cervantes Rosas, M. de los Á. (2016). La responsabilidad social universitaria desde la perspectiva del alumno. Ra Ximhai, 305-314. https://doi.org/10.35197/rx.12.01.e3.2016.20.ml

Mitchell, R. K., Van Buren, H. J., Greenwood, M., \& Freeman, R. E. (2015). Stakeholder Inclusion and Accounting for Stakeholders. Journal of Management Studies, 52(7), 851-877. https://doi.org/10.1111/joms.12151

Moya, J. V. (2010). Responsabilidad Social, 1, 90-100.

Olarte-Mejía, D. V., \& Ríos-Osorio, L. A. (2015). Enfoques y estrategias de responsabilidad social implementadas en Instituciones de Educación Superior. Una revisión sistemática de la literatura científica de los últimos 10 años. Revista de La Educacion Superior, 44(175), 19-40. https://doi.org/10.1016/j. resu.2015.10.001

Ramírez Vázquez, Y., Moctezuma Merlo, P., \& González Muñoz, O. (2017). 53 IMPORTANCIA DE LA RESPONSABILIDAD SOCIAL EN LA FORMACIÓN DE LOS FUTUROS PROFESIONALES (Importance of Social Responsibility in the training of future professionals), 53-65.

Raufflet, E., Duque, J., \& De la Torre, M. (2011). Responsabilidad social empresarialb (Primera). Madrid, España: Pearson. Retrieved from https://books.google.com/ books?id=QYp8uAAACAAJ\&pgis $=1$

Raza Calderón, N. A., \& Loachamín Paucar, J. J. M. (2015). La responsabilidad social universitaria: Componente fundamental en la formación de los futuros docentes de la carrera de Pedagogía, de la Universidad Politécnica Salesiana. Alteridad, 10(1). https://doi.org/10.17163/alt.v10n1.2015.06

Sacco, F. (2009). gerencial Responsabilidad, responsabilidad social Perspectivas de tres conceptos . Visión Gerencial, Julio-dici(2), 383-397.

Salcedo-Muñoz, Virgilio;, Quezada, C., Novillo, E., Varela, G., Nuñez, L., \& Viteri, C. (2017). Bienestar estudiantil universitario en Ecuador : Caso unidades de bienestar estudiantil en las universidades de la provincia de El Oro. Espacios, 38(30). Retrieved from http://www.revistaespacios.com/a17v38n30/17383017.html 
Salcedo-Muñoz, Virgilio, Nuñez Guale, L., Campuzano Vásquez, J., Saltos, L. J., \& Nuñez De La Cruz, W. (2017). Enfoque exploratorio sobre acciones de Responsabilidad Social en universidades del Ecuador: Caso UPSE y UTMACH Exploratory focus on Social Responsibility actions in universities in Ecuador: Case of UPSE and UTMACH. Año, 38(35), 40.

Salcedo Muñoz, V., Brito Gaona, L., \& Campuzano Vásquez, J. (2015). El desafío de la Educación Superior . Caso : Universidad Técnica de Machala y su acercamiento a la responsabilidad social universitaria The challenge of Higher Education . Case : Machala Technical University and its approach to university social responsib, 3(2), 97-107.

Santeli, G. E., \& Montoya, M. G. (2017). La responsabilidad social universitaria en Ecuador. Estudios de La Gestión. Revista Internacional de Administración, 1(1), 9-27. https://doi.org/10.32719/25506641.2017.1.1

Sethi, S. P. (1975). Dimensions of Corporate Social Performance: An Analytical Framework. In Managing Corporate Social Responsibility, 69-75. https://doi. org/10.2307/41162149

United Nations Educational Scientific and Cultura Organization (UNESCO). (2009). Conferencia Mundial sobre la Educación Superior - 2009: La nueva dinámica de la educación superior y la investigación para el cambio social y el desarrollo (p. 9). Paris.

Universidad: Construye Pais. (2002). Observando la Responsabilidad Social Universitaria. Chile. Retrieved from http://www.cyta.com.ar/biblioteca/bddoc/bdlibros/ rse/334_as_observando_la_rsu.pdf

Universidad de Palermo. (2020). Responsabilidad Social Universitaria | Universidad de Palermo. Retrieved May 5, 2020, from https://www.palermo.edu/RSU/

Universidad de Vigo. (2020). Vicerrectorado de Responsabilidad Social, Internacionalización y Cooperación | Universidade de Vigo. Retrieved May 6, 2020, from https:/www.uvigo.gal/es/universidad/gobierno-uvigo/equipo-gobierno/ vicerrectorado-responsabilidad-social-internacionalizacion-cooperacion

Valarezo, K., \& Túñez, J. M. (2014). Responsabilidad Social Universitaria. Apuntes para un modelo de RSU University Social Responsibility. Indicators for a model of USR. Revista de Comunicación, 13, 84-117.

Valdivieso, C., \& Valarezo, K. (2013). Responsabilidad social universitaria: caso Ecuador. Dictamen Libre, (17), 81-91. https://doi.org/10.18041/2619-4244/ dl.17.3083

Vallaeys, F. (2008). ¿ Qué es la responsabilidad social universitaria. ... Universidad Católica Del Perú. Recuperado de: ..., 1-18. 
Vallaeys, Francois, De la Cruz, C., \& Sasia, P. (2009). Responsabilidad social universitaria (Manual de primeros pasos). Mc Graw Hill.

Vallayes, F. (2006). Breve marco teórico de responsabilidad social universitaria, en CD: Responsabilidad social universitaria. Retrieved from https:/www.uv.mx/ APPS/CUO/TALLERRSU/Docs. RSU para INEGI/Breve marco teórico de Responsabilidad Social Universitaria.pdf

Valle Chirinos, A., \& Pérez Peralta, C. M. (2016). La responsabilidad social universitaria: emprendimiento sostenible como impacto de intervención en comunidades vulnerables. Revista EAN, (81), 91. https://doi.org/10.21158/01208160. n81.2016.1560

Vera J, B. M. (2015). Responsabilidad Social Universitaria: Una aproximación al concepto en la educación del siglo XXI. Dictamen Libre, Julio-Dici(17), 81-91. 



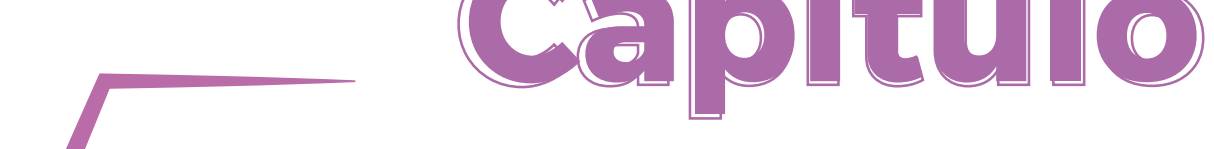

Responsabilidad social en el sector público del Ecuador

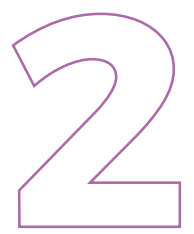


Responsabilidad social en el sector público del Ecuador

\author{
Zaida Patricia Morocho Román \\ Eduardo Vinicio Pulla Carrión \\ Ernesto Xavier González Ramón
}

Autores 


\section{Responsabilidad social en el sector público del Ecuador}

\section{Zaida Patricia Morocho Román}

Ingeniera Comercial, Magister en Tributación por la Escuela Superior Politécnica del Litoral, Certificación Internacional en NIIF por el Instituto Tecnológico de Monterrey-México, Doctorando de la Universidad del Zulia-Venezuela. Con experiencia profesional en el sector público y privado. Actualmente Docente Titular de la Universidad Técnica de Machala.

\section{Eduardo Vinicio Pulla Carrión}

Catedrático Universitario desde el año 2008, actualmente Docente Titular de la Universidad Técnica de Machala, Ingeniero Comercial, Magister en Administración de Empresas por la Universidad Nacional de Loja. Actualmente continúa sus estudios de Doctorado en la Universidad de Zulia, Venezuela.

\section{Ernesto Xavier González Ramón}

Abogado de los Tribunales y Juzgados de la República del Ecuador - Magister en Derechos Fundamentales y Justicia Constitucional - Profesor Titular de la Universidad Técnica de Machala - Autor de Artículos relacionados a Educación y Derecho.

DOI: http://doi.org/10.48190/9789942241405.2 


\section{Resumen}

A partir del análisis de bases bibliográficas respecto de responsabilidad social, normas y acuerdos sobre el interés en la implementación de compromisos prospectivos para alcanzar el desarrollo sostenible, la presente investigación realiza una aproximación desde la perspectiva de la gestión pública y su grado de corresponsabilidad ética en las prácticas de buen gobierno mediante el análisis de las prácticas de responsabilidad social aplicadas en el sector público, frente a sus principales categorías, derivadas de la teoría expuesta, para orientar los cambios estructurales en la redefinición de políticas públicas incluyentes que se alineen a los objetivos de desarrollo según el Plan Nacional del Desarrollo 2017-2021 -Toda una Vida-, este alcance inicial se realiza mediante un diagnóstico y evaluación de la situación actual de las prácticas de responsabilidad social adoptadas en el sector público en el Ecuador, en busca de un equilibrio en la gestión en contextos similares basados en los efectos de buenas prácticas de responsabilidad en el sector público. Dentro de los instrumentos considerados importantes, está el marco normativo y las leyes que regulan la gestión pública, ya que señala el camino que permite ampliar el ámbito de acción y medir su ejecución, estableciendo las debilidades y fortalezas institucionales que posteriormente son los insumos que generan un plan de acción para mejorar la gestión de la responsabilidad social de las instituciones públicas, lo que contribuye al progreso de la sociedad mediante los valores de transparencia, ética política, participación ciudadana e igualdad, generando más confianza entre el Estado y la Sociedad.

Palabras claves: responsabilidad social, sector público, gestión.

\section{Introducción}

Las manifestaciones asociadas a la Responsabilidad Social en el sector público generan incentivos de buenas prácticas que permite tensionar tanto la filosofía como la gestión organizacional, generando los círculos de mejora continua y de sostenibilidad en la forma de hacer las cosas.

La integración voluntaria de las preocupaciones sociales y de las exigencias de los ciudadanos en las decisiones de los poderes públicos implica una aproximación al modelo socialmente responsable; como también al ajuste de la política a las peticiones ciudadanas y un uso responsable de la misma. No obstante, el voluntarismo inherente a la Responsabilidad Social y su carácter para jurídico comienza a ceder en su traslación a la esfera pública, a través de su mutación en normativa legal y exigible. (Ruiz \& Ruiz, 2014, pág. 4) 
El Estado y, por lo tanto, todas las instituciones públicas, por definición, deben ejercer un rol en lo social, cuyo objetivo prioritario es la generación de políticas públicas en beneficio de toda la ciudadanía. Bajo este contexto, se podría decir que, la Responsabilidad Social es parte inherente de la política del Estado.

González y León (2013), sostienen que las administraciones públicas han concientizado la importancia de la gestión de responsabilidad social, poniendo en marcha políticas orientadas a la administración integrada como estrategia a largo plazo, que se traduce en beneficios económicos y sociales. En este sentido, las instituciones públicas transforman el contexto de la toma de decisiones empresariales.

Los poderes públicos tienen distintos tipos de responsabilidad según el ámbito y las obligaciones por las que tienen que responder, por lo que se puede decir que la responsabilidad política o responsabilidad administrativa de los poderes públicos se deriva de la obligación de actuar como garantes de los derechos de los ciudadanos y del interés general. Por lo que responsabilidad social pública implica un deber más, que es el de vincularse en la defensa del interés general mediante la protección y promoción de los bienes y derechos que ésta propone, garantizando las expectativas de la ciudadanía (Puig i Campmany \& Martínez i Hernández, 2008).

La Comisión de las Comunidades Europeas (CCE, 2001) define a la Responsabilidad Social Empresarial, como el instrumento mediante el cual las empresas integran aspectos sociales y ambientales en sus operaciones y en la interacción con sus grupos de interés, donde más allá de las exigencias legales lo hacen con interés y voluntad. Por lo que Responsabilidad Social se entiende como una contribución empresarial al desarrollo sostenible con enfoque de gestión que impulsa la competitividad y cohesión social.

Para la Comisión Económica para América Latina (CEPAL, 2004), la Responsabilidad Social es la forma de hacer negocios considerando los efectos sociales, ambientales y económicos de la acción empresarial integrando en ella el respeto por los valores éticos, las personas, las comunidades y el medio ambiente.

Desde la mirada de (Viteri \& Jácome, 2011, págs. 3-9), es el compromiso de la empresa para identificar los problemas que afecten a sus grupos de interés y emprender acciones que generen impactos sociales, económicos y ambientales positivos, con el aporte de soluciones basadas en la transparencia, pluralidad, sustentabilidad y ética; la meta es el desarrollo sustentable del ser humano y de su entorno.

En este contexto, la responsabilidad social es un compromiso de las organizaciones públicas y privadas para contribuir al desarrollo sostenible, trabajando con los empleados y sus familias, con la comunidad y la sociedad para mejorar la calidad de vida, cuyo objetivo es que tanto las organizaciones como la comunidad obtengan beneficios mutuos (Canovas García \& Mateos García, 2014).

El concepto de Responsabilidad Social Corporativa (RSC) está intrínsecamente ligado al desarrollo sostenible definido en el Informe Bruntdland de la Organización 
de las Naciones Unidas ONU (2015) que condiciona de forma permanente, tanto a agentes privados como a públicos, en la medida en que sus actividades deben "satisfacer las necesidades del presente sin poner en peligro la capacidad de las generaciones futuras para satisfacer las suyas propias” (p.1).

El desarrollo sostenible es un tema en el cual participan actores tanto a nivel nacional como internacional. Las reformas económicas, sociales y estructurales que requieren muchos países necesitan de un gobierno eficiente, responsable, transparente y con mayor participación ciudadana, que permita una mejor y más rápida respuesta a los retos de democratización y rendición de cuentas, de la globalización económica, la descentralización del poder a niveles locales, y la corrección de desequilibrios sociales (Banco Mundial, 2000).

La tradicional voluntariedad en la ejecución de las acciones de responsabilidad social corporativa, se debe complementar con una actuación por parte del Estado materializada en la implementación de políticas públicas que permitan promover, incentivar y consolidar prácticas responsables (Lozano, Albareda, Ysa, Rosher, \& Marcuccio, 2005).

Las políticas públicas se encuentran relacionadas de forma directa con la responsabilidad social ya que es la manera que tiene el estado para dar respuesta o soluciones a las demandas de la sociedad, con la finalidad de promover mejores estándares sociales, económicos y medio ambientales. Fox, Ward, \& Howard (2002) afirma:

Las políticas públicas en materia de responsabilidad social corporativa se clasifican en:

- Políticas reguladoras del sector público, mediante la cual se definen los estándares mínimos de la actuación empresarial dentro del marco legal.

- Políticas facilitadoras o de apoyo, que permiten estimular la implicación de actores clave a través de la puesta en marcha de formación, comunicación, o de difusión.

- Políticas de colaboración y acuerdos estratégicos, pueden agrupar y poner en común las capacidades y los logros de los sectores públicos y privado y la sociedad civil.

- Políticas de promoción o reconocimiento directo de los esfuerzos de otras organizaciones, o el mismo efecto ejemplarizante que tienen las prácticas de gestión del sector público. (p.6)

El impacto de éstas políticas no sólo se entiende en la relación tradicional de la acción de los gobiernos hacia el sector privado, sino que permite la existencia de una relación multilateral y puede orientarse a su integración en la propia administración pública, en la relación entre gobierno y sociedad civil; o en a una relación multilateral entre gobiernos, empresa y sociedad civil (Lozano et al., 2005).

La condición general es que las organizaciones ejercen su responsabilidad social cuando su visión enmarca las expectativas que tienen sus diferentes grupos 
de interés (stakeholders), acerca de sus comportamientos. En el contexto de una nueva gestión pública, la intersectorialidad entendida como el trabajo coordinado con otro tipo de organizaciones (empresas, organizaciones sociales y ciudadanas) y otras instituciones estatales, promueve la conformación de redes que optimizan el uso de recursos y enfoques, dirigiéndoles en forma eficiente hacia la satisfacción de las necesidades de la sociedad. Al mismo tiempo, los cambios en las demandas y aspiraciones de la sociedad civil, hacen necesario incorporar la "transversalidad" en la implementación de la política pública, a partir de la generación de buenas prácticas, en un modelo de responsabilidad social que se caracterice por atender estas nuevas demandas como variables dinámicas en los procesos de gestión pública (Zenck Huerta, Rios Rivera, Pogo García, \& Cueto Cedillo, 2017).

En la actualidad, el modelo de gestión para la responsabilidad social ha cambiado. Se pasa de un modelo donde los ciudadanos son clientes y consumidores, a otro donde son socios, capaces de participar (Navarro Galera, Ruiz Lozano, De Los Rios Berjillos, \& Tirado Valencia, 2013). Analizando esta teoría, los autores indican que la responsabilidad social de las organizaciones no debería estar basada en logros, sino en relación con las demandas de los stakeholders, esto con el propósito de dirigir esfuerzos de una manera más organizada, eficiente y oportuna, convirtiéndolos en participantes de un cambio. También se presenta una gran modificación al interior de la organización, teniéndose que implementar políticas de responsabilidad social en los procesos de planificación, considerando el punto de vista de los grupos de interés involucrados.

Hoy en día surgen nuevos elementos que enriquecen a la responsabilidad social empresarial, por ejemplo, la moral y la ética; la problemática ambiental y la sostenibilidad aparecen en el debate conceptual y entran a formar parte concomitante de la definición de la responsabilidad social empresarial, para ampliarla y complementarla, dándole mayor trascendencia dentro de los modelos de gestión empresarial (Orjuela Cordova, 2011).

Las entidades del sector público realizan su gestión hacia la ciudadanía más allá de la racionalidad económica, por tal razón la información sobre sostenibilidad en el ámbito público toma un papel fundamental para la evaluación de una gestión transparente y responsable (Navarro et al., 2013). Es importante que este sector genere información que reporte riesgos financieros futuros, oportunidades y debilidades de su gestión, buscando definir aspectos claves para la sostenibilidad.

Las políticas públicas de responsabilidad social corporativa, encuentran su antecedente en el marco normativo internacional con distintas convenciones, declaraciones y guías (CCE, 2001).

1. Pacto Global de Naciones Unidas (United Nations Global Compact).

2. Principios Rectores de las Naciones Unidas sobre Empresas y Derechos $\mathrm{Hu}-$ manos (Observatorio de Responsabilidad Social Corporativa, 2003).

3. ISO 26000 (International Organization for Standardization). 
4. Declaración tripartita de principios sobre las empresas multinacionales y política social Organización Internacional del Trabajo (OIT, 2001).

5. Directrices para Empresas Multinacionales. Organización para la Cooperación y el Desarrollo Económico (OCDE, 2011).

En el año 2015, la ONU aprobó la Agenda 2030 sobre el Desarrollo Sostenible, una nueva oportunidad para que los países emprendan un camino para mejorar la vida de todos. La agenda cuenta con 17 Objetivos de Desarrollo Sostenible (ODS), los que incluyen erradicar la pobreza, proteger el planeta, la educación, la prosperidad para todos como parte de una nueva agenda de desarrollo sostenible. Cada objetivo tiene metas específicas que deben alcanzarse en los próximo 15 años; para alcanzarlas debe existir una interrelación entre los gobiernos, el sector privado y la sociedad civil (Organización de las Naciones Unidas).

Mediante la propuesta de los ODS, se busca dar continuidad al compromiso adquirido por los países, para abordar problemas de acción urgente que representan desafíos para todos; gobierno, organizaciones, sociedad civil; este contexto se vincula de forma directa con la Responsabilidad Social especialmente en los ODS 16 y 17; promover sociedades justas, pacíficas e inclusivas y revitalizar la alianza mundial para el desarrollo sostenible, respectivamente.

Internacionalmente se han desarrollado estándares que ayudan a las organizaciones a revelar la ejecución de sus planes de acción en desarrollo sostenible y responsabilidad social. El Global Inititiative Reporting GRI-G4 (GRI Empowering Sustainable Decisions) son los primeros estándares globales para informes de sostenibilidad; cuentan con una estructura modular, interrelacionada, y representan la mejor práctica global para informar sobre una gama de impactos económicos, ambientales y sociales, otras de las asociaciones profesionales que han contribuido a normalizar y transparentar la información sobre responsabilidad social, por ejemplo en Ecuador el Consorcio Ecuatoriano para la Responsabilidad Social (CERES) y en España, la Asociación Española de Contabilidad (AECA).

En el Ecuador, el Estado tiene como prioridad, prestar servicios a la comunidad, cumpliendo con los principios de eficacia, eficiencia y transparencia conforme lo establece la Constitución de la República del Ecuador (2008), la acción de estas actividades, los planes y programas en ejecución, metas e informes de gestión e indicadores de desempeño, se transparenta con la difusión de la información pública a través del portal de información o página web mediante el mecanismo de rendición de cuentas a la ciudadanía, de acuerdo a lo que establece el Art. 7 de la Ley Orgánica de Transparencia y Acceso a la Información Pública LOTAIP (Asamblea Nacional, 2004).

Todas las instituciones públicas en Ecuador se encuentran reguladas a través de un marco legal y normativo, el mismo que contiene procesos, modelos de gestión, indicadores, seguimiento y evaluación de resultados; en fin, todo un esquema pro- 
tocolario a cumplir, que si bien es cierto se cumple o no, no es el tema de discusión, sino el cómo se cumple y cuál es la repercusión por la forma de ejecutar dichos procesos.

No se puede dejar de mencionar la gran ventaja que tienen las instituciones del sector público frente a otras organizaciones cuyo fin es totalmente diferente, dada su naturaleza. Sin embargo, el sector público tiene un "deber" respecto a la implementación coordinada y planificada de buenas prácticas en materia de responsabilidad social, a pesar de haber impulsado la implementación de una serie de herramientas de gestión, por mencionar un ejemplo, en el año 2010 entra en vigencia el proyecto Gobierno por Resultados (GPR), herramienta que presenta algunos objetivos como el de mejorar la ejecución del presupuesto gubernamental, mejorar la calidad de toma de decisiones, orientar al gobierno en las áreas de mayor urgencia de mejora, estimular la colaboración entre las instituciones del Estado, ayudar en el desmantelamiento de los procesos burocráticos, desarrollar competencias institucionales en la planificación estratégica, operativa y de gestión de resultados; entre otras, es decir un proyecto que enmarca casi todos los enfoques de responsabilidad social tanto para los actores internos como externos (Norma Técnica de Implementación y Operación de la metodología y herramienta de Gobierno por Resultados, 2011).

\section{Justificación}

Hay que mencionar, que en la gran mayoría de instituciones públicas existe una cultura establecida para hacer las cosas, que limita la implementación de nuevas ideas porque "siempre se han hecho las cosas así", esto conlleva a mantener la gerencia tradicional y no dar paso a nuevos retos que coadyuven a mejorar la gestión pública.

Para vencer estas dificultades, es necesario que el Estado, sus instituciones y sus directivos, revisen sus estructuras, competencias, funciones, procesos, directrices, etc. y puedan definir las mejores estrategias para que los resultados sean mejores.

Se requiere conocer, también cómo la responsabilidad social puede ser aplicada a nivel de instituciones públicas, debido a que el enfoque ha sido la aplicación de acciones a nivel empresarial privado.

Por todo lo expuesto, la manifestación de responsabilidad social en el sector público, promueve en las instituciones públicas la revisión de sus objetivos y metas institucionales, su desempeño considerando el concepto "socialmente responsable" (social, económico, de medio ambiente y su impacto en los stakeholders, preocupándose de mejorar continuamente su gestión para satisfacer a la ciudadanía (cliente principal del Estado), lo que contribuye directamente con el desarrollo del país.

La investigación de este tema busca la inserción de medidas adecuadas en la toma de conciencia, de no solo pensar en sí mismo sino en el entorno institucional a beneficio de la ciudadanía, lo que conlleva a plantear una alternativa de trabajo 
que permita mejorar las fortalezas y eliminar las debilidades mediante un plan de acción ejecutable y flexible donde se evidencie el alcance de metas institucionales con el fin de cumplir lo que abarca el ámbito de responsabilidad social institucional.

A partir de la conceptualización teórica de desarrollo sostenible y responsabilidad social, y en observancia a la política social establecida en el país, desde el Plan Nacional de Desarrollo (PND) 2017-2021, el cual enmarca la búsqueda de la transparencia de la gestión pública y privada, el Estado en todo su contexto, ha impulsado leyes y procesos que fomentan la transparencia, mediante herramientas que promueven la participación ciudadana, el acceso a la información y la rendición de cuentas; por lo que de acuerdo al enfoque del eje 3 "Más sociedad, mejor Estado" desarrollado en el Plan Nacional de Desarrollo, busca la transparencia de la gestión pública y privada, por tanto, esta investigación se vincula de forma directa con el Objetivo 8 del PND donde se busca "Promover la transparencia y la corresponsabilidad para una nueva ética social”, desprendiéndose de éste, el objetivo fomentar prácticas socialmente responsables en la gestión pública, como aporte significativo para el funcionamiento general y mejorar los procesos en la institución, generando confianza y valor agregado en la implementación de acciones a beneficio de la ciudadanía (Senplades, 2017).

Así mismo, se considera que el control interno es un proceso integral orientado a cumplir con el ordenamiento jurídico, técnico y administrativo, promoviendo la eficacia y la eficiencia de las operaciones de la entidad y garantizar la confiabilidad y oportunidad de la información, así como la adopción de medidas oportunas para corregir las deficiencias de control (Contraloría General del Estado, 2009).

El impacto y repercusión del no cumplimiento o cumplimiento a medias del marco normativo, ante los hechos y circunstancias originadas en las instituciones del sector público, recae de manera directa sobre la ejecución del presupuesto institucional, derivándose otros aspectos negativos, como el mal uso e inversión de los recursos económicos, no optimización del presupuesto, bienes de larga duración sin ser utilizados, bienes adquiridos por necesidad personal y no institucional; si bien es cierto, en un primer momento el tema de responsabilidad social quería tornarse como una obligación gubernamental pero con el pasar del tiempo se establece que este tema fuese una adopción voluntaria por parte de las entidades tanto del sector público como privado, considerando aquello se determina, que es una herramienta de gestión más que de carácter obligatorio, necesaria, dado que el impacto en las entidades públicas aborda el contexto social, económico y de medio ambiente.

El presente trabajo investigativo, se aplica en las instituciones del sector público no financiero, con el objetivo de mejorar sus procesos, los mismos que necesitan generar confianza, tendientes a lograr la recuperación de espacios públicos, para el disfrute de la comunidad. 


\section{Objetivo general}

Analizar las prácticas de responsabilidad social aplicadas el sector público, frente a sus principales categorías.

\section{Objetivos específicos}

1. Diagnosticar las principales manifestaciones de responsabilidad social adoptadas en el sector público.

2. Evaluar las prácticas de responsabilidad social en el sector público en el Ecuador.

\section{Metodología}

Se trata de un trabajo de investigación de carácter exploratorio, donde se emplean métodos cualitativos acordes a un enfoque inductivo.

La metodología utilizada, inicia con la investigación de bibliografía y las principales referencias internacionales en materia de gestión socialmente responsable. Con esta aplicación se busca determinar el marco de aplicación existente, así como la revisión crítica de la literatura de campo. Con ello se identifica las fuentes principales para la determinación del marco conceptual del trabajo, señalando definiciones y elementos que lo conforman.

De acuerdo a Hernández, Fernández \& Baptista (2006), las investigaciones cualitativas se fundamentan en un proceso inductivo (explorar y describir, y luego generar perspectivas teóricas). Van de lo particular a lo general. Por ejemplo, en un estudio cualitativo, el investigador entrevista a una persona, analiza los datos que obtuvo y saca algunas conclusiones; posteriormente, entrevista a otra persona, analiza esta nueva información y revisa sus resultados y conclusiones; del mismo modo, efectúa y analiza las entrevistas para comprender lo que busca. Es decir, procede caso por caso, dato por dato, hasta llegar a una perspectiva más general.

Así mismo, se revisa la normativa específica existente. En primera instancia la emitida por los organismos internacionales, a continuación, las políticas públicas que rigen en el Ecuador, así como las normas que rigen la responsabilidad social. Finalmente se revisan informes de organismos públicos y guías de buenas prácticas o de buen gobierno, especialmente del sector público. 


\section{Materiales y métodos}

En el proceso investigativo se pretende analizar las prácticas de responsabilidad social aplicadas en el sector público, iniciando por el diagnóstico y posterior evaluación de las manifestaciones aplicada; bajo este esquema, como parte del diseño metodológico de investigación y con la finalidad de definir las prácticas de responsabilidad social, se realiza una investigación por el método exploratorio y descriptivo, con un enfoque cualitativo; con el afán de describir, analizar y evaluar los resultados encontrados.

Para realizar el análisis de la información cualitativa se estableció parámetros comparativos y de ejecución de herramientas a aplicar en la responsabilidad social.

\section{Resultados y Discusión}

Al ser un estudio exploratorio se precisa una herramienta adaptable que incluya elementos cuya pertinencia ha sido contrapuesta con la normativa, competencias legales y la consideración de los ODS para su adecuada aplicación. La herramienta - Listado de Comprobación - original contiene 112 ítems y está dividida en cuatro secciones principales.

Tabla 1. Listado de Comprobación

\begin{tabular}{|l|c|}
\hline \multicolumn{1}{|c|}{ Secciones } & Ítems \\
\hline Información sobre el desempeño general de la entidad & 39 \\
\hline $\begin{array}{l}\text { Información sobre el desempeño de responsabilidad } \\
\text { social a nivel económico }\end{array}$ & 27 \\
\hline $\begin{array}{l}\text { Información sobre el desempeño de responsabilidad } \\
\text { social a nivel social }\end{array}$ & 24 \\
\hline $\begin{array}{l}\text { Información sobre el desempeño de responsabilidad } \\
\text { social a nivel ambiental }\end{array}$ & 22 \\
\hline
\end{tabular}

Fuente: Adaptado de (Navarro Galera, Alcaraz Quilez, \& Ortiz, 2010)

Bajo este esquema se busca la posibilidad de realizar un análisis basado en la teoría expuesta sobre las principales categorías de la responsabilidad social.

El listado de comprobación adaptado al contexto local, luego de la revisión de la normativa, competencias legales y la consideración de los ODS vinculados al modelo de gestión del Ministerio del Interior, permitiría evaluar la información económica, social y medioambiental. 
Tabla 2. Componentes del análisis de información

\begin{tabular}{|l|}
\hline BLOQUE I. Información sobre el desempeño general del Ministerio del Interior \\
\hline Enfoque político-estratégico de la RS (Responsabilidad Social) \\
\hline Enfoque ético-buen gobierno y transparencia \\
\hline Enfoque integrador de los Grupos de Interés \\
\hline BLOQUE II. Información sobre el desempeño de la RS a nivel económico \\
\hline Información económica, contable y presupuestaria \\
\hline Indicadores de ingresos y gastos \\
\hline Indicadores de Control Interno \\
\hline BLOQUE III. Información sobre el desempeño de la RS a nivel social \\
\hline Responsabilidad en la gestión del personal del Ministerio del Interior \\
\hline Relaciones y operaciones con proveedores y contratistas \\
\hline Relaciones y operaciones con la comunidad \\
\hline BLOQUE IV. Información sobre el desempeño de la RS a nivel ambiental \\
\hline Información sobre políticas medioambientales \\
\hline
\end{tabular}

Nota: Adaptado de (Navarro Galera, Alcaraz Quilez, \& Ortiz, 2010)

El análisis realizado mediante los instrumentos de revisión bibliográfica y documental, se complementa con la observación y hallazgos; además de asegurar el acceso a la información de la ciudadanía de acuerdo a lo que establece la ley, se hace necesario verificar la calidad, pertinencia y veracidad de dicha información, con el fin de concretar políticas públicas para una gestión responsable con desarrollo sostenible (Zenck Huerta, Rios Rivera, Pogo García, \& Cueto Cedillo, 2017). Dicho modelo de gestión debe contribuir a la consolidación de una política de responsabilidad social corporativa y de donde se deriven insumos para una eficiente transparencia del desempeño del Ministerio del Interior del Ecuador y las necesidades de información de sus grupos de interés.

La coherencia entre la práctica de estrategias de responsabilidad social y la información oportuna, se debe demostrar en el cumplimiento de los indicadores que conforman las dimensiones de los componentes de la herramienta planteada para el diagnóstico de acuerdo al cuadro No. 2.

De acuerdo al principio de transparencia de responsabilidad social presente en la ISO 26000, las organizaciones deben suministrar toda la información requerida por las partes interesadas, de esta forma, pueden tomar decisiones basadas en datos presentados de forma completa, comprensible, receptiva, precisa, equilibrada, oportuna y accesible (Argandoña \& Isea Silva, 2011). Como el acceso a la información pública es una garantía constitucional regulada por la Ley Orgánica de Transparencia y Acceso a la Información (LOTAIP 2004), los grupos de interés no sólo deben estar informados por parte del Ministerio del Interior sobre los programas 
que promueven el desarrollo sostenible, sino que además el marco legal ecuatoriano les garantiza el acceso de manera abierta a cierta información de la gestión administrativa de la entidad, por pertenecer al sector público (Zenck et al., 2017).

Como punto de partida para dimensionar los resultados del estudio, se presenta un mapa de la construcción de las prácticas de responsabilidad social que ejecuta el Ministerio del Interior; luego, una breve descripción de los programas que generan las interacciones y relaciones con sus grupos de interés; y finalmente, su compromiso con la transparencia de la información que brinda en sus páginas web oficiales, a través del Listado de Comprobación, de tal forma que se pueda validar las políticas de responsabilidad social ejecutadas y las necesidades de información que tienen los grupos de interés y ciudadanía en general.

Siendo el Ministerio del Interior una institución pública, cuyo objetivo institucional es garantizar la convivencia social pacífica y la seguridad ciudadana de todos los ecuatorianos, teniendo como visión que la seguridad ciudadana y convivencia posesiona al ser humano como el centro de las políticas, programas y proyectos para garantizar el derecho de las personas a ser y sentirse protegidos de la violencia y cometimiento de infracciones (delitos y contravenciones); teniendo como ejes estratégicos, la previsión, prevención y respuesta, el ministerio ha venido desarrollando durante mucho tiempo programas de ayuda y apoyo a la comunidad independientemente de la labor constitucional encomendada como parte de prácticas de responsabilidad social.

Tabla 3. Acciones de Responsabilidad Social del Ministerio del Interior

\begin{tabular}{|c|c|}
\hline Denominación/Proyecto & Acción/ Grupo beneficiado \\
\hline Hipoterapia & $\begin{array}{l}\text { Dirigido a personas con capacidades especiales, motivando e incentivando a mejorar sus } \\
\text { destrezas; lo realizan con la Unidad de Equitación y Remonta UER. }\end{array}$ \\
\hline Caravana de la Salud & $\begin{array}{l}\text { Acción de RS donde a través de sus profesionales de higiene y salud, brindan atención y } \\
\text { asistencia a poblaciones marginales. }\end{array}$ \\
\hline Pirotecnia responsable & $\begin{array}{l}\text { Difunde a la ciudadanía, las causas y efectos producidos por el mal uso de material piro- } \\
\text { técnico. }\end{array}$ \\
\hline Yo educo a mi mascota & $\begin{array}{l}\text { Capacita a la ciudadanía en adiestramiento canino con ejercicios prácticos, para que ten- } \\
\text { gan el control de sus mascotas y puedan corregir ciertas conductas no deseadas. }\end{array}$ \\
\hline Alas de inclusión & $\begin{array}{l}\text { Se coordina la participación de instituciones que trabajan con niños de capacidades dife- } \\
\text { rentes, a fin de programar sobrevuelos con el helicóptero de la institución e incentivar la } \\
\text { recuperación y realización de sueños anhelados. }\end{array}$ \\
\hline $\begin{array}{l}\text { No arranques la piel de } \\
\text { los bosques }\end{array}$ & $\begin{array}{l}\text { Charlas en planteles educativos, con el fin de dar a conocer la importancia de la conser- } \\
\text { vación de los ecosistemas. }\end{array}$ \\
\hline $\begin{array}{l}\text { Grupo lúdico Paquito y } \\
\text { sus amigos }\end{array}$ & $\begin{array}{l}\text { A través del personal capacitado en artes lúdicas, se realizan estrategias de prevención para } \\
\text { fortalecer la formación en temas de prevención, seguridad ciudadana, principios y valores } \\
\text { a niños, niñas y adolescentes. }\end{array}$ \\
\hline
\end{tabular}




\begin{tabular}{|l|l|}
\hline Grupo Teatrino & $\begin{array}{l}\text { Es una acción de RS que va en beneficio de los niños, niñas y adolescentes. Consiste en } \\
\text { capacitar a niños y niñas comprendidos entre las edades de 5 a } 10 \text { años, sobre temas de } \\
\text { autoprotección, seguridad, bullying, derechos y obligaciones. }\end{array}$ \\
\hline $\begin{array}{l}\text { Feria de Seguridad Ciu- } \\
\text { dadana }\end{array}$ & $\begin{array}{l}\text { Acción que realiza la institución a través de sus diferentes servicios para estrechar lazos } \\
\text { con la sociedad y que ésta conozca las diferentes actividades extras de la institución, en } \\
\text { donde se fomentan temas como: charlas de solidaridad y convivencia pacífica ciudadana, } \\
\text { recuperación de valores y principios cívicos, etc. }\end{array}$ \\
\hline Campaña de Prevención & $\begin{array}{l}\text { Programa que realiza la entidad, a través de los servidores policiales en cada uno de los } \\
\text { circuitos en la cual se analiza y se realizan estrategias en los temas de mayor incidencia } \\
\text { delictual, peligrosa y violenta. }\end{array}$ \\
\hline
\end{tabular}

Si bien la responsabilidad social es un compromiso asumido de forma voluntaria y que va más allá de lo que exige la ley, para el Ministerio del Interior, la responsabilidad social se convierte en una voluntad política a ser promovida desde las prácticas socialmente responsables, tanto dentro de la institución como fuera de ella y esta se ve reflejada en el desarrollo de sus estrategias y programas que marcan el liderazgo, tal como lo demuestra el haber alcanzado el reconocimiento Ecuatoriano Ambiental Punto Verde ${ }^{1}$, que lo logró a través de la evaluación comparativa de indicadores en la medición de las actividades en los ejes temáticos como: la gestión de deshechos, gestión de papel, uso eficiente de agua, energía y combustibles; capacitación y compras responsables.

El bloque político, incorpora el enfoque sobre la estrategia de responsabilidad social, además del buen gobierno, la transparencia y la relación con los grupos de interés. La mayoría de los ítems se encuentran publicados en las diferentes páginas web del Ministerio del Interior; la normativa base para una estrategia de responsabilidad social está al acceso de la ciudadanía, como la planificación estratégica, los objetivos, misión, visión, servicios ofrecidos, los canales de participación abiertos a los usuarios para el entendimiento de las prácticas de responsabilidad social, consultas, opiniones, sugerencias o denuncias que podrán hacer los ciudadanos; siendo sumamente importantes en relación a la rendición de cuentas.

El bloque económico es el que cuenta con mayor número de ítems publicados. $\mathrm{Al}$ analizar la totalidad de la información publicada, se constata que es bastante completa. Indicadores macroeconómicos, presupuestos, informes sobre transferencias, liquidez, superávit, ingresos fiscales e inversión.

El bloque de desempeño social tiene un alto porcentaje de publicación en lo referente a las relaciones y operaciones con la comunidad, ya que los ítems se enfocan en el servicio a la sociedad, que es un aspecto central al momento de hablar de responsabilidad social. Se puede notar en cambio que la información publicada

${ }^{1}$ El Ministerio del Ambiente del Ecuador, con el objetivo de incentivar al sector público y privado, a emplear nuevas y mejores prácticas productivas y de servicios 
relacionada a proveedores y contratitas es escasa y muy general; y en cuanto a sus servidores públicos, la información es escasa, dejando fuera información básica como salarios, rotación, antigüedad y formación. La no publicación de estos aspectos podría denotar que se considera un aspecto importante en la rendición de cuentas.

En el bloque medioambiental, se publica la implementación de la política ambiental, capacitación continua y campañas de comunicación interna que se ejecutan. Éstas le permitieron alcanzar el reconocimiento ecuatoriano ambiental Punto Verde.

\section{Conclusiones}

Durante el desarrollo de este trabajo de investigación, se evaluó las prácticas de responsabilidad social en el sector público en el Ecuador, tomando como objeto de estudio al Ministerio del Interior, entidad que realiza acciones sociales encaminadas a desarrollar plenamente la RS. En la actualidad dichas acciones son llevadas a cabo desde el escenario de la administración pública como un factor de desarrollo para la ciudadanía en general, impulsando así la participación de manera activa e incluyente.

El fortalecimiento del modelo de gestión del Ministerio del Interior se promueve mediante el desarrollo ciudadano; a través de la aplicación de una estrategia desde la organización y participación ciudadana para intervenir en su entorno y mejorar sus condiciones de vida, actuando de manera comprometida, consciente y crítica, para lograr la transformación de su barrio y/o sector, por medio de actividades autogestionadas que responden a sus necesidades y aspiraciones; a través de la aplicación de una estrategia donde la organización y participación ciudadana son los pilares fundamentales de este accionar, con lo que se logra que la sociedad, tanto urbana como rural, comience a comprender la importancia de identificar los problemas que afectan y buscar soluciones, no solo en su entorno, sino a través de los organismos competentes.

Paralelamente y de acuerdo a lo expresado por gestores de los proyectos, se pudo evidenciar que la premisa de estos programas de RS, radica en brindar ayuda de forma desinteresada y voluntaria, sin limitaciones frente a los inconvenientes económicos que en la actualidad afrontan, sumado a la presión por parte de la leyes impuestas actualmente, que obligan al cumplimiento de programas sociales, lo que se alinea con la teoría sobre RS expuesta, la misma que busca el desarrollo de sus grupos de interés tomando en cuenta los aspectos económico, social y ambiental.

Las estrategias y programas implementados en Ecuador han sido desarrollados en función de las necesidades sociales de los ciudadanos y de las exigencias de las 
normativas y las leyes, lo que ha llevado a elaborar mecanismos para incrementar la transparencia y el control de la corrupción. De esta manera, la aplicación de las herramientas de evaluación en este análisis, indican que el concepto de responsabilidad social y la práctica de la transparencia y rendición de cuentas, están relacionados con informar sobre los aspectos económicos, más de carácter legal impositivo, y los aspectos medio ambientales, generalmente asociados a los impactos en el desarrollo territorial. Esta innovación pública mediante el recurso de estrategias de Responsabilidad Social contribuye al progreso de la sociedad mediante los valores de transparencia, ética política, participación ciudadana e igualdad, generando más confianza entre el Estado y la Sociedad. 


\section{Referencias}

Argandoña, A., \& Isea Silva, R. (2011). ISO 26000 una guía de responsabilidad de las organizaciones. Instituto Politécnico Nacional.

Asamblea Nacional. (18 de Mayo de 2004). Ley Orgánica de Transparencia y Acceso a la información pública. Quito, Pichincha, Ecuador: Reg. Oficial No. 337.

Asamblea Nacional. (20 de Octubre de 2008). Constitución de la República del Ecuador. Quito, Ecuador.

Banco Mundial. (2000). Anticorruption in Transition: A Contribution to the Policy Debate. Washington, D.C.: World Bank-International Bank for Reconstruction and Development.

Canovas García, J., \& Mateos García, J. (2014). Responsabilidad Social Corporativa: más que un modelo de gestión, un reto para las Administraciones Públicas. Escuela de Formación e Innovación, 8.

CCE, C. d. (18 de Julio de 2001). Libro Verde. Fomentar un marco europeo para la responsabilidad social de las empresas. Obtenido de http://www.europarl.europa. eu/meetdocs/committees/deve/20020122/com(2001)366_es.pdf

CEPAL, C. E. (Abril de 2004). Responsabilidad Social corportiva en América Latina: una visión empresarial. Obtenido de https://repositorio.cepal.org/bitstream/ handle/11362/5621/1/S044214_es.pdf

Contraloría General, d. E. (14 de Diciembre de 2009). Normas de Control Interno de la Contraloría General del Estado. Quito, Pichincha, Ecuador: Registro Oficial No. 87 .

Fox, T., Ward, H., \& Howard, B. (2002). Public sector roles in strengthening corporate social responsability: a baseline study. Banco Mundial.

González, M., \& León, M. (2013). Responsabilidad Social Empresarial: Aproximación a las líneas de actuación públicas de la Unión Europea, América Latina y el Caribe. Actualidad Económica, 4-11.

GRI Empowering Sustainable Decisions. (s.f.). Obtenido de www.globalreporting.org/ standards/

Hernández Sampiere, R., Fernández Collado, C., \& Baptista Lucio, P. (2006). Metodología de la investgación. México: McGraw-Hill Interamericana.

International Organization for Standardization. (s.f.). Obtenido de https://www. iso.org/standards.html 
Lozano, J., Albareda, L., Ysa, Rosher, \& Marcuccio. (2005). Políticas Públicas más alla de la regulación y la voluntariedad. Los gobiernos y la responsabilidad social de las empresas.

Navarro Galera, A., Alcaraz Quilez, F., \& Ortiz, D. (2010). La divulgación de la información sobre responsabilidad corporativa en administraciones públicas: un estudio empírico en gobiernos locales. Revista de Contabilidad, 285-314.

Navarro Galera, A., Ruiz Lozano, M., De Los Rios Berjillos, A., \& Tirado Valencia, P. (2013). La responsabilidad social corporativa en los gobiernos locales: el caso de Reino Unido e Irlanda. Innovar.

Norma Técnica de Implementación y Operación de la metodología y herramienta de Gobierno por Resultados. (28 de Diciembre de 2011). Quito, Pichincha, Ecuador: Registro Oficial No. 606.

Observatorio de Responsabilidad Social Corporativa. (2003). Obtenido de : http://observatoriorsc.org/normas-sobre-las-responsabilidades-de-las-empresas-transnacionalesy-otras-empresas-comerciales-en-la-esfera-de-los-derechos-humanos/

OCDE. (2011). OECD.org. Obtenido de http://www.oecd.org/daf/inv/mne/oecdguidelinesformultinationalenterprises.htm

OIT. (2001). Oficina Internacional de Trabajo . Obtenido de http://www.ilo.org/wcmsp5/groups/public/---dgreports/---dcomm/documents/normativeinstrument/ kd00121es.pdf

ONU, O. d. (2015). Informe Bruntdland. Obtenido de www.un.org/sustainabledevelopment/es/

ONU, O. d. (s.f.). Organización de las Naciones Unidas. Obtenido de https://www. un.org/es/about-un/

Orjuela Cordova, S. (2011). La comunicación en la gestión de responsabilidad social empreasrial. Correspondencia y Análisis.

Puig i Campmany, M., \& Martínez i Hernández, A. (2008). La Responsabilidad Social de la Administración. Un reto para el siglo XXI. Desarrollo Económico, 49.

Ruiz, C., \& Ruiz, R. (2014). Responsabilidad Social Pública y Calidad Democrática. Derecho y Cambio Social, 4.

Senplades, S. N. (22 de Septiembre de 2017). Plan Nacional de Desarrollo 2017 2021. Toda una Vida. Quito, Pichincha, Ecuador.

United Nations Global Compact. (s.f.). Obtenido de www.unglobalcompact.org/whatis-gc/mission/principles 
Viteri, J., \& Jácome, M. (2011). La responsabilidad social como modelo de gestión empresarial. EIDOS, 3-9.

Zenck Huerta, M. C., Rios Rivera, I., Pogo García, L., \& Cueto Cedillo, C. (2017). Análisis de la transparencia sobre las políticas locales de responsabilidad social en Ecuador: Estudio de los casos de Quito, Guayaquil y Machala. Revista Iberoamericana de Contabilidad de Gestión. 


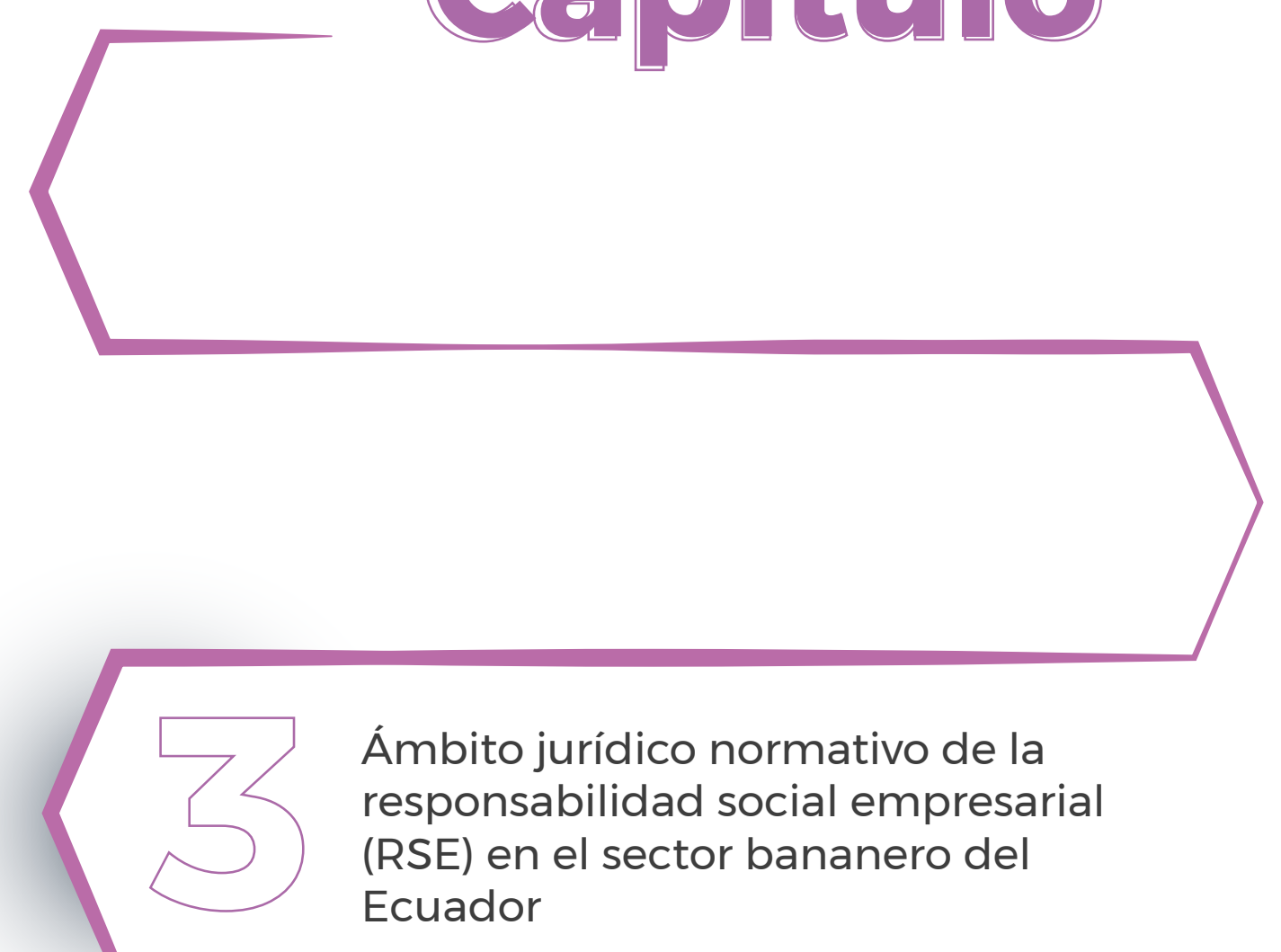


Ámbito jurídico normativo de la responsabilidad social empresarial (RSE) en el sector bananero del Ecuador 


\section{Ámbito jurídico normativo de la responsabilidad social empresarial (RSE) en el sector bananero del Ecuador}

\section{Rocío de Lourdes Guzmán Arias}

Docente e investigadora de la Universidad Técnica de Machala, Abogada de los Tribunales y Licenciada en Ciencias Políticas y Sociales, Magíster en Derecho Civil, Doctoranda en Derecho- Universidad Da Coruña. 


\section{Resumen}

La importancia de la Responsabilidad Social Empresarial, en adelante RSE, ha evolucionado en los últimos tiempos; en este sentido, el gobierno ecuatoriano ha creado políticas y programas para hacer efectiva su aplicación. En la presente investigación, se analiza la importancia y papel que desempeña el derecho en la aplicación de la RSE en el ordenamiento jurídico ecuatoriano, y cómo estos inciden específicamente en el sector bananero. La normativa jurídica existente al respecto, contempla leyes, reglamentos, decretos, resoluciones, entre otros. Sin embargo, la balanza se inclina al aspecto económico y la protección de los bienes, llamados derechos colectivos o derechos humanos. El objetivo de este trabajo, es analizar la incidencia del marco normativo jurídico respecto a los principios de la RSE, en las áreas de los derechos humanos, ambientales y laborales del sector bananero del Ecuador. En la metodología cuenta con una investigación de tipo documental que abarcó la revisión de trabajos investigativos y normativas, mediante un estudio descriptivo y de corte transversal, basado en información cualitativa. Se concluye que, las normativas de RSE se encuentran vinculadas con las normativas ecuatorianas, así como, en los tratados y convenios Internacionales de que Ecuador es parte y por ende vinculantes, por ejemplo, la Declaración de Derechos Humanos, Convenio Marco de las Naciones Unidas sobre cambio climático, convenio sobre abolición trabajo forzoso, Convenio sobre la discriminación, sobre todo a lo relacionado al respeto de los derechos humanos, al medio ambiente y los derechos laborales de los trabajadores, aspectos relacionados al sector bananero del Ecuador.

Palabras claves: responsabilidad social empresarial, ordenamiento jurídico, sector bananero.

\section{Introducción}

\section{Antecedente}

El mandato constitucional que existe en Ecuador en sus diversas aristas, acompañada con el "Plan toda una vida", nos obliga a plantearnos la interrogante, de que, ¿si en el sector bananero ecuatoriano se cumple con los principios de la RSE? La Constitución ecuatoriana impulsa el régimen del desarrollo mediante sus principios generales que establece directrices para construir un sistema económico sostenible justo y respetuoso de la naturaleza (Morán, 2016). De la lectura rápida que realizamos a la normativa ecuatoriana, en cuanto al cumplimiento de la responsabilidad social empresarial, podría decirse, que si se legisla en cuanto al tema, del análisis hecho a las normativas existentes sobre la RSE, se encontró que se acopla en beneficio de los cuatro aspectos, que son; económicos, laborales, sociales y ambientales. 
El tema de la responsabilidad social empresarial, en los últimos años, ha tenido su auge en todo el mundo, las empresas hacen sus esfuerzos por dar cumplimiento a esta normativa, sin embargo, pese al esfuerzo realizado, se puede evidenciar la vulneración de los derechos humanos y de los derechos de la naturaleza. En ese mismo orden de ideas, la actual constitución del Ecuador en su artículo 71 considera a la naturaleza como sujeto de derechos, y no, objeto de derechos, como era considerada anteriormente (Constitución del Ecuador, 2008). Por lo tanto, surge la necesidad de adaptar la actuación de las empresas, en respeto al medio ambiente.

En Ecuador, se han realizado importantes cambios en cuestión de legislación y exigencias a las empresas, haciendo que las empresas se preocupen cada vez más por la preservación ambiental, concientización de la naturaleza, reducir la desigualdad social. En la actualidad, se toma muchas medidas proteccionistas para el medio ambiente por lo que, las empresas deben acogerse a los lineamientos establecidos para su conservación y que es una responsabilidad y obligación para las empresas (Poveda \& Parrales, 2018). Las organizaciones públicas y privadas para el debido cumplimiento de la RSE, toman en cuenta el marco jurídico vigente, haciendo que sus prácticas empresariales sean responsables.

La RSE llega a generar bienestar y desarrollo en las empresas, así como también en el entorno en donde se desarrolla. Su implementación, especialmente si se realiza de forma adecuada contribuye a que las administraciones empresariales cumplan sus objetivos y generen confianza en su entorno. De esta manera, a partir de la aplicación de estrategias empresariales, las empresas buscan obtener beneficios tanto internos como externos, los mismos que deben verse reflejados en el entorno empresarial y en el medio ambiente, a través del progreso y la mejora en la calidad de las relaciones sociales de la empresa con el entorno en donde se desenvuelve.

En el tema que nos compete, las empresas bananeras en el afán de obtener mayores beneficios, no deben descuidar la ética en sus actuaciones; este tema reviste gran relevancia, debido a que la ética es parte fundamental de todos los aspectos de la vida humana, lo que incluye a las organizaciones, independientemente de la actividad económica a la que se dediquen; y, una de las formas en que se materializa la ética es con el cumplimiento de las leyes establecidas para el efecto.

El irrespeto a los derechos de los colaboradores y por el medio ambiente ha hecho que la RSE alcance un mayor desarrollo en los últimos años, Ecuador ha incluido en sus distintas leyes del país, normativas que indirectamente contribuyen a la responsabilidad social empresarial. Las empresas en su afán de conseguir un desarrollo económico más elevado, realizan prácticas socialmente responsables (Coba, Díaz, Zurita, \& Proaño, 2017). No solo las empresas han tenido la necesidad de aplicar dicha responsabilidad por las buenas prácticas, sino también por proyectar una buena imagen, y también está considerada como parte importante de la sustentabilidad de las empresas, por ello, debería estar incluida en toda cultura organizacional para lograr así un respeto hacia las personas, comunidades y el medio ambiente en general. Por otro lado, algunas empresas, toman a dicha res- 
ponsabilidad como una estrategia para dar una buena imagen; en fin, es analizada desde distintos puntos de vista. En Ecuador, actualmente la responsabilidad social es considerada como un método de sostenibilidad, mejora de procesos y optimización de los recursos que influyen en la reducción de costos (Acosta, 2018).

La RSE solicita de las empresas una buena actuación a nivel corporativo, que se evidencie tanto en el interior como en el exterior de la misma. Esto significa que son necesarias establecer buenas relaciones con el personal que labora en las bananeras del país, transparencia en la ejecución de sus actividades, respeto hacia los clientes y preocuparse por el impacto de sus operaciones en el medio ambiente (Wojtarowski, Silva, Piñar, \& Negrete, 2016). Este aspecto es de suma importancia, puesto que al ser Ecuador uno de los países con mayor producción de banano; las bananeras se encuentran muy cerca de zonas pobladas, que, en la mayoría de los casos, se sienten afectadas, por los olores químicos de las fumigaciones aéreas. Frente a estas situaciones el gobierno nacional y local han impulsado la adopción de políticas formales para difundir la RSE, motivando en el hecho de que puede favorecer en la convivencia armónica, así como, con las ventajas competitivas en determinados mercados que buscan entablar relaciones con empresas socialmente responsables (Chumaceiro, Hernández, \& Ziritt, 2013).

En otro orden de ideas, las empresas medianas y pequeñas - Pymes, llevan a cabo prácticas de RSE de forma incipiente, y, sus esfuerzos se traducen en acciones poco sistemáticas. En Ecuador se han llevado a cabo grandes esfuerzos para que las empresas cumplan con las leyes ambientales y realicen las inversiones necesarias para un correcto funcionamiento, siendo esto un factor determinante para que las empresas consideren importante a la RSE (Coba, Díaz, Zurita, \& Proaño, 2017). Por lo tanto, se estima que en Ecuador existe un avance significativo en prácticas como: producción orgánica y comercio justo, además del impulso a un turismo responsable, enfocados en un mercado que conoce la importancia de este tema (Villacís, Suárez, \& Güillín, 2016).

\section{Justificación}

La presente investigación tiene su impacto, en la medida que el derecho y el ordenamiento jurídico de un país, no es estático, sino al contrario, es dinámico, y, en ese dinamismo obedece a las necesidades que reclama la sociedad, siendo una de esas necesidades, el cuidado de la naturaleza, protección en el ámbito laboral dentro de una empresa, el aspecto social, y por supuesto, el aspecto económico, que es el generador clave en la riqueza de un país.

La Constitución ecuatoriana del 2008, señala que Ecuador es un "Estado de Derecho y Justicia Social” (CE, 2008), por lo cual, el estado debe regir su actuación, al cumplimiento de las responsabilidades sociales en beneficio de la comunidad toda. En este orden de ideas, hablar de responsabilidad social empresarial, se está hablando también de desarrollo sostenible y sustentable, que nos sirve para elevar 
la calidad de vida de todas las personas miembros de un país, sin menoscabar los derechos consagrados a la naturaleza, ni los derechos de las personas trabajadoras; y, al centrarse la investigación en el sector bananero, el cual, es un sector que abarca muchas áreas a proteger, por ejemplo: el medio ambiente, ámbito laboral con el respeto al derecho de los trabajadores, impacto social y apoyo a la comunidad o acción social, sector productivo y económico, pago de impuestos, la igualdad de condiciones, entre otros.

La posición de la autora en este capítulo, es sostener que la RSE constituye un nuevo reto para el Derecho, porque en Ecuador falta aún mucho por hacer en materia legislativa, la RSE no se ha regulado de manera específica, sino más bien, existen un conjunto de normas independientes que merecen ser refundidas en un solo cuerpo normativo, por lo tanto, este capítulo pretende abrir el debate jurídico en torno a esta figura, para proponer cambios sustanciales dentro del abanico del ordenamiento jurídico ecuatoriano, con respecto a la RSE.

\section{Objetivo general}

Analizar la incidencia del marco normativo jurídico respecto a los principios de la RSE en las áreas de los derechos humanos, ambientales y laborales del sector bananero del Ecuador.

\section{Objetivos específicos}

- Revisar la evolución de la normativa nacional e internacional acerca de la RSE.

- Analizar el impacto de la RSE en la actividad del sector bananero del Ecuador, desde el ámbito del ordenamiento jurídico establecido.

\section{Materiales y métodos}

En la presente investigación se utilizó una metodología de análisis - síntesis. Es una investigación de alcance descriptivo y de corte transversal, basada en información cualitativa. Se revisaron diversas normativas sobre la temática, tanto nacionales como internacionales, destacando su crecimiento normativo a nivel mundial. Se hizo una revisión bibliográfica para identificar fuentes primarias relacionadas a la RSE a nivel internacional y su aplicación en Ecuador. 


\section{Resultados y discusión}

Uno de los fines importantes de esta investigación fue tener una visión clara de la perspectiva de la RSE en el sector bananero, teniendo en cuenta las normativas que se han ido desarrollando y que van en armonía con esta temática, sobre todo lo relacionado con el medio ambiente y el derecho de los trabajadores. Es evidente la lucha que tienen que continuar los sectores afectados; en el tema laboral sólo existe un pequeño avance en las Comisiones sectoriales de los trabajadores, carecen de programas de salud ocupacional y ambiental del sector bananero. En el área ambiental, Ecuador acoge algunos tratados y convenios internacionales que coadyuvan a la protección de la naturaleza, tales como, Declaración de Río sobre Medioambiente y Desarrollo, Convenio Marco de las Naciones Unidas sobre cambio climático, el Protocolo de Kioto. Estos tratados y convenios van de la mano con lo establecido en la Carta Magna ecuatoriana con respecto a los derechos de la naturaleza.

Se evidencia una marcada tendencia en varios países, incluido Ecuador, en reglar y normar con respecto a la RSE, sobre todo acogerse a varios acuerdos entre actores globales, los mismos que son tendencias a nivel mundial y van de la mano con los Derechos Humanos, los Principios de la Organización Internacional del Trabajo (OIT), el Desarrollo y la Convención de la Organización de las Naciones Unidas (ONU) contra la corrupción.

El debate sobre la obligatoriedad de la RSE aún se mantiene, sin embargo, los principios especiales de este sistema van cobrando fuerza, a través de las leyes aprobadas de los diferentes convenios y tratados internacionales, los mismos que son vinculantes para Ecuador, como país suscrito. En la legislación ecuatoriana no existe una normativa específica que regule la RSE, algunas leyes mencionan tangencialmente el término, por otra parte, la doctrina realiza ciertas aportaciones, sin que se llegue a un profundo análisis y tratamiento legislativo, por lo tanto, se trataría de un derecho blando. Las iniciativas de RS invitan a las empresas de forma voluntaria a acoger los principios de la RSE, sin que en caso de incumplimiento, se sancione.

\section{La responsabilidad social en el sector bananero}

El sector bananero se caracteriza por ser uno de los sectores productivos más importantes del país, pese a las continuas crisis que le ha sobrevenido, se mantiene en una posición referencial, como generador de divisas en el país y como fuente de trabajo para miles de ecuatorianos. Según (Sánchez, 2016) "La exportación bananera representa también el 2\% del PIB general, 26\% del PIB agrícola, $8 \%$ de las exportaciones generales, $27 \%$ de las exportaciones agropecuarias y $20 \%$ de las exportaciones no petroleras".

La forma como se lleva a cabo el proceso de monocultivo del banano es una de las características más problemáticas del sector, pues el uso de químicos altamente 
peligrosos desencadenan una serie de enfermedades a los trabajadores; enfermedades que van desde enfermedades respiratorias hasta enfermedades catastróficas como el cáncer. Esto debido a la falta de cuidados y políticas de seguridad empleados para el trabajo. Algunas empresas bananeras tienen creadas fundaciones con servicios de salud, sin embargo, el trabajo estas realizan, son muy superficiales, sin prestar mayor atención a las diversas enfermedades existentes, como por ejemplo, trastornos musculares, enfermedades mentales, problemas a los órganos, en la piel, entre otros. Al parecer, algunas empresas crean una especie de cortina de humo, haciendo creer que cumplen con las leyes y fomentan la RSE.

Otra de las problemáticas identificadas en el área laboral dentro del sector bananero es, relacionado a la inexistencia de contratos laborales y pago de salario por debajo de los establecidos en las tablas sectoriales de cada año. Extensión de horarios por más de 12 horas en los tiempos de cosecha y la polivalencia de las tareas del trabajador (Vitali, 2017).También se ha identificado en el sector bananero, la discriminación del trabajo realizado por mujeres, a pesar de que realizan similar trabajo que un hombre, no existe el mismo reconocimiento salarial, a esto se suma, los despidos por situaciones de embarazos, quedando indefensas en un momento muy importante de sus vidas.

Por lo expresado, en Ecuador se han realizados importantes cambios en la legislación; en especial en lo laboral y empresarial. Sin embargo, las empresas de manera general no prestan mucha atención a los temas sociales y ambientales, siendo escasas las empresas que de manera voluntaria implementan la filosofía del RSE de manera sostenible (Coba Molina, Díaz Córdova, Zurita Meza, \& Proaño López, 2017).

\section{Exigencia o voluntariedad en la aplicación de la RSE}

Según lo hemos expresado la RSE y su aplicación en el ámbito empresarial surge de factores voluntarios, sin embargo, en diferentes países del mundo, se han plasmado diferentes normativas en torno a esta temática. Y, Ecuador no se ha quedado rezagado en esta regulación. Cuando nos referimos al carácter voluntario de la aplicación de los instrumentos de la RSE estamos frente al régimen de softlaw, un ejemplo claro de este régimen son los códigos de buen gobierno en donde se expresa la voluntad y la disposición de la empresa para el reconocimiento de todos los intereses en juego (González \& García, 2006).

El softlaw tiene su importancia en la medida que no es exigible para ninguna empresa, y no esta revestido del poder sancionatorio del Estado. Mas bien, se trata de un recurso que es acogido y respetado de manera voluntaria por parte de los involucrados, como parte de un compromiso a respetar. Es decir, es una autorregulación que desean afrontar las empresas. Algunos de los defensores de este sistema, consideran que existe mayor agrado en la satisfacción de los consumidores y clientes y que, por lo tanto, no es necesario que exista la exigibilidad de la ley 
para tener una empresa socialmente responsable (Ibarra Padilla, 2014). Ejemplo de este sistema son los instrumentos internacionales que la RSE quiere establecer de manera voluntaria, quedando a discreción de las empresas el acogerlas, careciendo de fuerza obligatoria y su incumplimiento no genera sanción ni afectación en la empresa(Acevedo Guerrero , Zárate Rueda , \& Garzón Ruiz , 2013).

Lo contrario a este sistema voluntario es el sistema hard law, los defensores de este sistema enfatizan que la RSE no puede dejarse al libre albedrío de las empresas, ya que algunas empresas consideran que la "RSE solo tiene sentido si el costo de desplegar un comportamiento más virtuoso continúa siendo menor que los beneficios” (Vogel, 2005).

Bajo estos criterios, algunos países han optado por incentivar a aquellas empresas que son socialmente responsables, manteniendo una serie de incentivos para aquellas empresas que cumplan con los estándares de RSE, pudiendo ser, rebajas en los impuestos, destacar y aplaudir su gestión públicamente,

La puesta en marcha de la RSE debe ser considerada como un acto voluntario por parte de las empresas, donde impere la consciencia social, mas no, como una imposición al que se deban ajustar. El sector empresarial a más de obtener un beneficio financiero, busca ser bien visto ante la sociedad, porque eso realzará su nivel competitivo, pues, aquellas empresas que son socialmente responsables, son mayormente reconocidas por el consumidor, y esto conlleva a su divulgación, provocando beneficios en la publicidad de la empresa (Lizarzaburu \& Brito , 2016) . Sin embargo, lo que en la actualidad mueve en gran medida al empresario a acogerse a la RSE es tener armonía con la protección a la naturaleza y por ende al entorno social. En este sentido, hoy en día una empresa no puede estar alejada de las exigencias actuales, siendo estas: creatividad, innovación, mejora de la cadena de producción, calidad y sostenibilidad, aceptación de referentes y normativas internacionales, entre otros. En una investigación profunda realizada en Europa, se pudo verificar que por ejemplo, en la mayoría de las empresas europeas no conciben la RS como una nueva forma de hacer negocios, sino como una novedosa herramienta de gestión que les permite realizar acciones responsables y comunicarlas (Sánchez, 2018).

Pues, la alarmante situación que enfrenta el planeta, ha llevado a plantearnos alguna solución para mitigar los daños causados por el hombre. Las consecuencias del calentamiento

se hacen visibles en nuestros días, los desastres naturales se han desencadenado a nivel mundial con efectos desastrosos. La extinción de animales y plantas también nos hacen pensar en una solución. El crecimiento de enfermedades raras y catastróficas también son efectos del mal manejo del medio ambiente. Todos estos ejemplos enunciados son una clara muestra de la urgente necesidad de tener consciencia en la actividad empresarial. Además, tenemos las enfermedades profesionales, y sobre esto, existe la percepción de que las innovaciones no son necesarias, razón por la cual, se siguen utilizando prácticas antiguas que van en desmedro de la salud y condiciones físicas de los trabajadores (Murillo Barrera, 2018). 
Sin embargo, pese a esta difícil situación, podemos también evidenciar que muchos empresarios, llámense pequeños o grandes, no tienen interés en la RSE, sus actuaciones en desmedro de la propiedad privada, inmoralidad, corrupción, afectación a clientes, violación de derechos, entre otros, no tienen límites, lo importante son sus estados financieros (Moya Arana, 2014).

Las organizaciones deben tener claro que es lo que desean con la RSE, si desean ser realmente responsables con la sociedad, y hacer del RSE parte de su estructura organizacional; ser empresas sólo con programas de responsabilidad social, aplicando únicamente uno de los objetivos del RSE; o simplemente negarse a una realidad empresarial que cada vez toma más vigencia en mundo, debido a la globalización(VVAA, 2017).

La aplicación de la RSE en los diferentes sectores no es una tarea tan sencilla, es una cuestión de tiempo. Las empresas deberían contribuir a la formación y capacitación de los jóvenes y futuros empresarios, con programas de divulgación de los conceptos empresariales, de emprendimiento, de buena gobernanza y responsabilidad social, así como de transparencia y ética en los negocios (Olcese, 2015) y de esta forma estamos creando una conciencia de responsabilidad social a los futuros empresarios de la sociedad. También es importante que desde la academia debe reforzarse el tema de adhesión al RSE ya que permite alcanzar sostenibilidad y sustentabilidad (Luzurriaga, 2018).

\section{Evolución de la RSE en el marco normativo internacional}

A partir de los años sesenta, la RSE era conocida bajo el concepto de Corporate Social Responsibility (CSR) en Estados Unidos, luego, esta idea empezó a plasmarse en Europa en el año de 1990. La comisión Europea acoge el concepto CSR haciéndolo oficial en los lineamientos de la Unión Europea, plasmándose en el Libro Verde, documento que en lo posterior servirá de base para que las empresas de manera voluntaria, decidan considerar aspectos económicos, sociales y ecológicos en sus actividades empresariales (Schulze \& Pszolla, 2011).

La comunidad, exige que la actividad empresarial y económica cumpla con un bien común. Es descifrable que las organizaciones busquen como a dé lugar el beneficio propio a un camino de éxito empresarial, siempre y cuando sigan los lineamientos sobre los derechos de una sociedad.

La Responsabilidad Social Empresarial es el conjunto de las acciones innovadoras de una organización, basadas en el cumplimiento de las leyes y en los valores éticos, para institucionalizar un gobierno corporativo transparente que integre en las actividades en curso de la organización la generación de riqueza respetuosa de los derechos humanos con las responsabilidades de sus actividades sobre la sociedad y el medio ambiente. De todas estas acciones debe rendir cuentas a la sociedad. (Martínez, 2010). 
Para concretar la RSE se la puede comprender como una gran cantidad de actividades escrupulosas y metódicas, que las empresas realizan en su interior, para aumentar la satisfacción personal, la protección de la tierra y el avance social de la nación.

Según, (Hurtado, 2008) por lo general, es frecuente encontrar referencias al uso de la Responsabilidad Social en las Empresas en declaraciones públicas o en las comunicaciones generales. Sin embargo, pese a la cantidad de la misma aún existe escases de información académica y científica sobre estos propósitos.

En el siglo XX se empieza a desarrollar la RSE de una manera moderna, Estados Unidos fue uno de los países en donde comenzó a tener un crecimiento económico, lo cual produjo cambios sociales. La separación que se dio entre las propiedades empresariales y la extensión de las mismas organizaciones fueron el principal motivo para impulsar la información y la gestión sobre la responsabilidad social empresarial. (Acuña, 2014).

Otros de los primeros enfoque de la RSE fue la Segunda Guerra Mundial, donde se señaló que las empresas americanas deberían llevar ciertas obligaciones sociales. Se buscada sacar provecho a la búsqueda del interés público por parte de las empresas en apoyar la educación, la estabilidad económica, la solidaridad y conservación de los recursos naturales.

En Ecuador las primeras empresas que empiezan a incorporar este concepto en sus actividades, son las empresas multinacionales y las empresas exportadoras. En relación a esta temática, Ecuador ha tomado impulso, sobre todo a lo relacionado a la producción agrícola, empresas asociativas, empresas turísticas. Sin embargo, esta actuación antes del año 2008, todavía era considerada como aislada, debido a la falta de modelos de gestión con indicadores en materia ambiental y social. La adopción de la RSE como modelo de gestión no es fácil, porque necesitan mantener un equilibrio entre la dimensión social, medioambiental y económica (Armijos, 2017).

Es a partir de la entrada en vigencia de la Constitución del año 2008, en que empieza visualizarse cambios significativos en torno a la RSE. El Plan Nacional del Buen Vivir, también cumplió un papel importante en las políticas de gobierno de ese entonces, donde la frase SumakKawsay era considerada como la meta a seguir, basado en el cumplimiento de responsabilidad social y compromiso ético relacionado con la naturaleza, considerado como pilar básico de la humanidad (Villacís, Suárez, \& Güillín, 2016).

El Instituto de Responsabilidad Social Empresarial, también jugó un papel importante en Ecuador, cuya misión era plasmar una cultura de desarrollo sostenible basada en la RSE. Otra de las normas internacionales a los cuáles Ecuador se ha acogido con respecto al RSE y que se vincula al área de la producción agrícola, son las Normas GLOBALG.A.P, que nace de la organización sin fin de lucro que lleva su mismo nombre y que es la encargada de recopilar las certificaciones de buenas prácticas agrícolas para todas las cadenas de comercialización (Sánchez, 2016). 
Según lo manifestado por el gerente de Global Forum en Ecuador, más de 970 empresas ecuatorianas cuentan con el certificado de Global Gap. Para tener acceso a esta certificación, las empresas deben aprobar criterios de inocuidad alimentaria, trazabilidad, aseguramiento de la calidad, seguridad ocupacional, buen manejo de productos de uso agrícola y que resultan en su mayoría nocivos para el ser humano y por ende para el entorno social. La obtención de esta certificación puede demorar más de un año, dependiendo si la empresa es pequeña o grande (Anchundia \& Quinatoa, 2018).

La certificación, además, facilita el ingreso de los productores a los procesos de exportación contribuyendo a la expansión del mercado. En la actualidad Global Gap se ha establecido en el mercado global como requisito indispensable para en cuanto a las buenas prácticas agrícolas se refiere, logrando que los derechos del consumidor se vean reflejados en la producción agrícola de mas países. En este sentido, Ecuador al ser uno de los máximos exportadores de banano en el mundo, es el país con mayor superficie de banano certificada por Global Gap, seguido por Colombia, Costa Rica y la República Dominicana.

El marco legal en que se basa la RSE, es la regulación de los organismos externos, la propia normativa nacional, como, por ejemplo, la aplicada por la Superintendencia de Economía Popular y Solidaria del Ecuador, así como, los propios estamentos de cada empresa. Como normativa principal en el RSE está El Pacto Global, iniciativa de la ONU que quiso establecer en los procesos de producción, el acatamiento a diez principios básicos, principios basados en cuatro ejes: los derechos humanos, situaciones laborales, cuidado de la naturaleza y procesos libres de especificar.

En los derechos humanos, invita a las empresas a reconocer y respetar todos los derechos humanos reconocidos universalmente. Considerar el tema de los derechos humanos enmarcado al área empresarial no es algo nuevo, este tema fue una de las bases que sustentó el nacimiento de las Naciones Unidas, organismo creado para garantizar la paz universal y el desarrollo de las naciones (Gómez \& Riquelme, 2019).

Los derechos laborales se hacen hincapié a la libertad de asociación, la eliminación de trabajo forzoso, la erradicación del trabajo infantil y toda práctica discriminatoria en el trabajo. Pues, por mucho tiempo se creía que el tema del respeto de los derechos humanos eran un tema que sólo debía preocupar al Estado, y que el papel de la empresa era tan solo de asumir un deber general de cumplimiento de tales derechos, sin que las empresas tuvieran un papel importante en la promoción y defensa (Bonilla, 2017).

En relación con la protección del medio ambiente, se insta a la prevención en el daño a la naturaleza, la responsabilidad ambiental y el crecimiento tecnológico respetuoso del medio ambiente. Y, el último eje que aborda el Pacto Global es el combate a todas las formas de corrupción, incluidos el soborno y la extorsión. 
Los principios del Global Compact, es un código de referencia a nivel mundial, esta normativa constituye una iniciativa voluntaria para aplicar diez principios universales en materia de RSE basados en los ejes de: derechos humanos, derechos laborales, medio ambiente y corrupción.

Otra de las normativas que han sido referentes para las empresas que buscan adaptarse a la RSE son las normativas de la familia ISO. Las normativas de Organización Internacional de Normalización (ISO), es aquella estructura sistemática de alcance mundial y está integrada por 162 países, incluido Ecuador. Es una organización de naturaleza no gubernamental. La misma busca promover el desarrollo de la estandarización y las actividades relacionadas con ella en todo el mundo.

La mayoría de las normas internacionales adoptan un enfoque basado en procesos, cuando se desarrolla, implanta y mejora la eficacia de un Sistema de Gestión de la Calidad (SGC), con el objeto de aumentar la satisfacción del cliente. Un enfoque basado en procesos, dentro de un SGC, destaca la importancia de la comprensión y el cumplimiento de los requisitos, la necesidad de considerar los procesos en términos que aporten valor, la obtención de resultados del desempeño y eficacia del proceso, y la mejora continua de los procesos basada en mediciones objetivas. En las organizaciones de hoy, la dirección debe tomar decisiones a tiempo basándose en hechos. La implantación y certificación de un SGC, basado en esta norma, proporciona una serie de herramientas para priorizar la toma de decisiones, como son la definición de indicadores claves y sus objetivos, así como la identificación de acciones a corregir o mejorar en todas las áreas de la organización (ISO 9001 Gestión de la calidad ).

Otras normativas, dentro de las cuales tenemos la ISO 14001, encargada del Sistema de Gestión Ambiental; la ISO 14004 que se basa en los principios de un Sistema de Gestión Ambiental; la ISO 14010 establece todos los principios generales sobre las auditorias de la Responsabilidad Social dentro de la empresa, es una iniciativa de la escuela europea de excelencia sobre la gestión ambiental; la ISO 19011 sustitutiva de la ISO 14011 abarca una amplia gama de funciones relacionadas con las auditorías en general; la ISO 14012, establece los criterios fundamentales para poder calificar a los auditores; la ISO 14013 establece una guía de consultas a la hora de realizar la revisión de la certificación ambiental. Como vemos, es amplia la familia de las ISO, también se destacan dentro de la temática que nos competen, las ISO 14014, 14015, 14031, 14032, 14060.

Dentro de los integrantes de la familia ISO merece especial consideración la ISO 26000, siendo esta una guía sobre la aplicación de mejores prácticas en responsabilidad social empresarial en todo el mundo. Esta normativa permite la comprensión y la implementación de la RSE mediante el desarrollo de un consenso internacional sobre lo que significa RSE y la difusión de las mejores prácticas realizadas y la asesoría para que se sigan presentando en otras empresas. Al contrario, con otras normas ISO, la ISO 26000 no es una norma de sistema de gestión y por 
lo tanto no es certificable. Esta se presenta como una guía voluntaria que no propone requisitos, sino más bien, pretende ser una guía práctica sobre la operatividad de los procesos relacionados con la RSE.

Sin embargo, la norma ISO 26000 nos aporta siete principios básicos, a través de los cuales se orienta específicamente la gestión del medio ambiente en la empresa, desde el punto de vista de la organización, la gobernanza, los derechos humanos, las prácticas laborales, el medio ambiente, las prácticas de operación, los consumidores y el desarrollo de la comunidad.

Otra de las normativas alineadas a la RSE, es el Reglamento EMAS (Programa Europeo del Ecogestión y Ecoauditoría), que es un sistema voluntario de auditoría de la gestión medioambiental en las organizaciones. Los EMAS se implementan para evaluar y mejorar las acciones de RSE de las organizaciones, para difundir la información pertinente con la gestión ambiental y para mantener un proceso de buena gestión de RS en las empresas. El objetivo específico del Reglamento EMAS es promover la mejora continua del comportamiento medioambiental de las organizaciones.

Siguiendo con el análisis de las normativas internacionales alineadas a la RSE está la SA 8000 (estándar de certificación internacional), la misma que tiene como objetivo, velar por mejores condiciones laborales, mediante el cumplimiento de los acuerdos internacionales y el marco regulatorio de los derechos de los trabajadores y justicia social. También, a más de la normativa anterior están los Indicadores Ethos de RSE, las cuales buscan ofrecer a las empresas un insumo para reforzar su compromiso con la RS y el desarrollo sustentable; esta organización se basa en siete aspectos: valores, transparencia y gobernanza, público interno, medio ambiente, proveedores, consumidores y clientes, comunidad y gobierno y por último sociedad. Además, se considera relevante la normativa AA1000, normativa creada por el Instituto para la Responsabilidad Social y Ética- ISEA (Instituto for Social and Ethical Accountability); esta normativa es un estándar para medir e informar sobre el comportamiento ético en los negocios. El propósito de esta organización británica es, promover el rendimiento de las cuentas a través de una valoración de la empresa, en el marco del cumplimiento de sus expectativas y derechos de los grupos de interés.

Se evidencia que, existen diversas normativas alineadas a la Responsabilidad Social Empresarial; en el siglo actual ha sido evidente el aceleramiento en la búsqueda de la aplicación de la RSE en las empresas. Una de las fuentes principales se encuentra, los acuerdos internacionales, que han colaborado en su expansión y aplicación. También dentro de esta misma lógica, las empresas utilizan ciertas pautas de medición y de esta forma alcanzar su crecimiento.

Una organización muy importante en las políticas de implementación y apertura de responsabilidad social corporativa es el Pacto Mundial de las Naciones Unidas, nace de una iniciativa voluntaria para promover el desarrollo sustentable y la ciudadanía corporativa, el mismo que cuenta con el apoyo de cinco agencias de las 
Naciones Unidas: Programa de las Naciones Unidas para el desarrollo, la Oficina de Alto Comisionado para los Derechos Humanos, la Organización Internacional del Trabajo, el Programa de las Naciones Unidas para el Desarrollo Industrial y el Programa de las Naciones Unidas para el Medio Ambiente (Montoya \& Martínez, 2012)

\section{Relación de la RSE y el ordenamiento jurídico ecuatoriano}

Como norma general o inicial la RSE surge como una cuestión voluntaria, no imperativa, por lo tanto, cabe preguntarse si su cumplimiento debe exigirse o no. Sin embargo, la misma sociedad tanto nacional e internacional clama por su regulación. Este tema reviste de importancia en los dos sectores: por un lado, el empresarial, que prefiere que la RSE siga siendo voluntaria, y, por otro lado, la sociedad civil y las ONG que desean que al menos algunas normativas sean jurídicamente exigibles.

En este orden de ideas, el tema de la RSE aplicable especialmente al área laboral y de los derechos humanos, cobra importancia en los últimos tiempos, sobre todo porque estas áreas son de gran interés a nivel internacional. Existen postulados normativos que exigen el cumplimiento mínimo de sus enunciados. Dentro de estos instrumentos normativos están: La Declaración Universal de Derechos Humanos, La Organización Internacional del Trabajo, El Convenio 87 sobre la Libertad Sindical y la Protección del Derecho de Sindicación, El Convenio 29 sobre el Trabajo Forzoso, El Convenio 111 sobre la Discriminación en el empleo (Camacho, 2015).

Al decir de (Kun, 2015) el derecho del Trabajo y la RSE van de la mano, a pesar de tener diferentes instrumentos de regulación, persiguen objetivos similares, siendo uno de ellos el equilibrio entre la eficiencia del negocio y la protección social, desarrollar medidas que garanticen un mejor trato a los trabajadores, de una manera socialmente responsable, modificando las culturas internas de las mismas. La RSE crea una nueva visión en las empresas, resaltando nuevos enfoques éticos y normativos; visión que es acogida por grandes empresas ecuatorianas, que además adoptan seguir las normativas legales vigentes.

Los lineamientos internacionales de la RSE han servido de sustento y guía en la aplicación de este modelo en Ecuador, sobre todo en aquellas empresas que desean ser responsables y sostenibles. Un papel muy importante lo han tenido los diversos organismos internacionales, la Organización Internacional del trabajo (OIT), la CEPAL, la International Organization for Standardization (ISO), entre otros. La norma ISO 26000 coadyuva para que las empresas demuestren su compromiso con la RSE, encaminados sobre todo a los derechos laborales, cuidados del medio ambiente, protección a los consumidores y usuarios y desarrollo social (Remache, Villacis, \& Guayta, 2018).

Merece especial referencia las normas ISO 26000, ya que éstas han sido una guía de orientación para las empresas, organizaciones, universidades, entidades del 
Estado, entre otros actores. Esta normativa tiene como visión plasmarse como un referente a nivel mundial que busca entre otros la sostenibilidad ambiental y el desarrollo sostenible (Andía, 2015).

La relación existente entre la RSE y el ordenamiento jurídico ecuatoriano es evidente, ya que muchas de las leyes ecuatorianas son concordantes con normativas internacionales no obligatorias y también con las obligatorias, como por ejemplo con lo regulado en los Tratados y Convenios Internacionales, que son normativas vinculantes para el país. La RSE trata de garantizar una convivencia armónica en varios sectores: laborales, ambientales, sociales, que es lo que persigue un ordenamiento jurídico de determinado país.

\section{La Responsabilidad Social en el sector bananero}

El sector bananero se caracteriza por ser uno de los sectores productivos más importantes de país, pese a las continuas crisis que le ha sobrevenido, se mantiene en una posición referencial, como generador de divisas en el país y como fuente de trabajo para miles de ecuatorianos. Según (Sánchez, 2016) "La exportación bananera representa también el 2\% del PIB general, 26\% del PIB agrícola, 8\% de las exportaciones generales, $27 \%$ de las exportaciones agropecuarias y $20 \%$ de las exportaciones no petroleras".

La forma como se lleva a cabo el proceso de monocultivo del banano es una de las características más problemáticas del sector, pues el uso de químicos altamente peligrosos desencadena una serie de enfermedades a los trabajadores; enfermedades que van desde respiratorias hasta catastróficas como el cáncer. Esto debido a la falta de cuidados y políticas de seguridad empleados para el trabajo.

Otra de las problemáticas identificadas en el área laboral dentro del sector bananero es, relacionado a la inexistencia de contratos laborales y pago de salario por debajo de los establecidos en las tablas sectoriales de cada año. Extensión de horarios por más de 12 horas en los tiempos de cosecha y la polivalencia de las tareas del trabajador (Vitali, 2017).También se ha identificado en el sector bananero, la discrimación del trabajo realizado por mujeres, a pesar de que realizan similar trabajo que un hombre, no existe el mismo reconocimiento salarial, a esto se suma, los despidos por situaciones de embarazos, quedando indefensas en un momento muy importante de sus vidas.

En Ecuador se han realizados importantes cambios en la legislación; en especial en lo laboral y empresarial. Sin embargo, las empresas de manera general no prestan mucha atención a los temas sociales y ambientales, siendo escasas las empresas que de manera voluntaria implementan la filosofía del RSE de manera sostenible (Coba, Díaz, Zurita, \& Proaño, 2017).

Se ha evidenciado en una de las mayores provincias productoras de banano como es la provincia de El Oro que, los empresarios están más interesados del 
proceso comercial del banano y que este le genere ganancias, despreocupándose de la RSE, por lo que se debería prestar mayor atención y ejecutar mejores estrategias para implementar normativas ISO 26000, indicadores de medición continua de RS, así como el uso de manuales de buenas prácticas empresariales (Vera, 2018).

El sector bananero del país, es uno de los sectores más contaminantes, porque en el proceso de cultivo hasta su exportación, las bananeras son focos de alta contaminación por la utilización de productos químicos que no solo afectan a los trabajadores del lugar, sino también a las zonas aledañas. Los plásticos que resultan del proceso, no son tratados adecuadamente, e incluso no son recolectados como basura, los mismos que desembocan en los ríos y mares. Las fumigaciones también es otro aspecto dañino que se debe considerar en las bananeras. Por lo que es importante emprender acciones de auditoría ambiental, capacitación para la correcta manipulación y educación continua.

\section{Exigencia o voluntariedad en la aplicación de la RSE}

La RSE y su aplicación en el ámbito empresarial surge de factores voluntarios, sin embargo, en diferentes países del mundo, se han plasmado diferentes normativas en torno a esta temática. Y, Ecuador no se ha quedado rezagado en esta regulación. Cuando nos referimos al carácter voluntario de la aplicación de los instrumentos de la RSE estamos frente al régimen de softlaw, un ejemplo claro de este régimen son los códigos de buen gobierno en donde se expresa la voluntad y la disposición de la empresa para el reconocimiento de todos los intereses en juego (González \& García, 2006).

El softlaw tiene su importancia en la medida que no es exigible para ninguna empresa, y no está revestido del poder sancionador del Estado. Más bien, se trata de un recurso que es acogido y respetado de manera voluntaria por parte de los involucrados, como parte de un compromiso a respetar. Es decir, es una autorregulación que desean afrontar las empresas. Algunos de los defensores de este sistema, consideran que existe mayor satisfacción en la satisfacción de los consumidores y clientes y que, por lo tanto, no es necesario que exista la exigibilidad de la ley para tener una empresa socialmente responsable (Ibarra, 2014). Ejemplo de este sistema son los instrumentos internacionales que la RSE quiere establecer de manera voluntaria, quedando a discreción de las empresas el acogerlas, careciendo de fuerza obligatoria y su incumplimiento no genera sanción ni afectación en la empresa (Acevedo, Zárate, \& Garzón, 2013).

Lo contrario a este sistema voluntario es el sistema hard law, los defensores de este sistema enfatizan que la RSE no puede dejarse al libre albedrío de las empresas, ya que algunas empresas consideran que la "RSE solo tiene sentido si el costo de desplegar un comportamiento más virtuoso continúa siendo menor que los beneficios” (Vogel, 2005). 
Bajo estos criterios, algunos países han optado por incentivar a aquellas empresas que son socialmente responsables, manteniendo una serie de incentivos para aquellas empresas que cumplan con los estándares de RSE, pudiendo ser, rebajas en los impuestos, destacar y aplaudir su gestión públicamente,

La puesta en marcha de la RSE debe ser considerada como un acto voluntario por parte de las empresas, donde impere la consciencia social, mas no, como una imposición al que se deba ajustar. El sector empresarial a más de obtener un beneficio financiero, busca ser bien visto ante la sociedad, porque eso realzará su nivel competitivo, pues, aquellas empresas que son socialmente responsables, son mayormente reconocidas por el consumidor, y esto conlleva a su divulgación, provocando beneficios en la publicidad de la empresa (Lizarzaburu \& Brito , 2016) . Sin embargo, lo que en la actualidad mueve en gran medida al empresario a acogerse a la RSE es tener armonía con la protección a la naturaleza y por ende al entorno social. En este sentido, hoy en día una empresa no puede estar alejada de las exigencias actuales, siendo estas: creatividad, innovación, mejora de la cadena de producción, calidad y sostenibilidad, aceptación de referentes y normativas internacionales, entre otros. En una investigación profunda realizada en Europa, se pudo verificar que, por ejemplo, en la mayoría de las empresas europeas no conciben la RS como una nueva forma de hacer negocios, sino como una novedosa herramienta de gestión que les permite realizar acciones responsables y comunicarlas (Gil, 2018).

Pues, la alarmante situación que enfrenta el planeta, ha llevado a plantearnos alguna solución para mitigar los daños causados por el hombre. Las consecuencias del calentamiento global se hacen visibles en nuestros días, los desastres naturales se han desencadenado a nivel mundial con efectos desastrosos. La extinción de animales y plantas también nos hacen pensar en una solución. El crecimiento de enfermedades raras y catastróficas también son efectos del mal manejo del medio ambiente. Todos estos ejemplos enunciados son una clara muestra de la urgente necesidad de tener consciencia en la actividad empresarial. Además, tenemos las enfermedades profesionales, y sobre esto, existe la percepción de que las innovaciones no son necesarias, razón por la cual, se siguen utilizando prácticas antiguas que van en desmedro de la salud y condiciones físicas de los trabajadores (Murillo, 2018).

Sin embargo, pese a esta difícil situación, podemos también evidenciar que muchos empresarios, llámense pequeños o grandes, no tienen interés en la RSE, sus actuaciones en desmedro de la propiedad privada, inmoralidad, corrupción, afectación a clientes, violación de derechos, entre otros, no tienen límites, lo importante son sus estados financieros (Moya, 2014).

Las organizaciones deben tener claro que es lo que desean con la RSE, si desean ser realmente responsables con la sociedad, y hacer del RSE parte de su estructura organizacional; ser empresas sólo con programas de responsabilidad social, aplican- 
do únicamente uno de los objetivos del RSE; o simplemente negarse a una realidad empresarial que cada vez toma más vigencia en mundo, debido a la globalización (VV.AA, 2017).

La aplicación de la RSE en los diferentes sectores no es una tarea tan sencilla, es una cuestión de tiempo. Las empresas deberían contribuir a la formación y capacitación de los jóvenes y futuros empresarios, con programas de divulgación de los conceptos empresariales, de emprendimiento, de buena gobernanza y responsabilidad social, así como de transparencia y ética en los negocios (Olcese, 2015) y de esta forma estamos creando una conciencia de responsabilidad social a los futuros empresarios de la sociedad. También es importante que desde la academia debe reforzarse el tema de adhesión al RSE ya que permite alcanzar sostenibilidad y sustentabilidad (Luzurriaga, 2018).

\section{Conclusiones}

Las normativas analizadas tienen su relevancia en la RSE porque su aplicación ayuda a la medición de los estándares necesarios para el logro de objetivos a alcanzar, basados en los diferentes organismos internacionales; los cuales permiten definir si una empresa u organización es socialmente responsable, ya que esta va en sintonía con los derechos humanos, los derechos ambientales y los derechos de los trabajadores.

El desarrollo y evolución de los principios del RSE ha sido significante a nivel mundial, y que en Ecuador estas bases han sido acogidas en muchas empresas, sobre todo, en las multinacionales. Sin embargo, existen otras empresas que no muestran interés en ser socialmente responsables, siendo el sector bananero uno de los sectores que más perjuicio causa al medio ambiente y al sector laboral.

El impacto que llegaría a tener el sector bananero con la aplicación del RSE fuera relevante, pues evitaría causar tanto daño al medio ambiente, a la salud de los trabajadores que ahí laboran y a la sociedad misma, que recibe sus efectos. Por ello, la mejora de nuestras acciones es cosa de nosotros mismos, la empresa busca cada día ser competitiva; todos los fallos, errores, las imperfecciones, los accidentes son sin duda inevitables, son consecuencias de una mala gestión (Fernández, 2018). Sin embargo, la decisión de querer ser una empresa socialmente responsable, le corresponde a los integrantes de cada empresa.

Cuando se hace la afirmación de daños al medio ambiente, se debería indicar que tipo de daños, extensión del daño y si es causa de la aplicación incorrecta de prácticas de RSE. Igual para los trabajadores. Cuantos trabajadores tiene el sector bananero ecuatoriano? Y como es el antes y después de la aplicación de los principios de RSE. 
La adopción de normativas de RSE en el ordenamiento jurídico ecuatoriano es relevante, la puesta en marcha de varios Tratados y Convenios Internacionales ayuda de una $u$ otra forma adecuar la normativa interna a los beneficios que procura una actuación social responsable. En Ecuador aún falta normar de manera específica la RSE en las empresas bananeros, existen adelantos, pero estos no son significativos. Se tiene que trabajar arduamente en el tema laboral, la salud, impacto ambiental y seguridad. Para ello, es indispensable legislar al respecto, capacitación continua de las fortalezas y oportunidades de la RSE en el sector bananero, que permitan cristalizar políticas sociales y medio aplicables a este sector. 


\section{Referencias}

Acevedo Guerrero , J., Zárate Rueda , R., \& Garzón Ruiz , W. (diciembre de 2013). Estatus jurídico de la responsabilidad social empresarial (RSE) en Colombia. $22(2), 303-332$.

Acosta-Véliz, Marjorie, Lovato-Torres, Sofía, \&Buñay-Cantos, Jahaira. (2018). La responsabilidad social corporativa y su rol en las empresas ecuatorianas. Revista Lasallista de Investigación, 15(2), 105- 117. https://dx.doi.org/10.22507/rli. v15n 2 a 8

Anchundia Gende, S., Quinatoa Vera, P., (2018). Análisis de los factores de responsabilidad social empresarial que inciden en las productoras y exportadoras de mango en el cantón Guayaquil. Tesis. Recuperado de http://repositorio.ug.edu. ec/handle/redug/30318

Andía Valencia, W. (julio-diciembre de 2015). La responsabilidad social: análisis del enfoque de ISO 26000. Industrial Data, 18(2), 55-60. doi:1560-9146

Bonilla Sanabria , F. (2017). Comentarios sobre la responsabilidad social empresarial,el derecho societario y la empresa de grupo. (F. Bonilla Sanabria , Trad.) 134Vniversitas , 21-58. Recuperado el 15 junio de 2019, de http://dx.doi. org/10.11144/Javeriana.vj134.crse

Camacho Solís, J. (enero-junio de 2015). Las normas de responsabilidad social. Su dimensión en el ámbito.

LABORAL DE LAS EMPRESAS. Latinoamericana de Derecho Social(20), 3-29. Obtenido de http://biblio.juridicas.unam.mx

Coba Molina, E., Díaz Córdova, J., Zurita Meza, E., \& Proaño López, P. (2017). La responsabilidad social empresarial en las empresas del Ecuador. Un test de relación con la imagen corporativa y desempeño financiero. Ingeniería Industrial. Actualidad y Nuevas Tendencias, 5(18), 23-44. Recuperado el 15 junio de 2019, de https://www.redalyc.org/pdf/2150/215052403003.pdf

Cordero, J. A. (2017). La responsabilidad social empresarial. Una óptica desde los stakeholders. Revista Economía y Política, (26), 103-123.

Chumaceiro, A., Hernández, J. Y., \& Ziritt, G. (2013). Responsabilidad social empresarial y políticas públicas. Revista de Ciencias Sociales (Ve), 19(2), 309-321.

Obtenido de https://www.redalyc.org/articulo.oa?id=28026992010

Fernández, \& Lluch . (2015). Familias empresarias y grandes empresas familiares en america latina y españa:Una visión de largo plazo. BBVA. Recuperado el junio de 2019, de https://ebookcentral.proquest.com

Fernández, G. (2018). La responsabilidad social corporativa como modelo de gestion empresarial. Recuperado el 16 junio de 2019, de https://ebookcentral.proquest.com 
Gil Sánchez. (2018). Responsabilidad social corporativa:Revision crítica de una nación empresarial. Recuperado el 16 junio de 2019, de https://ebookcentral. proquest.com

Gómez, \& Fernández. (2019). La acción social empresarial como instrumento de Justicia Social: la empresa como garante de los Derechos Humanos. Obtenido de https://dialnet-unirioja es.accedys.udc.es/servlet/articulo?codigo $=6816986$

Atehortúa Hurtado, F., (2008). Responsabilidad social empresarial: entre la ética discursiva y la Racionalidad técnica. Revista Escuela de Administración de Negocios, (62), undefined-undefined. 2019]. ISSN: 0120-8160. Recuperado de: https://www.redalyc.org/articulo.oa?id=206/20611457009

Kun, A. (2015). Innovadores métodos de regulación en la periferia del Derecho del Trabajo: propuestas desde la responsabilidad social empresarial, softlaw, Derecho de la Empresa, entre otros. Ius et Praxis,, 21(1), 577-598. Recuperado el junio de 2019, de http://www.redalyc.org/articulo.oa

Lizarzaburu, E., \& Brito , J. (2016). Responsabilidad Social Corporativa y Reputacioón Corporativa en el sector financiero de paises en desarrollo . Journal Globalization, Competitiveness Y Governability, 10(1), 42-65. doi:10.3232

Luzuriaga, K. (2018). Análisis de la evolución de la Responsabilidad Social en el Ecuador, según las corrientes teóricas de Garriga y Melé. Obtenido de: https:// dialnet-unirioja-es.accedys.udc.es/servlet/articulo? codigo $=6850179$

Martínez Herrera, H. (2010). Responsabilidad social y ética empresarial. Ecoe Ediciones.

Montoya Arévalo, B. E., \& Martínez Ramos, P. (2012). Responsabilidad social empresarial: Una respuesta ética ante los desafíos globales. 84. Recuperado el 15 junio de 2019. https://www.kas.de/c/document_library/get_file?uuid=0ade669e-4a46-3edf-bd16-e7eb6403e0fb\&groupld=252038

Morán, C., Rodríguez, L., Torres, M., Aguilar , A., \& Villalta, M. (2016). Stakeholders, responsabilidad social en ecuador Stakeholders, social responsibility in ecuador. Revista Científica Y Tecnológica UPSE, 3(2), 21-30. https://doi. org/10.26423/rctu.v3i2.147

Moreno, M. (30 de Marzo de 2013). RSE en Latinoamérica. ¿Qué es y hacia dónde vamos? Obtenido de EOI: https://www.eoi.es/blogs/ embacon/2013/03/30/rse-en-latinoamerica-\%C2\%BFque-es-y-hacia-donde-vamos/

Murillo Barrera, C. (2018). Evaluación de las condiciones de ambiente de trabajo y empleo como parte de la Responsabilidad Social Empresarial en las empresas de cultivo de banano del cantón Milagro. 118. Recuperado el 15 junio de 2019, de http://repositorio.ucsg.edu.ec/bitstream/3317/11159/1/T-UCSGPOS- MAE-192.pdf 
Olcese, A. (2015). La responsabilidad social, motor del cambio empresarial: Una propuesta española para Europa y América latina. Recuperado el junio de 2019, de https://ebookcentral.proquest.com

Poveda , G., \& Parrales , J. (2018). Una visión a la responsabilidad Social ambiental en el Ecuador. Revista DELOS Desarrollo LocalSostenible, $31 . \quad$ Obtenido de https://www.eumed.net/rev/delos/31/guido-poveda4.html

Remache Rubio, M. M., Villacis Torres, S., \& Guayta Toapanta, N. A. (1 de enero de 2018). La responsabilidad social empresarial vista desde un enfoque teórico. Dominio de las ciencias, 4(1), 550-568. Recuperado el 18 junio de 2019, de http://dominiodelasciencias.com/ojs/index.php/es/index

Sánchez Gutiérrez, J. (2016). Las normas de calidad GLOBAL G.A.P. y su incidencia en la responsabilidad social empresarial - Caso Bananera Pacidel S.A. del cantón El Guabo, provincia de El Oro. Maestría , Universidad Andina Simón Bolívar, Quito . Recuperado el 15 junio de 2019, de http://repositorio.uasb.edu. ec/bitstream/10644/5565/1/T2251 - MBA-Sanchez-Las\%20normas.pdf

Schulze, F., \& Pszolla, V. (2011). Situación de la responsabilidad social empresarial en Europa. Strategy \& management.

Business review, 2(2), 1-21. Recuperado el 15 junio de 2019, de https://mba.americaeconomia.com/sites/mba.americaeconomia.com/files/responsabilidadsocial. pdf

VV.AA. Responsabilidad social empresarial : Decisiones, reflexiones y casos de estudio. (2017). Retrieved from https://ebookcentral.proquest.com

Vera Salas, L., (2018). Factores que explican la Responsabilidad Social Empresarial en el Sector Exportador de la Provincia de El Oro, Ecuador. Recuperado de http://192.188.52.94:8080/bitstream/3317/10776/1/T-UCSG-POSMAE-164.pdf

Villacís, C., Suárez, Y., \& Güillín, X. (2016). Análisis de la Responsabilidad Social en el Ecuador. Revista Publicando, 3(8), 452-466. Recuperado 20 el junio de 2019. Dialnet-AnalisisDeLaResponsabilidadSocialEnElEcuador-5833426

Vitali, S. (enero-junio de 2017). Precariedad en las condiciones de trabajo y salud de los trabajadores del sector bananero del Ecuador. Salud de los trabajadores , 25(1), 9-22. Recuperado el 20 junio de 2019, de http://www.redalyc.org/ articulo.oa

Wojtarowski, A., Silva, E., Piñar, M., \& Negrete, J. (2016). La Responsabilidad Social Empresarial como pieza clave en la transición hacia el desarrollo sustentable en el sector turístico. PASOS. Revista de Turismo y Patrimonio Cultural, 14(1), 127-139. Obtenido de https://www.redalyc.org/articulo.oa?id=88143642009 


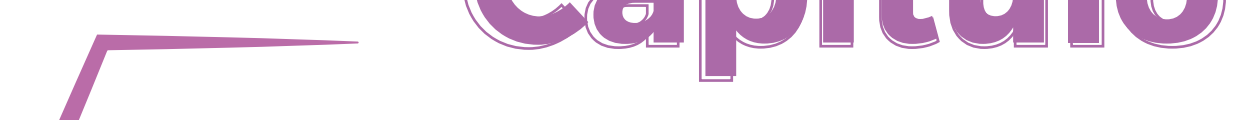

\section{Capítulo}

Costeo de actividades por responsabilidad social empresarial en el sector bananero

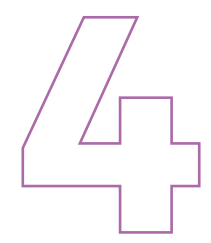


Costeo de actividades por responsabilidad social empresarial en el sector bananero

\author{
Mariana Del Rocío Verdezoto Reinoso \\ Mónica Del Carmen Vargas Jiménez
}

Autores 


\section{Costeo de actividades por responsabilidad social empresarial en el sector bananero}

\section{Mariana Del Rocío Verdezoto Reinoso}

Ingeniera en Contabilidad y Auditoría - CPA por la Universidad Técnica de Machala. Magíster en Auditoría Integral por la Universidad Técnica Particular de Loja. Profesor Titular Auxiliar Nivel 2, Grado 2, Docente Investigador de Facultad de Ciencias Empresariales de Universidad Técnica de Machala. Doctoranda Programa Ciencias Sociales mención Gerencia Fces. LUZ.

\section{Mónica Del Carmen Vargas Jiménez}

Ingeniera en Gestión Empresarial, y Contadora Pública Auditora por la Universidad Tecnológica San Antonio de Machala. Magíster en Auditoría Integral por la Universidad Técnica Particular de Loja. Doctoranda en Ciencias Sociales mención Gerencia, Universidad del Zulia. Docente Investigador Ocasional de la Facultad de Ciencias Empresariales de Universidad Técnica de Machala.

DOI: http://doi.org/10.48190/9789942241405.4 


\section{Resumen}

Este estudio engloba a las empresas del sector bananero de Machala, dedicadas al cultivo de banano. Se ha establecido como propósito analizar el sistema de acumulación de costos que contribuya al Sistema de Información Gerencial en la esfera de la Responsabilidad Social Empresarial, para la evaluación del impacto social - medioambiental que las actividades productivas representen para el entorno, la sostenibilidad y la ventaja competitiva de las empresas bananeras de la provincia de El Oro. A tal efecto, se ha considerado como estrategia principal proveerse de una de las aristas de investigación de los avances del proyecto Responsabilidad Social Empresarial en el sector bananero del cantón Machala, Provincia El Oro del Grupo de Investigación GRP - 045, Investigación para la Potencialidad Universidad - Empresa, INPUNIEM, de la Universidad Técnica de Machala. De acuerdo a su naturaleza según este objetivo, como metodología se ha esbozado un enfoque de investigación cuantitativo relacionado con el método deductivo, con estudio de tipo descriptivo y diseño no experimental; afirmada en técnicas de investigación de fuentes primarias y secundarias, con los adecuados instrumentos de recolección y análisis de datos. En referencia a los antecedentes de esta investigación y sobre la base de los análisis de los resultados se concluye con que el sistema de acumulación de costos $\mathrm{ABC}$ es el más adecuado para el apoyo en la toma de decisiones en cuanto a la responsabilidad social para las empresas del sector. Es necesario considerar una reducción de costos, para mejorar la competitividad del banano ecuatoriano a nivel internacional.

Palabras claves: cadena de valor, Empresas, Responsabilidad Social Empresarial, Sector Bananero, Sistema de Costos ABC.

\section{Introducción}

Cada una de las organizaciones es una conjunción de valores, cultura, costumbres que configuran su identidad. Se puede dar una concepción desde distintas esferas, mas en este trabajo se lo ha realizado en función de la RSE. La habilidad para detectar, actuar en consecuencia, comunicar y satisfacer las necesidades de sus stakeholders en relación al reconocimiento que hacen de ella (proveedores, clientes, accionistas, gobierno, competencia, trabajadores, entre otros), la inclusión de estos grupos de interés alrededor de sus actividades como la afectan y/o benefician, y que convienen ser encarados asertivamente para su gestión.

Por lo que, las empresas deben considerar a la Responsabilidad Social Empresarial (RSE) como un instrumento de su gestión: calidad de sus productos con valor agregado, derivaciones económicas - financieras, posibilidad de abrirse 
nuevos mercados, buena reputación interna que se verá reflejada en la reacción del entorno, ética y RSE proveniente de su reputación, e innovación para proyectarse a largo plazo en pro de recibir los efectos de distintos aspectos en los grupos de interés como una mayor fidelización de clientes, aumento en las ventas producto de su buena reputación, mejores relaciones redituales con ellos, mayor estabilidad de colaboradores representada por una buena calidad laboral, reflejada en el sentido de pertenencia de los trabajadores, alta eficiencia y productividad de la empresa, excelentes relaciones con los proveedores al generar acciones vinculadas con ellos, organismos gubernamentales que propicien un buen escenario en el comercio, mayor valor de acciones y participaciones para los inversionistas, excelente relaciones con medios de comunicación.

En suma, la rentabilidad de una empresa no es el fin sino el resultado de un buen accionar del conjunto de la organización y parte de ello es la RSE conforme Aguilera \& Puerto (2012) afirman:

a la RSE.

La Responsabilidad Social Empresarial (RSE) ofrece una nueva alternativa de “competir", que está concebida como la transferencia de valor agregado a la sociedad; valor que se espera que en el mediano o largo plazo se convierta en fuente de ventaja competitiva, evidentemente, si así lo advierte oportunamente la organización. (pág. 3)

Por otra parte, es acertado referir lo manifestado por el Instituto Boliviano de Comercio Exterior (2013) “La RSE va más allá de lo que la empresa debe hacer por obligación legal, cumplir la ley no hace a una empresa ser socialmente responsable”. (pág. 5). Es decir, para que haya verdadera Responsabilidad Social las empresas deben realizar actividades que no solo sean de carácter obligatorio, sino algunas espontáneas que generen beneficios para su entorno.

A nivel internacional existen organismos que promueven la RSE como una aliada en los negocios conjuntamente con sus respectivas normativas, a saber: ISO 26000, Economía del bien común de la UNESCO, Pacto Global de las Naciones Unidas (GLOBAL COMPACT), Metas del Milenio, Economía Circular, Accountability AA1000, Dow Jones Sustaintability Indexes, IIRC International Reporting Council, OECD Organization for Economic Co-operation and Development, Global Reporting Iniciative.

En 1953, en una publicación denominada Social Responsabilities of the Businessman de Howard Bowen, se señaló que la edad moderna precisa a la responsabilidad social como las obligaciones de los empresarios para seguir políticas, tomar decisiones o adoptar líneas de acción deseables en términos de los objetivos y valores de la sociedad. (Dinamica Ubuntu, 2014). A partir de allí, ha tenido una larga trayectoria hasta la era contemporánea.

Por otra parte, Bretton Woods Project (como se citó en Cobo 2016) resalta acerca de la Responsabilidad Social Corporativa (R.S.C.): 
(...) que lo que distingue a la forma en la cual la R.S.C. funciona en América Latina de los países desarrollados es la influencia de los actores internacionales. En Latinoamérica, la R.S.C. es apoyada financieramente por actores externos, como la OCDE, BID, OEA, Banco Mundial, fundaciones privadas, ONGs internacionales y las oficinas de las empresas multinacionales. Existen críticas en cuanto a las condiciones impuestas por la mayoría de estas instituciones, puesto que generan grandes efectos a nivel económico y social en los países que reciben estos fondos. (pág. 46)

Además, la normativa legal de Ecuador implica al sector bananero en el fomento y la aplicación de la Responsabilidad Social Empresarial, desde la Constitución de la República del Ecuador promulgada para cumplimiento obligatorio por sus habitantes (Asamblea Nacional República del Ecuador, 2008), así como también el Plan Nacional para toda una vida (Consejo Nacional de Planificación, 2019), Código Orgánico Integral Penal, Ley de Gestión Ambiental, Ley de Desarrollo Agrario, entre otras disposiciones en el contexto ecuatoriano.

En definitiva, en Ecuador existe legislación y normas donde implícitamente se defiende la necesidad de implantar la Responsabilidad Social Empresarial, es imperante no solo desde la perspectiva de cumplimiento legal sino de orientación en el accionar de la RSE en las empresas.

\section{Justificación}

Partiendo de la concepción que la ISO 26000, expresa que:

Responsabilidad Social es la responsabilidad de una organización ante los impactos que sus decisiones y actividades ocasionan en la sociedad y en el medio ambiente, mediante un comportamiento ético y transparente que: contribuya al desarrollo sostenible, incluyendo la salud y el bienestar de la sociedad; tome en consideración las expectativas de sus partes interesadas, cumpla con la legislación aplicable y sea coherente con la normativa internacional de comportamiento, y está integrada en toda la organización y se lleve a la práctica en sus relaciones

El hacer negocios hoy en día no debería de ser solo cuestión de generar beneficios económicos presentes y futuros, sino también, medir los impactos en los componentes del medioambiente: agua, aire, suelo, fauna y flora, paisaje, entre otros, utilizados para la producción y/o prestación de servicios, con el propósito de buscar solución a problemas sociales y/o ambientales. En este sentido, identificar un sistema de información de costos de responsabilidad social empresarial que demuestre que los retornos económicos, sociales y ambientales pueden ir de la mano. (ISO, 2017) 
Un avance en los últimos tiempos a nivel internacional, en materia contable, lo constituye la Contabilidad Social y Medioambiental. Sin embargo, aunque ha transcurrido casi de un par de décadas de que los autores Jiménez \& Higón (2003) concluyan: "A pesar de los avances conseguidos en el campo de la contabilidad ambiental se sigue propulsando la investigación en este campo" (pág. 130)..., aún en la actualidad, la práctica de esta disciplina, en algunos entes, constituye un discurso tentativo, de la necesidad de que en las empresas, implementen esta herramienta a través de la instrumentación de un sistema de información de costos, que provea comunicación acerca de la gestión de la empresa, tras la consecución de satisfacer las necesidades de los trabajadores y mejorar el nivel de vida de la población mediante el aumento de la calidad de sus productos y/o servicios y de proyectos que preserven un ambiente sano dentro y fuera de los muros de la empresa.

De igual manera, que se identifiquen los impactos ambientales como externalidades negativas para poder prevenir, controlar, mitigar, compensar y/o remediar estos, a través de medidas que permitan materializar el impacto y con este, a su vez, obtener un objeto medible de costo, que es el que se contabiliza, basados en la recopilación de la información proporcionada por la aplicación de los indicadores de evaluación, para posteriormente generar informes a través del Balance de Responsabilidad Social (BRS), bajo las directrices del Global Reporting Initiative (GRI), organización que estandariza la presentación de los BRS. Cabe indicar que, la Contabilidad Ambiental se ocupa dentro de un Balance de Responsabilidad Social de los ámbitos: económico, social y medio ambiental, en las categorías ambiental, salud y seguridad en el trabajo y relaciones con la comunidad.

Acertado el comentario de Solís (2008) quien afirma que:

El fenómeno de la responsabilidad social empresarial (RSE) se ha convertido en uno de los temas más discutidos y menos comprendidos del debate actual. La mayor preocupación por el medio ambiente, los derechos humanos - particularmente los laborables y de género - y la vida comunitaria, mostrada por un importante segmento empresarial de las naciones industrializadas, ha experimentado una cierta difusión a nivel internacional de la cual, los países en vías de desarrollo no han estado exentos. (pág. 228)

Cabe acotar que el contexto de investigación es la ciudad de Machala, provincia El Oro, Ecuador, se enmarcan dentro de esta aseveración globalizadora, en consecuencia, es un tema que se encuentra en boga y su estudio es pertinente e innovador.

Además, Ecuador se encuentra como principal productor y exportador de banano en el mundo. El sector bananero pese a estar entre los importantes generadores de divisas del país, y si bien es cierto las grandes empresas denotan estar bien preparadas ante estos vertiginosos e incrementales cambios, las empresas dedicadas a la producción de banano carecen de lineamientos generales de costos que aporten información fiable para su registro contable. 
Lo anteriormente expuesto, ha motivado la elección de la temática propuesta para la presente investigación, determinada en un estudio específico al sector bananero en empresas que tengan la característica dedicadas al cultivo de banano, en razón de que conforman una parte del segmento considerado como motor sustentable e importante en la economía de la ciudad de Machala, la provincia de El Oro y, por ende, del país, como se argumentó anteriormente. Por otra parte, se denota un interés público y se pretende que las aportaciones preliminares derivadas de las aristas del proyecto de investigación: Responsabilidad Social Empresarial en el sector bananero del cantón Machala, Provincia El Oro tengan una proyección de carácter general, que contribuya al crecimiento de las empresas bananeras del sector bananero de la provincia de El Oro.

\section{Objetivo general}

Esta investigación indaga el conocimiento dirigido a satisfacer: lo qué se necesita, cuánto se necesita y cómo se necesita; para hacerlo de la mejor manera en el estudio que tiene como objetivo fundamental analizar el sistema de acumulación de costos que contribuya al Sistema de Información Gerencial en la esfera de la Responsabilidad Social Empresarial, para la evaluación del impacto social - medioambiental que las actividades productivas representen para el entorno, la sostenibilidad y la ventaja competitiva de las empresas bananeras de la provincia de El Oro.

\section{Objetivos específicos}

Para la consecución del objetivo específico, se plantea los siguientes objetivos específicos:

- Caracterizar las actividades inherentes al proceso de producción de banano.

- Identificar las actividades de responsabilidad social empresarial en la producción de banano.

- Establecer los generadores de valor que impulsan el costo de las actividades en la producción de banano y su relación con la Responsabilidad Social Empresarial.

- Describir el sistema de acumulación de costos que agrupe las actividades de producción de banano para el logro de la ventaja competitiva a raíz de las empresas estudiadas. 


\section{Metodología}

Se desarrolló con la consulta de distintos organismos de control, entes certificadores, empresas del sector bananero y profesionales en el ámbito contable y bananero.

Desde una perspectiva investigadora, el estudio propuesto se adscribe al enfoque de investigación cuantitativo, bajo una postura positivista en concordancia con el método deductivo. Además, se emprenderá la investigación de tipo descriptiva y de diseño no experimental, apoyados en las pertinentes técnicas de investigación que ameriten aplicarse en el proceso al método antes indicado. Se busca información de fuentes primarias como: libros, artículos, entrevista semiestructurada a empresas bananera dedicadas a la producción de banano, investigaciones académicas, indicadores de evaluación de RSE, presupuestos, estadísticas, análisis de contenidos, observación no participante del contexto y de la realidad de las empresas en estudio; y, de fuentes secundarias, así como: teorías, información documental, informes y datos estadísticos de los diferentes organismos de control. Entre los instrumentos se cuenta con una guía de observación. En cuanto a las técnicas de análisis se describió a través de tablas combinadas y gráficos con utilización del programa SPSS que permitió el estudio descriptivo propuesto, complementados con la observación no participante.

Una vez que los datos han sido recolectados se procedió al análisis de los mismos. Los procesos cognitivos que se pretendió desarrollar durante la recolección y análisis de datos e información son la comprehensión y determinación de los costos relacionados con la Responsabilidad Social Empresarial de las Pequeñas y medianas empresas, Pymes del sector bananero seleccionadas para el estudio. Para ello, se implica actividades estrechamente vinculadas entre sí, la primera procedente de la selección, aplicación del instrumento y método de recolección de datos de interés del estudio; y, la preparación de las mediciones obtenidas de la investigación.

Se considera que medir los impactos sociales y ambientales de las empresas bananeras consideradas, pueden realizarse de diversas maneras, todo está en función del método, técnicas, instrumentos seleccionados y anteriormente indicados. Claro está, que pueden variar de acuerdo a la jurisdicción en la que se encuentre la entidad. Así, el desafío está en definir adecuadamente el impacto y en cómo utilizar las herramientas e instrumentos propuestos para su medición, sin dejar de lado la medición económica, la cual se considera más sencilla, pero no por ello menos importante, puesto que existen normas internacionales de contabilidad que permiten la armonización contable y la evaluación del resultado financiero de la actividad de medir el impacto social y ambiental que exige métodos cualitativos y cuantitativos que combinan diferentes herramientas e instrumentos (Peña, Plaza, \& Fraiz, 2016).

Por lo tanto, aunque medir el impacto social - ambiental se considera un trabajo complejo, por la serie de factores que lo afectan, es fundamental, incluir la valoración de indicadores en las evaluaciones de gestión de las empresas, diseñadas a partir de su planificación empresarial, ya que así, se plantea controlar y conseguir 
garantía de una adecuada relación de negocios del sector, cumpliendo los objetivos empresariales planteados, pero sin descuidar a quienes lo hacen posible, que son las personas y el medio que nos facilita los recursos necesarios para el desarrollo sostenible.

\section{Materiales y métodos}

En el proceso de recolección de información se aplicaron cuarenta y seis (46) encuestas y entrevistas semiestructuradas a empresas bananeras de la cuidad de Machala, provincia de El Oro que fueron seleccionadas de acuerdo al criterio de constitución legal, del ranking empresarial de la Superintendencia de Compañías, Valores y Seguros (2019), aplicando como restricciones la actividad económica, cultivo de banano, y contrastando la misma con aquellas empresas que tengan la actividad económica principal: cultivo de bananos y plátanos, cultivo de banano, cultivo y producción de banano, producción de banano, a través de la consulta del Registro Único de Contribuyentes en el Servicio de Rentas Internas (2019). Con respecto al tamaño de empresa se ha seleccionado a las consideradas por la Superintendencia de Compañías, Valores y Seguros como microempresa, pequeña, mediana y grande empresa. En éstas, se efectuaron cuestionamientos a través de entrevistas a directivos. En cuanto a las encuestas, se averiguó acerca de los valores aproximados que la empresa invierte en Responsabilidad Social Empresarial; en correspondencia a la entrevista, se planteó interrogantes acerca de modelo o proyecto de Responsabilidad Social Empresarial y el costeo de actividades de producción de banano.

Se empleó una investigación descriptiva, para el efecto se asistió a las compañías productoras de banano para indagar con sus actores y observar procesos de las áreas de las empresas, para posteriormente, en este estudio, realizar la representación de los proveedores de la información, con un enfoque cuantitativo. Para el escogimiento de fundamentos se realizó distinguiendo las variables más significativas en relación al objeto de estudio. Cabe indicar, que se preservó la confidencialidad y está basada en información técnico - profesional y estadística, considerando además la opinión técnica y de expertos.

\section{Resultados y discusión}

Para demostrar el cumplimiento de los objetivos planteados en esta investigación, se exhiben los resultados primordiales:

En la tabla $\mathrm{N}^{\circ} 1$, se observa que el $67.4 \%$ de las empresas pymes productoras de banano encuestadas, invierten menos de \$999; el 19.60\% invierten entre \$1000 y \$1999; el $8.70 \%$ entre $\$ 2000$ y \$2999; el 2.20\% entre \$3000 y \$3999; y, más de 
$\$ 4000$ en igual porcentaje $2.20 \%$ invierten en RSE, manifestando que esto se debe a que las empresas bananeras se motivan a la inclusión de la RSE en ellas sólo por el cumplimiento ante organismos de control gubernamental principalmente.

Tabla 1. Valores aproximados de inversión en RSE de las empresas productoras de banano

\begin{tabular}{|l|l|r|r|r|r|}
\hline \multicolumn{2}{|c|}{} & \multicolumn{2}{c}{$\begin{array}{c}\text { Frecuencia } \\
\text { Absoluta }\end{array}$} & \multicolumn{2}{c|}{$\begin{array}{c}\text { Frecuencia Abso- } \\
\text { luta Acumulada }\end{array}$} \\
\end{tabular}

Nota: Elaboración propia a partir datos de empresas productoras de banano (2019)

También se puede apreciar gráficamente lo expresado:

Figura 1. Valores aproximados de inversión en RSE.

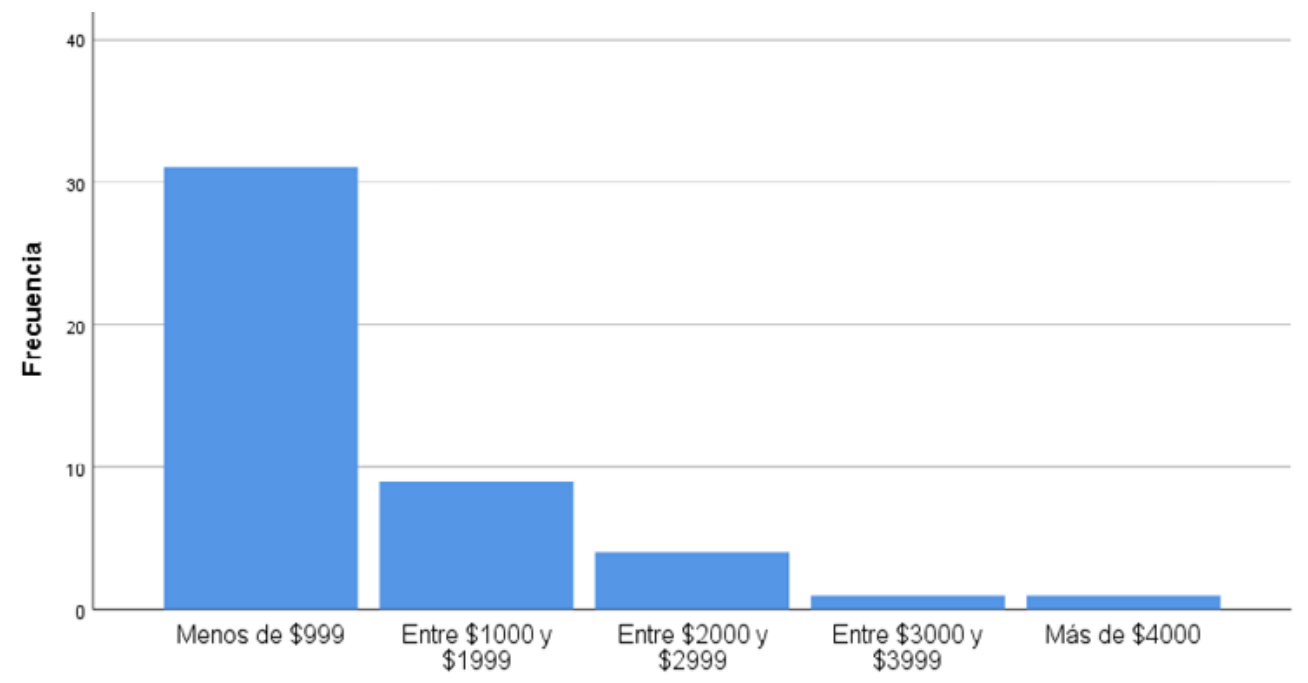

Nota: Elaboración propia a partir de datos proporcionados por empresas productoras de banano (2019).

En la tabla 2, describe los sistemas de control de costos que utilizan las empresas dedicadas al cultivo de banano en actividades de RSE entrevistadas, obteniendo los siguientes resultados: el 41.30\% manifestó la utilización del Costeo Basado en Actividades, 10,90\% Costeo por proceso, 8.70\% costeo histórico, 6.50\% costeo están- 
dar, $8.70 \%$ costeo variable, $4.30 \%$ costeo por órdenes de producción, y el $19.60 \%$ indicó utilizar otro sistema de control de costos en sus actividades. Sin embargo, el sistema de costos que emplean las empresas no es estandarizado, para todas ellas, lo que representa una oportunidad de abrir estudios más específicos y profundos sobre el tema, con la finalidad de brindar aportes novedosos y de contribución para el sector bananero.

Tabla 2. Sistema de costos en empresas de producción banano para actividades de RSE

\begin{tabular}{|c|c|c|c|c|c|}
\hline & & $\begin{array}{l}\text { Absoluta } \\
\text { Frecuencia }\end{array}$ & $\begin{array}{c}\text { Frecuencia } \\
\text { Absoluta } \\
\text { Acumulada }\end{array}$ & $\begin{array}{c}\text { Frecuencia } \\
\text { Relativa }\end{array}$ & $\begin{array}{c}\text { Frecuencia } \\
\text { Relativa } \\
\text { Acumulada }\end{array}$ \\
\hline \multirow[t]{8}{*}{ Válido } & Costeo ABC & 19 & 19 & 41,30 & 41,30 \\
\hline & Costeo por Proceso & 5 & 24 & 10,90 & 52,20 \\
\hline & Costeo histórico & 4 & 28 & 8,70 & 60,90 \\
\hline & Costeo estándar & 3 & 31 & 6,50 & 67,40 \\
\hline & Costeo variable & 4 & 35 & 8,70 & 76,10 \\
\hline & Costeo Orden de Producción & 2 & 37 & 4,30 & 80,40 \\
\hline & Otro & 9 & 46 & 19,60 & 100,00 \\
\hline & Total & 46 & & 100,00 & \\
\hline
\end{tabular}

Nota: Elaboración propia a partir datos de empresas productoras de banano (2019).

Descriptivamente se puede apreciar en el gráfico siguiente:

Figura 2. Sistema de costos en empresas de producción banano para actividades de RSE.

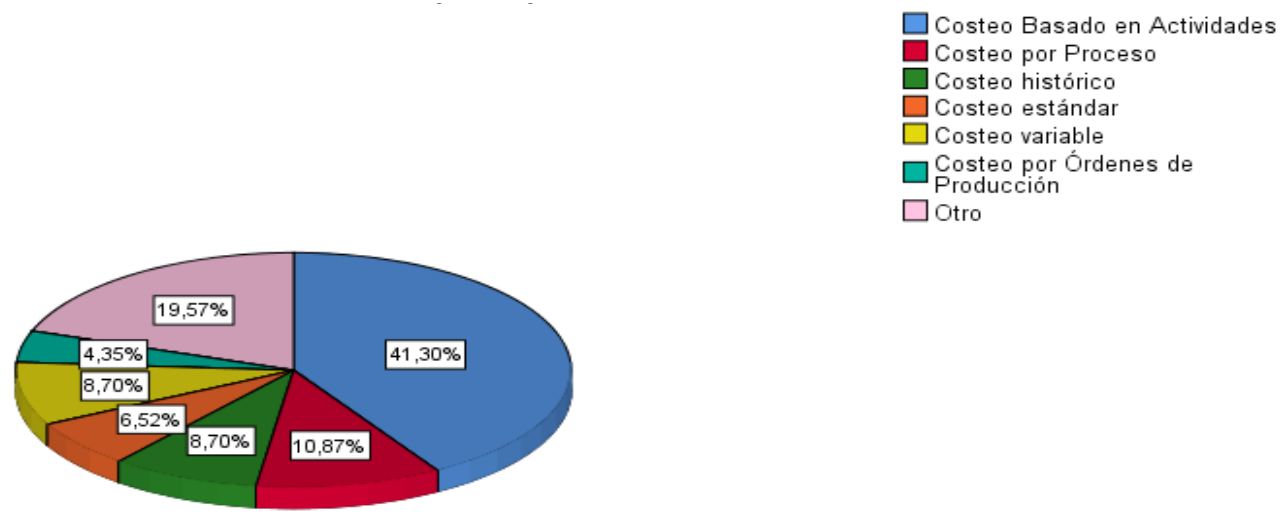

ura 2. Sistema de costos en empresas de producción banano para

Nota: Elaboración propia a partir de datos proporcionados por empresas productoras de banano (2019). 
Se recalca que el alcance del estudio de este trabajo se centra en la producción del banano, Cavendish Valery, que, de acuerdo con García, Juca, \& Juca (2016) "es la variedad más utilizada para la exportación, debido a la resistencia a plagas y enfermedades, además de su gran rendimiento y durabilidad en el proceso de transporte” (pág. 52) y, que confrontados en las empresas productoras de banano es el de mayor preponderancia en éstas.

Con respecto al Sistema del Costo Basado en Actividades, es preciso para un mejor entendimiento, citar lo manifestado por Warren, Reeve, \& Duchac (2010): "El método de costeo basado en actividades (ABC) se enfoca en el costo de las actividades y después asignar estos costos a productos al usar una gran variedad de bases actividad" (pág. 451). Es importante acentuar que las bases de actividad están dadas por las actividades generadoras de valor, lo cual se relaciona perfectamente con el precepto de valor en las empresas, que se fundamenta este estudio.

Por otra parte, Cuervo \& Osorio (2013), aseveran que el:

Costeo Basado en Actividades ABC: es una filosofía según la cual, se incluye dentro del costo del producto, tanto los costos de producción como los gastos administrativos y de ventas incurridos, pues parte de la premisa que todos ellos deben ser recuperados con la venta y que la estructura administrativa y comercial son necesarias para que el producto llegue hasta el consumidor final. Permite el cálculo de un costo por producto o servicio más acertado y útil para la toma de decisiones, por lo que es una herramienta interesante desde el punto de vista de la toma de decisiones; sin embargo, no es una metodología válida de acuerdo con la normatividad contable vigente, por lo que su rango de acción es netamente administrativo (...). (pág. 45)

Lo cual en el contexto ecuatoriano es adaptable, ya que en conformidad de organismos de control se aplica normativa internacional en cuanto al tratamiento de la información financiera como lo son las Normas Internacionales de Información Financiera. Lo asertivo en este caso, es la adaptación del mencionado sistema de costos a la normativa contable vigente ya que según Rocafort \& Ferrer (2008) "La contabilidad para la toma de decisiones constituye el proceso de identificación, medida, análisis e interpretación que se dispone para la gerencia con la finalidad de decidir sobre los recursos de una organización” (pág. 191).

De allí que, se debe tener en cuenta una visión sistémica del ciclo productivo del banano. Tal como Drucker (2011), afirma: "Identificar y comprender aquellas áreas de una empresa en las que se pueden medir los resultados” (pág. 26). Es por ello que, producto de la observación de campo es posible describir las actividades esenciales de las empresas dedicadas al cultivo de banano en el esquema $\mathrm{N}^{\circ} 1$.

La cadena de valor de una empresa bananera dedicada al cultivo de banano empieza con los requerimientos del cliente, para lo cual precisan de la contratación con un exportador a través de la legalización de un contrato de compraventa de 
banano, ante el Ministerio de Agricultura y Ganadería (2019), para regular Precios Mínimos de Sustentación, seguidamente de ello, se emite una orden de corte, que precisa el proceso de producción de banano, para lo cual se depende de las labores de campo antecedidas a este proceso: deshije, deshoje, desvío de hijos, enfunde, protección, control de maleza, apuntalamiento, control de rebrotes, regadores, canaleros, cuadrilla de corte, servicios varios, entre otros.

Se entiende por deshije a la "labor que consiste en seleccionar o regular el número de unidades de producción, cortando o podando los otros hijos (hijos de agua e hijos innecesarios)” (Aboboreira, 2001, pág. 7).

Deshoje, "consiste en eliminar total o parcialmente hojas, atacadas por la Sigatoka Negra, que puedan dañar el racimo y que hagan puente entre matas y causan reinfección” (Aboboreira, 2001, pág. 10).

Desvío de hijo, "corte de todo hijo que roce el racimo o que crezca en dirección a éste. Corte de todas las hojas que puedan causar daños en el racimo". (Aboboreira, 2001, pág. 13).

Enfunde, "es una práctica de protección mecánica y química de la fruta, con bolsa plástica de tubo continuo (tratado con insecticida en un estado de desarrollo temprano, que permite la obtención de un producto de buena calidad" (Aboboreira, 2001, pág. 12).

Control de malezas de acuerdo con ProMusa Mobilizing banana science for sustainable livelihoods (2019), "radica en eliminar las malezas que compiten con la planta de banano por recursos y favorecen el desarrollo de parásitos. Es importante realizarlo en los primeros meses, cuando las plantas de banano son pequeñas y hay poca sombra”.

El apuntalamiento, "consiste en dar apoyo, a través de sostén con mecates o bambú, a las matas de banano” (Aboboreira, 2001, pág. 11).

Control de rebrotes, actividad apoyada en método de eliminación de plantas para la erradicación de infestaciones (REPCar, 2019, pág. 21).

Regadores, encargados del "regadío de los cultivos agrícolas en el periodo seco" (Caicedo, Balmaseda, \& Proano, 2015, pág. 18).

Se refiere a canaleros, a los trabajadores que está relacionados con el drenaje en banano, que según De la Colina (1997) sirven: "para evacuar los excesos superficiales y subsuperficiales de agua” (pág. 99), ya que al tener demasiada agua la planta de banano, tiene riesgos de morir.

La cuadrilla de corte está relacionada con las actividades de cosecha en las cuales se encuentran implícitas: garrucha, destalle, cortador, arrumador, botada de tallo, calibrada de racimos, barreada plantas a poscosecha. (Cárdenas, 2016, pág. 58)

Consecutivamente, en la cadena de valor es cabal una evaluación de proveedores para la compra de materiales, contratación de servicios, certificaciones con la finalidad de cumplir con la orden de corte y aprobar la evaluación de calidad de la fruta. 
Muy concerniente con la recepción y almacenamiento está la compra de materiales. Seguidamente, con ésta se atiende el eslabón de la cosecha - poscosecha con el retiro de material de la exportadora de banano, empaque y evaluación de calidad para a su vez realizar la producción de cajas procesadas, todo esto con el propósito de dar cumplimiento a la satisfacción del cliente en base a sus necesidades.

Por otra parte, el eslabón de soporte, está dado por el mantenimiento: planificación y ejecución del mantenimiento y calibración de equipos; el área de recursos humanos: selección/contratación y capacitación del personal; financiero: gestión de pagos, créditos y cobranzas; control de calidad: de producto no conforme y de fruta; servicio posventa: atención de quejas y devoluciones, medición de satisfacción del cliente. Aunque éste no es un eslabón directo de la cadena de valor, es transcendental para la misma puesto que sin una eficaz planificación se afecta las áreas inmersas en la cadena de valor de la empresa.

Como estrato de apoyo, se encuentra la planeación la cual se da con el control de documentos, una planeación que debe surgir de la revisión gerencial, auditorías internas y la mejora continua que no es más que la planeación, ejecución y seguimiento de acciones preventivas, correctivas y de mejora, que germinan a raíz de la intención de prevenir situaciones potencialmente riesgosas para la organización, corregir hallazgos detectados y observaciones de los procesos estratégicos, operativos y de apoyo. Lo cual demuestra que, en estas empresas se da lo que refiere Alcalde (2007), la aplicación del ciclo de la mejora continua: Planificar, Hacer, Verificar, Actuar, invención de W. Edwards Deming. (pág. 22). Las actividades de responsabilidad social empresarial en las empresas dedicadas a la producción de banano, están inmersas en todo este proceso, puesto que contribuye a la cadena de valor de manera importante, al generar diferenciación dentro de su sector lo cual es muy apreciado por los actores inmersos en la Responsabilidad Social Empresarial como: trabajadores - comunidad - ambiente. Por ende, se obtiene mejor desempeño en relación a otras empresas de su sector, reducir costos, mantener seguridad económica, crecimiento empresarial, acceder a mejor posicionamiento en el mercado, puesto que las exportadoras de banano buscan proveedores con características singulares para ellas a su vez satisfacer a sus clientes, esto de por sí ya es una ventaja competitiva.

En cada actividad, la empresa bananera debe actuar con responsabilidad en torno a sus trabajadores, ambiente y sociedad. Entendiéndose por ésta lo que Martínez (2011) afirma: "Responsabilidad es responder a los llamados de los valores que piden ser realizados” (pág. 9).

Por lo anteriormente expuesto, el establecimiento de los costos de las actividades de la Responsabilidad Social Empresarial se ha fundado en la cadena de valor de Porter aplicado al sector bananero, en específico a la actividad de la producción de banano. Con la cadena de valor instituida, que según Porter (1986) es: "La herramienta básica con que se diagnostica la ventaja competitiva" se puede develar 
las actividades de la cadena de valor como una generalidad para estas empresas, que en sí es el cultivo de banano y el proceso de cajas de banano, conforme al requerimiento de su cliente que es el inicio y fin de su cadena de valor, representada esquemáticamente:

Figura 3. Visión Sistémica del Ciclo Productivo del Banano.

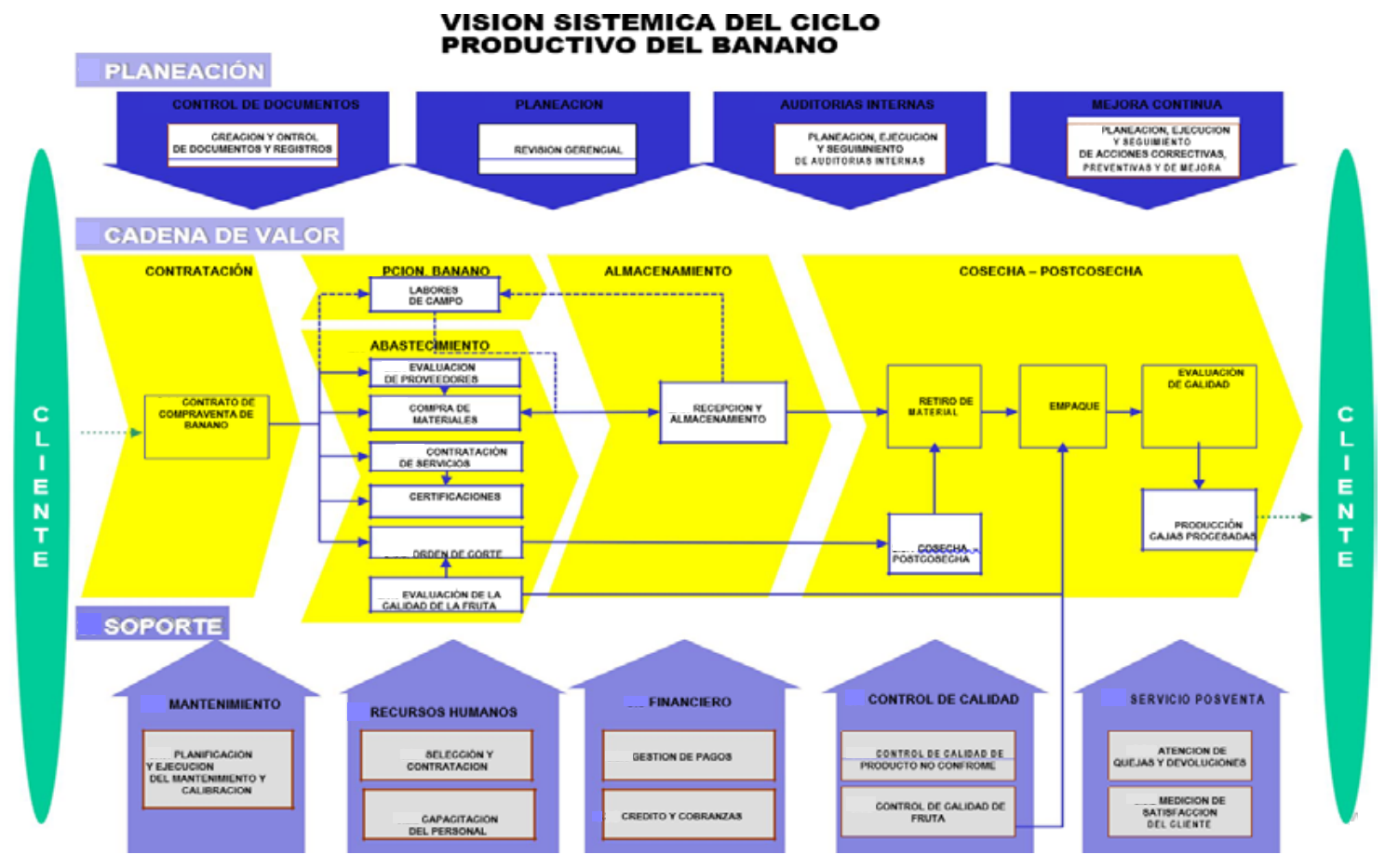

Nota: Elaboración propia a partir de información proporcionada por empresas productoras de banano (2019)

Para Porter (1986), "La cadena de valor es una herramienta básica para diagnosticar la ventaja competitiva y encontrar medios de crearla y mantenerla” con lo cual se crea un referente de análisis para las empresas del sector.

Siendo más explícito, Ramírez (2013) expresa que:

En la definición de la cadena de valor se consideran los diferentes procesos / actividades. Los procesos se definen de acuerdo con la similitud de actividades que cada uno agrupa, y su efecto en el valor que, a cada uno asigna el cliente, sin perder de vista que el valor total de la cadena es de gran interés para el administrador en la toma de decisiones, y para el accionista en cuanto al valor de su inversión.

Es conveniente que se cuantifique los costos de cada proceso y se identifiquen sus generadores de valor, lo cual da como resultado un panorama estratégico que demanda realizar esfuerzos para agregar valor y controlar los costos. (pág. 108) 
Así mismo, Quintero \& Sánchez, (2006) descifran que:

La cadena de valor de una organización, identifica pues, las principales actividades que crean un valor para los clientes y las actividades de apoyo relacionadas. La cadena permite también identificar los distintos costos en que incurre una organización a través de las distintas actividades que conforman su proceso productivo, por lo que constituye un elemento indispensable para determinar la estructura de costos de una compañía. Cada actividad en la cadena de valor incurre en costos y limita activos, para lograr su debido análisis y consideración permiten mejorar la eficiencia tecno-económica de una empresa, un grupo de empresas o de un determinado sector industrial.

En síntesis, Marketing, Publishing, (1997), alega que: "En el proceso de producción u operaciones, cada uno de los eslabones que integran la cadena total añade su cuota de valor hasta conformar el valor final que se entrega al mercado" (pág. 59).

Es así que, el precepto de Porter (1986) en el que afirma: "el valor es la cantidad que los compradores están dispuestos a pagar por lo que se le ofrece" se cumple en sector de las empresas bananeras dedicadas al cultivo de banano en el ámbito de la competencia de las exportadoras de banano, que es a quienes generalmente entregan su producto.

Un aspecto muy importante a donde lleva la cadena de valor es la ventaja competitiva que ha sido referida por Porter, y con el que Mas-Alique, Herráez, \& Muñoz, (2014) concuerdan que: "La ventaja competitiva se define como aquello que una empresa u organización hace mejor que su competencia y, de manera sencilla, se puede basar en costes o en diferenciación” (pág. 2), ratificando de esta manera la definición de ventaja competitiva.

Por otra parte, Tarí (2000), fundamenta que:

Aunque los factores externos pueden hacer que el grado de competitividad no sea el mismo para todas las organizaciones, son los factores internos y por tanto la forma de actuar en la empresa la que permite a la misma conseguir una ventaja competitiva. (pág. 49).

Bajo estas premisas, se deduce que es una oportunidad para la empresa la trilogía Cadena de Valor - Responsabilidad Social Empresarial - Ventaja Competitiva. Puesto que, se ha podido identificar que de cada una de las actividades de los eslabones de la cadena de valor, de los procesos de apoyo y de las distintas áreas de la empresa bananera dedicada a la producción de banano pueden generarse actividades de Responsabilidad Social Empresarial, por lo que el costeo nace de la erogación que realizan en materiales directos, mano de obra directa y otros costos en función de las actividades y producto de ella, identificar la ventaja competitiva desde una perspectiva interna. 
De acuerdo con Moura - Leite \& Padgett (2014) en su relato:

(...) en 1984, Peter Drucker en The new meaning of corporate social responsibility resalta la rentabilidad financiera que la responsabilidad social empresarial puede traer a los negocios y también como ésta puede ser una oportunidad de negocio. Otro excelente ejemplo de bibliografía que relaciona responsabilidad social empresarial y rentabilidad financiera en el mismo año es el estudio empírico de Philip Cochran y Donna J. Wood en Corporate social responsibility and financial performance. (pág. 14)

Confirmando una vez más las bondades que la RSE ofrece a las organizaciones. Además, Drucker (2018), afirma: "Lo que sí genera resultados es aprovechar las oportunidades" (pág. 79).

Finalmente, la RSE en las empresas bananeras dedicadas a la producción de banano brinda un cúmulo de oportunidades en las que estas empresas pueden remediar su explotación de recursos ya que su accionar está inmerso en los ámbitos económico, social y ambiental, propicios para su aplicación, de la cual puede obtener un sinnúmero de resultados para su beneficio y el de su entorno.

\section{Conclusiones}

En referencia a los antecedentes de esta investigación y sobre la base de los análisis de los resultados se concluye que:

La caracterización de las actividades del proceso de producción de banano es necesaria para la identificación de la cadena de valor en las empresas bananeras, porque es útil como un instrumento que tributa al análisis de las actividades esenciales en que se divide la organización y detectar áreas de oportunidad para competir. En este estudio se centra en las actividades de campo, con lo que se puede gestionar los costos.

La identificación de las actividades relacionadas con la Responsabilidad Social Empresarial en el proceso de cultivo de banano está implícita en las labores de campo que se llevan a cabo y en cada una de ellas existe la oportunidad de realizar un control ambiental.

Para la determinación de la ventaja competitiva producto de la cadena de valor en las empresas bananeras se ha reducido a la división de la empresa dedicada a la producción de banano en actividades esenciales, e identificado los generadores de valor, por lo que, de allí se concluye que lo apropiado es un sistema de costeo basado en actividades, que tribute al Sistema de Información Gerencial en pro de la contribución de la evaluación del beneficio, el impacto social y medioambiental que las actividades de estas empresas representen para el entorno y la sostenibilidad de las mismas. 
Si bien es cierto que, el Sistema de Costeo Basado en Actividades o Costeo ABC no se encuentra estipulado en las Normas Internacionales de Información Financiera a través de la Norma Internacional de Contabilidad 2: Existencias, como de obligatorio cumplimiento y aplicación en el tratamiento de los costos de los entes, los bananeros exteriorizan que este sistema contribuye de una manera extraordinaria, que provee información por las distintas actividades de campo con el que se apoya la toma de decisiones gerenciales en este tipo de empresas, por lo que es, una excelente herramienta aplicada en la gestión administrativa a todo nivel en la organización. La razón, porque la naturaleza de las labores de campo tiene características que deben ser controladas y calculadas de manera individualizada en función de los elementos del costo que en ellas intervienen: mano de obra, materiales y otros costos y el Costeo ABC por sus características es el más adecuado. Puesto que realizarlo de esta manera permite un control acerca del rendimiento hombre/actividad.

La cadena de valor y el producto de las empresas bananeras dedicadas a la producción y cultivo de de banano es importante para las exportadoras en cuanto al cumplimiento de requerimientos de necesidades de sus clientes, puesto que ellas buscan en sus proveedores calidad en la fruta y en sus procesos para sus exigentes clientes en el extranjero. Por lo que, se puede concluir que esa una cadena de valor complementaria en el eslabón del sector bananero del Ecuador.

La Responsabilidad Social Empresarial es considerada como herramienta en la ventaja competitiva para las empresas dedicadas a la producción de banano. 


\section{Referencias}

Aboboreira, M. (2001). Principales labores en el cultivo de banano. Costa Rica: Earth: OKUMOTO S. Obtenido de https://scholar.google.com.ec/scholar?hl=es\&as_sd$\mathrm{t}=0 \% 2 \mathrm{C} 5 \& \mathrm{q}=$ labores $+\mathrm{de}+$ campo $+\mathrm{en}+\mathrm{el}+$ cultivo $+\mathrm{de}+$ banano $\& \mathrm{btnG}=\# \mathrm{~d}=\mathrm{gs} \_\mathrm{ci}-$ $\mathrm{t} \& \mathrm{u}=\% 2 \mathrm{Fscholar} \% 3 \mathrm{Fq} \% 3 \mathrm{Dinfo} \% 3 \mathrm{AN}$ _SQGMURm6AJ\%3Ascholar.google . com\%2F\%26output\%3Dcite\%26scirp\%3D4\%26hl\%3Des

Aguilera, A., \& Puerto, D. (2012). Crecimiento empresarial basado en la Responsabilidad Social. Pensamiento ef Gestión, 32, 1-26. Obtenido de http://www.scielo. org.co/scielo.php?script=sci_arttext\&pid=S1657-62762012000100002\&ln$\mathrm{g}=\mathrm{en} \& \mathrm{tlng}=\mathrm{en}$

Alcalde, P. (2007). Calidad. Madrid: Internacional Thomson Editores Spain Paraninfo S.A.

Asamblea Nacional República del Ecuador. (2008). Constitución de la República del Ecuador. Ciudad Alfaro, Montecristi: Registro Oficial No. 449 , 20 de Octubre 2008, Manabí, Ecuador: Fiel Web Evolución Jurídica.

Asamblea Nacional República del Ecuador. (2018). Código Orgánico Integral Penal. Quito: LEXIS. Obtenido de http://www.lexis.com.ec/wp-content/ uploads/2018/07/LI-CODIGO-ORGANICO-INTEGRAL-PENAL-COIP.pdf

Caicedo, O., Balmaseda, C., \& Proano, J. (2015). Programación del riego del banano (Musa paradisiaca) en finca San José 2, Los Ríos, Ecuador. Revista Ciencias Técnicas Agropecuarias, 24(2), 18-22. Obtenido de http://scielo.sld.cu/scielo. php?script=sci_arttext\&pid=S2071-00542015000200003\&lng=es\&tlng=es

Cárdenas, K. (2016). Sistema de Costeo para la producción bananera en la hacienda "María Antonieta" del Cantón El Triunfo. Guayas, Ecuador: Repositorio UNEMI. Obtenido de http://repositorio.unemi.edu.ec/bitstream/123456789/3362/1/SISTEMA\%20DE\%20COSTEO\%20PARA\%20 LA\%20PRODUCCI\%c3\%93N\%20BANANERA\%20EN\%20LA\%20HACIENDA\%20\%e2\%80\%9cMAR\%c3\%8dA\%20ANTONIETA\%e2\%80\%9d\%20DEL\%20 CANT\%c3\%93N\%20EL\%20TRIUNFO.pdf

Cobo, J. (2016). Estudio del nuevo modelo de gestión de R.S.C. 2.0 para la obtención del certificado S2M. Caso de estudio Acerías del Ecuador ADELCA C.A. (Período 20042014). Quito: Repositorio Pontificia Universidad Católica del Ecuador. Obtenido de http://repositorio.puce.edu.ec/bitstream/handle/22000/11529/ESTUDIO\%2 0DEL\%20NUEVO\%20MODELO\%20DE\%20GESTI\%C3\%93N\%20 DE\%20R.S.C.\%202.0\%20PARA\%20LA\%20OBTENCI\%C3\%93N\%20DEL\%20 CERTIFICADO\%20S2M.\%20CASO\%20DE\%20.pdf?sequence=1\&isAllowed=y 
Consejo Nacional de Planificación. (1 de 07 de 2019). Plan Nacional de Desarrollo toda una vida. Obtenido de https://www.planificacion.gob.ec/plan-nacional-dedesarrollo-2017-2021-toda-una-vida/

Cuervo, J., \& Osorio, J. (2013). Costeo Basado en actividades ABC: gestión basada en actividades $A B M$ (2da. ed.). Ecoe Ediciones. Obtenido de http://ebookcentral. proquest.com/lib/utmachalasp/detail.action?docID $=4870521$

De la Colina, J. (1997). Diseño y Manejo de Sistemas de Drenaje. Memoria del Simposio Internacional sobre Riego y Drenaje en Banano, 99-105. Obtenido de http:// usi.earth.ac.cr/glas/sp/90017353.pdf

Dinamica Ubuntu. (2014). ¿Qué es la responsabilidad social? Obtenido de https:// www.youtube.com/watch?v=GsTwMDdcgFc

Drucker, P. (2011). La Gerencia Efectiva. México: Editorial Sudamericana S.A.

Drucker, P. (2018). Eficacia ejecutiva. Colombia: Editorial Nomos S.A.

Expok Comunicación de Sustentabilidad y RSE. (29 de 06 de 2019). Obtenido de https://www.expoknews.com/15-frases-de-responsabilidad-social/

García, M., Juca, F., \& Juca, O. (2016). Estudio de los eslabones de la cadena de valor del banano en la provincia de El Oro. Universidad y Sociedad, 51-57. Obtenido de http://rus.ucf.edu.cu/

Instituto Boliviano de Comercio Exterior. (2013). El ABC de la Responsabilidad Social Empresarial. Responsabilidad Social Empresarial, 1-14. Obtenido de https:// ibce.org.bo/images/publicaciones/ABC_responsabilidad_social.pdf

ISO. (2017). ISO 26000:2010. Obtenido de https://www.iso.org/obp/ui\#iso:std:iso:26000:ed-1:v1:es

Jiménez, L., \& Higón, F. (2003). Ecología y economía para un desarrollo sostenible. Valencia: Patronat Sud - Nord Solidaritat I Cultura - F.G.U.V. Publicacions de la Universitat de Valencia.

Marketing, Publishing. (1997). La ventaja competitiva. Madrid: Ediciones Díaz de Santos. Obtenido de https://basesdedatos.utmachala.edu.ec:2136/lib/utmachalasp/detail.action?docID $=3175200$

Martínez, H. (2011). Responsabilidad y ética empresarial. Bogotá: Ecoe Ediciones.

Mas-Alique, P., Herráez, F., \& Muñoz, D. (2014). La huella del carbono como ventaja competitiva. DYNA Energía y Sostenibilidad, 1-8.

Ministerio de Agricultura y Ganadería. (2019). Obtenido de https://www.agricultura.gob.ec/

Moura - Leite , R., \& Padgett, R. (2014). La evolución de la responsabilidad social de la empresa: Un abordaje histórico. Revista Espacios, 35(5). 
Peña Miranda , D., \& Serra Cantallops, A. (2013). La práctica de la responsabilidad social empresarial. Estudio de caso en el sector turístico. Innovar, 101-113.

Peña, D., Plaza, A., \& Fraiz, J. (2016). La Investigación De La Responsabilidad Social Empresarial En El Sector Hotelero. Análisis Y Revisión De La Literatura Científica. Revista Turismo y Sociedad, 137-158.

Porter, M. (1986). Ventaja Competitiva. México: Editorial C.E.C.S.A.

ProMusa Mobilizing banana science for sustainable livelihoods. (2019). Obtenido de http://www.promusa.org/Manejo+de+malezas

Quintero, J., \& Sánchez, J. (2006). La cadena de valor: Una herramienta del pensamiento estratégico. TELOS. , 8(3), 377-379.

Ramírez, D. (2013). Contabilidad Administrativa. Un enfoque estratégico para competir (Novena ed.). México: Mc Graw Hill/Interamericana Editores S.A. de C.V.

REPCar. (2019). Protocolo para la implementación de buenas prácticas agrícolas en los proyectos demostrativos de plátano y banano en Colombia. Obtenido de http://cep. unep.org/repcar/proyectos-demostrativos/colombia-1/publicaciones-colombia/ protocolos/protocolo-bpa-la-yudis.pdf

Rocafort, A., \& Ferrer, V. (2008). Contabilidad de Costes. Barcelona: Bresca Editorial S.L. .

Servicio de Rentas Internas. (2019). Obtenido de https://srienlinea.sri.gob.ec/srien-linea/\#/SriRucWeb/ConsultaRuc/Consultas/consultaRuc

Solís , J. (2008). Responsabilidad social empresarial: un enfoque alternativo. 227252. Obtenido de https://www.redalyc.org/pdf/413/41311449011.pdf

Superintendencia de Compañías, Valores y Seguros. (2019). Ranking de Empresarial 2019. Obtenido de https://appscvs.supercias.gob.ec/rankingCias/

Tarí, J. (2000). Calidad total: fuente de ventaja competitiva. Alicante: Publicaciones Universidad de Alicante. Obtenido de https://rua.ua.es/dspace/bitstream/10045/13445/1/Tari_Guillo_Calidad_total.pdf

Warren, C., Reeve, J., \& Duchac, J. (2010). Contabilidad Administrativa (10a. ed.). México: Cosegraf. 


\section{Capítulo}
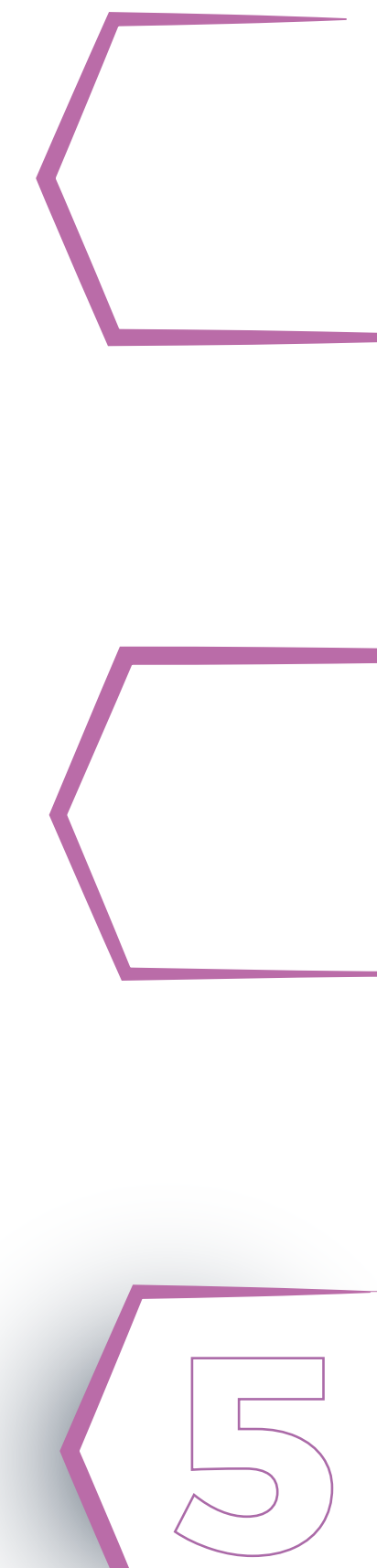

El emprendimiento como eje económico de las familias en la ciudad de Loja 
El emprendimiento como eje económico de las familias en la ciudad de Loja

\author{
Eduardo Vinicio Pulla Carrión \\ Zaida Patricia Morocho Román \\ Bernard Macías Sares
}

Autores 


\section{El emprendimiento como eje económico de las familias en la ciudad de Loja}

\section{Eduardo Vinicio Pulla Carrión}

Catedrático de la UTMACH. Graduado de la Universidad Nacional de Loja. $\mathrm{MsC}$ de la Universidad Nacional de Loja. Aspirante a doctor de la Universidad del Zulia, Venezuela.

\section{Zaida Patricia Morocho Román}

Catedrática de la UTMACH. Ingeniera Comercial. Master en Tributación de la Escuela Superior Politécnica del Litoral. Certificación Internacional en NIIF por el Instituto Tecnológico de Monterrey-México. Doctorando de la Universidad del Zulia-Venezuela.

\section{Bernard Macías Sares}

Catedrático de la UTMACH. Graduado en la Escuela Politécnica del Ejército. MsC de la Universidad Técnica Particular de Loja; y Aspirante a doctor de la Universidad del Zulia, Venezuela.

DOI: http://doi.org/10.48190/9789942241405.5 


\section{Resumen}

El emprendimiento ha cobrado interés en las economías mundiales, la creación de negocios constituye un aporte sustancial a la dinámica económica de un país o región, es así que el objeto del presente estudio es mostrar cómo los emprendimientos familiares contribuyen a la superación económica, familiar y social de las familias en la ciudad de Loja. Determinando así, en el transcurso del estudio, las ventajas y limitaciones que presentaron las organizaciones al momento de ser creadas. También describe cómo el negocio familiar contribuye a cubrir las necesidades básicas y mejora la vida de sus miembros, su connotación económica, social, emocional y de superación. La investigación fue de carácter cualitativo interpretativo, a partir del cual se trabajó con un grupo referencial de cinco emprendimientos en la ciudad de Loja; éstos informantes claves fueron seleccionados mediante un muestreo intencional u opinático, de tipo no probabilístico y que presentan características, tales como: ser emprendedores, sus emprendimientos son iniciativas familiares, emprendimientos que nacen en la provincia de Loja. A su vez la información obtenida fue analizada mediante cuadros categoriales e interpretativos, y caracterizados según el crecimiento económico de los negocios en estudio en los últimos años. Los resultados dejaron ver la representatividad económica para las familias locales, el aporte al Producto Interno Bruto, la cobertura de necesidades, el valor añadido en el mercado y el fomento al empleo. Las empresas familiares existentes basadas en los emprendimientos deben constituirse a mediano plazo en el eje constructor de las nuevas economías locales, regionales y nacionales.

Palabras claves: emprendimiento, economía, familia

\section{Introducción}

Una de las características del mundo competitivo y globalizado en el que vivimos, es la realidad cada vez más frecuente, de la creación de unidades económicas para la explotación por parte de las familias (Aira, 2016, pág. 4), en los últimos años, se ha podido apreciar un notorio interés por el emprendimiento como herramienta de creación e innovación empresarial, particularmente en los países de América y Ecuador, ya que la misma representa la nueva generación de ingresos per cápita, incremento de la clase media, disminución de la pobreza y reducción de la informalidad, aumento de la mejora de la calidad de vida y bienestar de los denominados emprendedores o innovadores empresariales mediante comportamientos isomorfos que poco tienen que ver con mejoras en el desempeño (Cortés, Betancourt \& Gonzalo, 2016, pág. 4). 
(Quejada Pérez \& Ávila Gutiérrez, 2018), sostienen que la temática de las empresas familiares aparece en el contexto actual de los tópicos académicos debido a la importancia que este tipo de compañías tienen dentro de las estructuras de producción de las economías, tanto desarrolladas como en vías de desarrollo. Su importancia radica en el poder generador de empleos que representa, y en el espíritu emprendedor que personifican sus fundadores, las empresas familiares juegan un papel fundamental en la economía mundial, ya que de acuerdo al informe del Global Entrepreneurship Monitor (GEM), se estima que aproximadamente el 90\% de las empresas en el mundo son familiares; además de su gran aportación al empleo y al producto interno bruto (PIB) mundial (Gutierres, 2015, pág.4).

Con el objetivo de crecer a corto plazo y ser sostenibles para las próximas generaciones, las empresas familiares deben abordar de manera efectiva varios desafíos únicos, lo que incluye una falta relativa de innovación, el compromiso empresarial, capacitación, financiamiento, entre otros.

Desde la visión de (Sukier, Neira, Rafael, \& Hernandez, 2017) en Latinoamérica las empresas familiares, específicamente las de servicios de distribución y comercialización de tecnología, se destacan por determinadas variables que ameritan su estudio, tales como el dinamismo de gestión, la capacidad para el crecimiento y producción, lo cual ha de redundar en la participación de mercados e inversiones desde un ámbito nacional e internacional, sumado a ello para que estas empresas familiares sean capaces de generar rentabilidad y sostenibilidad.

Según Salazar, Gonzalez, Paola \& Jhonnathan (2019), deben estar apoyadas en políticas públicas que fomenten el crecimiento de este tipo de organizaciones y les faciliten el apoyo financiero necesario por parte del Estado, mediante el otorgamiento de créditos que coadyuven a la puesta en marcha de la empresa familiar, las mismas que pretenden dinamizar la economía y acelerar el empoderamiento de los ciudadanos para su propio beneficio y el de la sociedad.

Para Zambrano, Vazquez, \& Urbiola (2019), el estudio de las empresas familiares requiere profundizar en los contextos regionales y culturales que las circunscriben; implica realizar un ejercicio que reconozca el conflicto derivado de la convivencia cotidiana. Se requieren interpretaciones desde diversos enfoques, ya que su falta de reconocimiento multidimensional, se debe en parte, a considerarlas informales, manejadas de manera intuitiva, dando como resultado miradas superficiales, carentes de rigor conceptual que no escapan de la óptica económica. Actualmente, la particularidad de las empresas familiares se fundamenta en la perseverancia que pretende conseguir los miembros de la misma, acentuando la esencia familiar en el compromiso del control de sus negocios, así como el compromiso familiar de mantenerse unidos. Los lazos entre los miembros de una familia hacen que se genere una reflexión conjunta sobre la gestión del nuevo emprendimiento, haciendo que los mismos creen su propio modelo de sucesión al momento de emprender.

Sin embargo, desde la perspectiva de Jara Nivelo, Contreras Caicedo, \& Barba López (2016), parece incuestionable que las empresas familiares se distinguen de 
otro tipo de empresas, y a la vez. que bajo el rubro de "empresas familiares" parecen encontrarse distintos tipos de empresas que pueden ser multigeneracionales.

Las empresas familiares requieren de la sucesión con responsabilidad para mantenerse en el tiempo, esto se logra con una adecuada planificación, que les permite establecer parámetros básicos de lo que puede suceder a futuro y las posibles herramientas a aplicar en su momento, así como los planes de contingencia a ejecutarse de ser el caso, sumado a ello se puede evidenciar el encausamiento que toman en cuenta las familias lojanas al momento de crear su empresa, sin imposiciones, con elección propia, privilegios y solidez que solo la familia le puede dar, todo esto entrelazado con el interés, sentimiento y conocimiento de cada uno de los miembros, una empresa familiar entendida como una de persona dentro de una organización en función de sus atribuciones societarias y valores familiares debe entrever que las condiciones organizacionales son las apropiadas (Maiane de Sousa Tavares \& Vasconcelos Rodrigues, 2018, pág. 2).

Para Arrubla Franco (2016), las empresas familiares consiguen ser de propiedad única, limitadas, sociedades anónimas, y pueden identificarse si en el nombre de la empresa figura también el nombre del dueño, tomando en cuenta que desde la visión de Parra \& La Madriz (2017), ante las circunstancias globales, una de las exigencias actuales de la empresas es la de emplear herramientas de gestión, como el presupuesto, orientadas hacia la planificación y el control de las utilidades, ya que la base del éxito de cualquier empresa en la actualidad, depende de la habilidad de la dirección para planificar y controlar las actividades de la organización, es por esto que acorde a lo mencionado por Giomar (2015), las empresas familiares se han expandido de tal modo que es necesario determinar a qué obedece su comportamiento en la toma de decisiones financieras y es a través de la trinidad financiera (rentabilidad, financiamiento y dividendos) que se intentará explicar el comportamiento de las empresas familiares, pues es que conociendo el por qué se podrá tomar decisiones más acertadas que permitirán a las empresas sostenerse en el tiempo.

Desde la mirada de (Gutiérrez et al., 2015, pág. 3), la palabra emprendimiento proviene del francés entrepreneur (pionero), y se refiere a la capacidad de una persona para hacer un esfuerzo adicional por alcanzar una meta u objetivo, siendo utilizada también para referirse a la persona que iniciaba una nueva empresa o proyecto, término que después fue aplicado a empresarios que fueron innovadores o agregaban valor a un producto o proceso ya existente.

El emprendimiento como tal constituye la iniciativa personal para satisfacer las necesidades de las personas, generando en las mismas la satisfacción de consumo de un bien o un servicio. Para (Zúñiga Jara, Soza Amigo, \& Soria Barreto, 2015), el emprendimiento ha ido adquiriendo cada vez mayor atención a nivel mundial, por cuanto se le considera como uno de los principales motores del crecimiento y del desarrollo económico y, por tanto, implícitamente se considera que el empren- 
dimiento está fuertemente vinculado a la dinámica del empleo, haciendo de esta actividad una representatividad en el ámbito de la economía mundial, así que emprender desde la óptica de (Mite Alban, Lovato Torres, Franco, \& Melvin, 2017), es crear una organización o empresa tomando en cuenta que las personas que emprenden deben tener competencias que le permitan desarrollar con dinamismo su proyecto para alcanzar el desarrollo económico que se proyectó, es importante educar para emprender, y que para (Núñez Ladeveze \& Núñez Canal, 2016), la tendencia al emprendimiento surge para cubrir una necesidad forzada por la subsistencia o la falta de alternativas de empleo, por lo que tiene una "calidad" diferente y un impacto menor en el crecimiento.

De allí que el emprendimiento requiera de componentes que le permitan generar un equilibrio en la sociedad y en la económica, por lo que para Suarez Vinueza (2018), los emprendimientos sustentables están destinados a generar herramientas, estrategias y guías de acción para la superación de la pobreza, reinsertándoles con negocios esperando que al crecer puedan revertir esta condición disminuyendo otros factores de riesgo al establecer redes de apoyo y trabajo mancomunado, sumando a ello el emprendimiento surge desde la intencionalidad.

Figura 1.

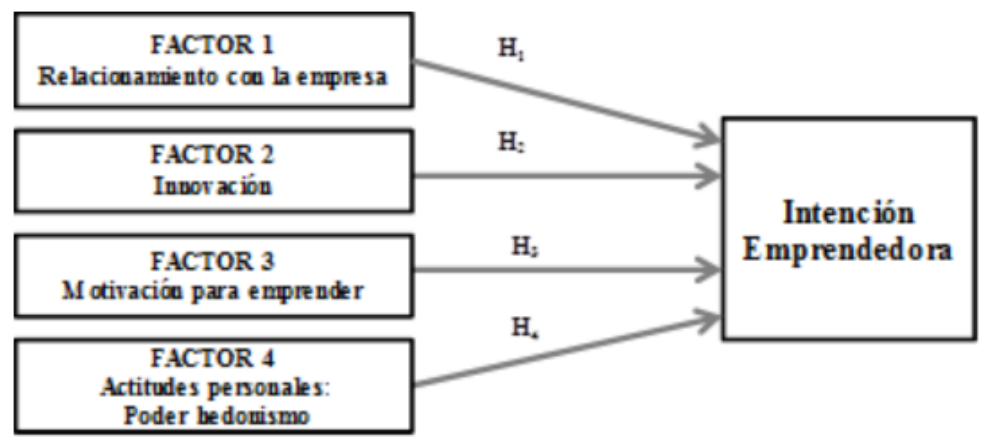

Nota: Modelo de Catherine Krauss Delorme 2001

En sintonía con lo anterior, Omaña Guerrero \& Briceño Barrios (2013), toda organización puede identificarse al ver en ella ciertas características que la distinguen de otras. Una organización es una agrupación estructurada de personas para el logro de algún propósito definido y cumplen una serie de características. Es así que, los emprendimientos ya sea basados en factores, herramientas o estrategias, no dejan de ser importantes para las economías locales, a partir de ello las empresas conformadas por familias retoman el papel de ejes motores de la economía, es así que para Zachary (2013), un emprendimiento familiar nace cuando un sistema-familia y un sistema-negocio se unen para conformar una empresa familiar, las empresas familiares gozan de una gran versatilidad: pueden estar listadas en Bolsa y 
ser enormes, o ser sociedades cerradas y muy pequeñas, sin obviar que estas últimas pueden crecer al punto de salir a la Bolsa e incluso internacionalizarse, desde la puntualidad objetiva de Amorós (2013), las familias suelen verse enfrentadas ante el dilema de esforzarse por sacar adelante un negocio o a la familia misma, pero, como en las empresas familiares a veces esos lazos son indisolubles, se generan una serie de tensiones, problemas y retos que hay que solucionar, sobre todo ante las diferencias de ritmo que presentan el crecimiento familiar y empresarial. Para Díaz Valbuena, Guerra, \& Urdaneta Montiel (2018), las empresas familiares constituyen un alto porcentaje entre las organizaciones productivas del planeta en general.

En el estudio "Cultura y Actividad emprendedora en la provincia de Loja”, desarrollado en el año 2015 por la Universidad Nacional de Loja se determinó que la tasa de actividad emprendedora es del $37 \%$, por encima de la media nacional de $30,6 \%$ en el año 2015, orientada especialmente al sector de servicios, la motivación principal de los emprendedores está entre la oportunidad y la necesidad con un $63,47 \%$, la necesidad le sigue con un $26 \%$ y por último la oportunidad de mejora con un $10,53 \%$. En relación a la edad de los emprendedores en la provincia el porcentaje más representativo se encuentra en la categoría de 35 a 50 años, el $90 \%$ son emprendimientos consolidados y solo el $7 \%$ son emprendimientos iniciados en el último año (emprendimientos nacientes). En lo que se refiere a la formación de los emprendedores el mayor porcentaje cuenta con educación de tercer nivel, seguido de bachillerato.

Las actuales dinámicas de los entornos empresariales en un mundo globalizado de acuerdo a Bedoya Villa, Toro Jaramillo \& Arango Alzate (2017), exigen repensar el rol del empresario tradicional ante los constantes cambios en las condiciones de los mercados, la competencia agresiva y la necesidad de adoptar nuevas estrategias organizacionales que promuevan la capacidad de capitalizar ideas innovadoras en productos y servicios, los cuales proveen mayores niveles de competitividad y crecimiento, es así que nace la importancia de la investigación sobre la empresa familiar, no solo como un simple objeto de estudio de una moda pasajera, sino por la necesidad imperiosa de conocer, describir y explorar el fenómeno que es un actor social, histórico y presente del tejido empresarial, tanto en los ámbitos nacionales como internacionales que, por tanto, tienen considerables efectos sobre los individuos (Basco, 2006), la supervivencia y el desarrollo de una empresa familiar, requiere la adopción de decisiones estratégicas en cada generación, desarrollando una nueva empresa o división, internacionalizándose y ayudando a los sucesores a adquirir habilidades que otros miembros de la familia no poseen (Cortés, García, \& Quer, 2008).

De acuerdo a (Valencia Maldonado \& Erazo, 2017), el Ecuador se encuentra en un momento oportuno para la implementación de estrategias concretas que fomenten el sistema dinámico de emprendimiento por medio del trabajo conjunto de los cuatro ejes claves de la economía: Academia, y los Sectores Público, Privado y Cívico. 
Según el reporte generado por el Global Entrepreneurship Monitor (GEM), en el 2017, Ecuador mantuvo la Tasa de Emprendimiento Temprano (TEA) más alta entre los países de América Latina y el Caribe, siempre por encima de la media regional y de las economías de eficiencia. Sin embargo, la TEA Ecuador ha venido declinando gradualmente de 36\% en 2013 hasta 29.6\% en 2017 y su Índice de Espíritu Emprendedor (GESI), Ecuador obtiene un puntaje positivo de 0.28 y se encuentra en un nivel óptimo en cuanto al desarrollo del Espíritu Emprendedor, el mismo que predomina en las economías de eficiencia; este índice está positivamente relacionado con la TEA, a su vez el 52\% de los ecuatorianos manifiestan intención de emprender, siendo el segundo porcentaje más alto en la región.

El 31.7\% de la población considera que el miedo al fracaso le impediría emprender, alrededor de la media regional pero inferior a la media para economías de eficiencia, cimentado en lo mencionado en el apartado anterior, el presente trabajo investigativo cuenta con el abordaje escrito y testimonial sobre emprendimientos familiares en la ciudad de Loja, ya que la construcción de las sociedades en términos económico nace de ellas, de las familias, cuya dinámica y funcionamiento permite conocer qué los impulsa a emprender, qué herramientas toman en cuenta al momento de crear su empresa y cómo afrontan las responsabilidades empresariales, así como la repercusión económica que conlleva la responsabilidad de hacer empresas a nivel de familias. Las condiciones en las cuales fueron creadas han cambiado en los últimos 10 años, ya que las políticas económicas, situaciones geográficas, demográficas y ambientales han sufrido un giro de 160 grados por lo que las formas de cómo emprender se han ajustado a esta realidad.

La empresa familiar y la interacción de sus miembros dentro de la misma, implica la atención de las fuerzas emocionales, las mismas que influyen al momento de enfrentar el reto de emprender, este tipo de empresas no están exentas de problemas, como; la comunicación errónea, toma de decisiones individuales, la no secuencia del traspaso generacional, entre otros.

El presente estudio se enfoca en conocer al nuevo emprendedor, el camino recorrido por el mismo y las condiciones en las cuales emprendieron, la secuencialidad del protocolo familiar para tener relevancia entre los miembros familiares, así como los beneficios en la calidad de vida que tienen sus integrantes.

Pero realmente ¿Por qué realizar la presente investigación?, desde una mirada científica (Manterola, 2013), establece que es indudable que pueden existir múltiples respuestas posibles a esta simple pregunta, una es que, para tener prestigio profesional, o sentirse bien, o alcanzar reconocimiento, o para publicar, obtener financiamiento, o viajar a congresos por otro lado, para ser parte del conocimiento, o hacer crecer su profesión, fortalecer una disciplina, beneficiar a la población, $u$ ofrecer lo mejor a los usuarios; hasta algunas muy profundas y de significado muy técnico como, para generar conocimiento útil, o fundamentar nuestras acciones, o invertir en lo necesario, o evitar riesgos, o fundamentar las prioridades en salud, o influir en la economía, entre otros; bajo la línea de trabajo establecida en la inves- 
tigación, lo fundamental es establecer el crecimiento económico familiar basado en la creación de las empresas, así como el bienestar emocional y de lazos familiares generados producto de la actividad emprendedora.

\section{Objetivo general}

Explicar la influencia del emprendimiento como eje económico en las familias en la ciudad de Loja.

\section{Objetivos específicos}

- Determinar el crecimiento de los emprendimientos en las familias lojanas.

- Comprender la influencia del emprendimiento en las economías de las familias lojanas

\section{Metodología}

La investigación tuvo un enfoque cualitativo interpretativo, a partir de la valoración de las actividades realizadas por los emprendedores familiares y su percepción. Tomando como base la pirámide de Maslow, el grupo de informantes claves, a criterio de los investigadores, fue de cinco emprendimientos en la ciudad de Loja; estos fueron abordados mediante técnica de informantes clave, la misma que se complementa con la aplicación de entrevistas a miembros de dichas formas asociativas, la información obtenida fue analizada mediante cuadros categoriales e interpretativos, los mismos que fueron representados de manera gráfica para su mejor ilustración, así mismo la investigación fue realizada sobre la base de consultas a artículos científicos, ponencias y documentos doctorales los mismos que se tomó como referencia para el sustento del mismo.

\section{Materiales y métodos}

En el proceso investigativo se pretende indagar, el por qué y el cómo se produce el proceso del emprendimiento en cierto sector del país, que características se consideraron al momento de emprender, de qué manera funcionaron y su evolución, basado en lo anterior se llevó a cabo un estudio longitudinal, retrospectivo de las empresas con mayor aceptación en la ciudad de Loja, tomando en cuenta el crecimiento que han tenido desde su año de creación. El estudio se realizó mediante la 
revisión del Servicio de Rentas Internas (SRI) de las empresas seleccionadas como parte de la muestra y sus declaraciones anuales en términos de rentabilidad.

Tabla 1. Empresas seleccionadas para la investigación.

\begin{tabular}{|c|c|c|c|c|c|c|}
\hline Empresas & Sector & $\begin{array}{c}\text { Año de } \\
\text { constitución }\end{array}$ & Tamaño & $\begin{array}{c}\mathrm{N}^{\circ} \text { de Trabaja- } \\
\text { dores }\end{array}$ & Activos & $\begin{array}{c}\text { Accionistas de } \\
\text { la familia }\end{array}$ \\
\hline A & & 1987 & Pequeña & 11 & 8.884 .957 & 15 \\
\hline B & & 2003 & Pequeña & 12 & 6.734 .489 & 4 \\
\hline $\mathrm{C}$ & & 2013 & Pequeña & 11 & 5.924 .482 & 5 \\
\hline $\mathrm{D}$ & & 2013 & Pequeña & 13 & 3.100 .000 & 3 \\
\hline E & & 2013 & Pequeña & 12 & 2.200 .000 & 4 \\
\hline
\end{tabular}

Las empresas fueron seleccionadas de acuerdo al ranking empresarial establecido por la Superintendencia de Compañías del Ecuador.

El proceso de recolección de información se basó en el principio de la triangulación con la finalidad de garantizar la validez de la información. En efecto las fuentes de información utilizadas, fueron; entrevistas semi estructuradas, observación directa y documentos proporcionados por las empresas. En la tabla No 2, se muestran algunas de las características de los emprendedores a quienes se realizó la entrevista.

Tabla 2. Características de los emprendedores.

\begin{tabular}{|c|c|c|c|c|c|c|}
\hline Empresas & Entrevistado & Cargo Actual & Edad & Género & Nivel de Educación & $\begin{array}{c}\text { Año en la } \\
\text { empresa }\end{array}$ \\
\hline A & Manuel Godoy & Gerente & 49 & M & Superior & 2018 \\
\hline B & Ixania Azanza & Gerente & 48 & $\mathrm{~F}$ & Superior & 2015 \\
\hline $\mathrm{C}$ & Jorge Toro & Gerente & 46 & M & Superior & 2015 \\
\hline $\mathrm{D}$ & Harold Brown & Gerente & 51 & $\mathrm{M}$ & Superior & 2016 \\
\hline E & Jorge Páez & Gerente & 49 & M & Superior & 2015 \\
\hline
\end{tabular}

En el caso de la empresa A cuyo objeto social es la compraventa de terrenos, la construcción de edificios, la compra venta de casas o departamentos, almacenes u oficinas, arrendamiento y administración de inmuebles y cualquier otra actividad afín y declarada como compañía de responsabilidad limitada, cuyas características determinadas por el informante de esta empresa, señaló que al momento de emprender se tomó en cuenta consideraciones de responsabilidad, afinidad familiar, condición general de la familia, herencia, prestaciones financieras, respaldo económico de los familiares, conocimiento del mercado donde iban a participar; 
enfatizando que para la familia lo importante es la expansión en los negocios, así como la conexión entre los mismos, para fortalecerse como compañías. Las circunstancias en las cuales nació la empresa fueron favorables, es así que al momento de emprender dependieron de la solidez económica del resto de sus miembros y la experiencia en el mundo empresarial, así como la conformación de nuevas empresas en la ciudad.

En el caso de la empresa B, (CEVASCOP) cuyo objeto social es la prestación de servicios de laboratorio clínico, gabinete de diagnóstico médico por imagen, venta de servicios de salud en hospital clínica, venta de medicinas, insumos, equipos y productos varios que normalmente se comercializan en farmacias, servicios de ambulancia, arriendo y venta de locales de la clínica para consultorios o actividades afines, venta de prótesis, entre otros; entre otras. Declarada como sociedad anónima, cuyas características determinadas por el informante establecen que la empresa nació con la finalidad de solventar económicamente a toda una generación, este emprendimiento cuenta con profesionales de la salud lo que le permite dotar de un eficiente servicio, la empresa tiene como política dejar que los aspectos administrativos los maneje un tercero, el mismo que sea un profesional que responda a las necesidades de la empresa, a su vez CEVASCOP, constituye una de las compañías con mayor rentabilidad, además, se han generado nuevos negocios, los mismos que son impulsados por los familiares, las condiciones de superación económica, así como las profesionales hacen que la misma se constituya en una empresa sólida. A través del tiempo las condiciones financieras no fueron favorables, sin embargo, la decisión de los miembros de una familia la hicieron lo que hoy es, una de las empresas con mayor cobertura en los servicios de salud.

En el caso de la empresa C, la sociedad tiene como objeto toda clase de actividades agropecuarias, $\mathrm{y}$, de madera particular, la siembra, cultivo, tratamiento y comercialización o industrialización de caña de azúcar, declarada como sociedad anónima, cuyas características determinadas por el informante y en la entrevista, establecieron que las actividades empresariales se iniciaron con capital semilla, producto de la gestión de un miembro de la familia, inicialmente se conformó por dos integrantes para luego incorporarse el resto de accionistas, una de las características de este emprendimiento es el conocimiento sobre el tema agrícola y agropecuario, motivados por las condiciones físicas y ambientales que tiene el medio, conjuntamente con la creciente demanda de los derivados de los productos agropecuarios hacen de la misma un negocio rentable.

En el caso de la empresa D, la sociedad tiene como objeto la crianza de larva y producción de camarón en cautiverio, venta, comercialización y exportación al mayor y por menor de camarón, actividades camaroneras complementarias de cualquier índole, a su vez la importación de toda clase de equipos, suministros y maquinaria liviana y pesada, para el desarrollo de la actividad camaronera o complementarias, entre otras. Las características determinadas por el informante, establecen que las necesidades de consumo y las preferencias familiares apuntaron 
al emprendimiento de la sociedad cuyas características apuntan al mejoramiento de la calidad de vida de cada uno de sus familiares y, por tanto, el de su entorno, a pesar de no haber contado con el capital necesario en su momento. La empresa comenzó con dos miembros familiares con capital semilla generado por las entidades financieras, sin embargo, el conocimiento sobre el negocio, hizo que la inversión realizada fuera en la dirección correcta, la confianza entre sus accionistas y la responsabilidad que conlleva la superación económica en la familia, sostiene a una empresa que pretende ser en los años próximos una gran empresa.

En el caso de la empresa E, cuya razón social es LOJALAC es una empresa de producción, tratamiento, envasado y comercialización de leche y derivados lácteos, así como la importación y comercialización de insumos, materia prima, equipos y maquinaria necesarios para llevar a cabo el procesamiento de lacteos. Compra-venta de ganado lechero, producción agrícola de alimentos tanto para consumo humano como para animal. La información aportada por el informante da cuenta de las condiciones iniciales favorables a la implementación de la misma, ya que solo contaba con un capital inicial, de menos del 10\% de la inversión requerida, por lo que la unión familiar y sentido de superación económica desus miembros, hicieron que la empresa tuviera su inicio. Las condiciones generales de conocimiento en el área contribuyeron a que la empresa funcionara de manera adecuada. La familia Páez, cuyos accionistas son hermanos, detectaron la necesidad de mercado de productos derivados de esta actividad, siendo en la actualidad una de las mejores empresas del país.

El estudio realizado pone en evidencia las características por las cuales los emprendimientos nacieron, y sobre todo el conocimiento previo con el que se manejaron, para ello se procesó la información, lo que permitió que se caracterice a los emprendedores en sus diferentes áreas. Sin embargo, las herramientas aplicadas pasaron por un proceso de validez, el cual que permitió realizar el comparativo de sus respuestas.

Es así que la validez y la flexibilidad de los instrumentos aplicados se basan en criterios específicos que permiten evaluar la objetividad con la que se realizo el estudio

Tabla 3. Pruebas para evaluar la calidad y la objetividad del estudio.

\begin{tabular}{|c|c|c|}
\hline \multicolumn{1}{|c|}{ Prueba } & Técnica de estudio de caso & Fase en que se aplica \\
\hline Validez de la & $\begin{array}{c}\text { Uso de varias fuentes de evidencia } \\
\text { Establecer la cadena de evidencia } \\
\text { construcción }\end{array}$ & Obtención datos \\
& $\begin{array}{c}\text { Revisión de información proporcionada por infor- } \\
\text { mantes }\end{array}$ & \\
\hline Validez interna & $\begin{array}{c}\text { Establecer patrones de comportamiento } \\
\text { Explicación del fenómeno }\end{array}$ & Análisis de datos \\
\hline
\end{tabular}




\begin{tabular}{|c|c|c|}
\hline Validez externa & Replicación de estudios & Diseño de la investigación \\
\hline Fiabilidad & $\begin{array}{c}\text { Protocolo de estudio } \\
\text { Construcción de base de datos }\end{array}$ & Obtención de datos \\
& & \\
\hline
\end{tabular}

Nota: Yin (1994).

Los materiales utilizados dentro del estudio fueron:

- Formulario de entrevista semiestructurada.

- Computador.

- Insumo de oficina.

- Transporte.

El estudio se basó en el método cualitativo, el mismo que permitió establecer de manera objetiva el crecimiento y evolución que tuvieron los negocios en la ciudad de Loja, tomando en cuenta que la muestra descrita se encuentra en la base de datos del Municipio de Loja, en donde estableció el ranking de las mismas.

\section{Rersultados y discusión}

En este apartado se exponen los resultados del análisis de las características evolutivas de las empresas familiares en la ciudad de Loja.

Para (Gutiérrez Montoya, 2013) resulta una tarea compleja el desarrollar un emprendimiento, como consecuencia de la articulación y colaboración entre muchos actores para que esta tarea sea llevada de forma exitosa, sin embargo, las condiciones del entorno donde se desarrolla uno o varios emprendedores hace que las posibilidades de acierto sean mayores, es así que no solo el emprendimiento y el emprendedor son actores importantes en un sistema sino también el cliente, su comportamiento, la visión que tiene del negocio, necesidades, deseos y por ende la demanda del servicio (Sanabria Navarro, Pérez, \& Digna, 2019).

De acuerdo a Moreno Gavilánes, Miranda López \& Vásconez Fuentes (2017), muchas personas dicen que en tiempos pasados los productos tenían una mayor durabilidad, esto se debe a que en aquella época los productos no tenían un tiempo determinado de vida útil, es decir, algunos de ellos eran de por vida, pero esos productos llevaron a la quiebra a muchas empresas, ya que las personas únicamente compraron sus productos una sola vez, sumado a ello los cambios y las innovaciones que surgen hacen que los productos deban modificarse y mejorarse, es ahí donde las empresas ven la necesidad de crear productos que posean un tiempo determinado de duración para que sus productos sean adquiridos cada cierto tiempo.

Es así que, de acuerdo a Llanos Contreras \& Álvarez de Eulate (2019), el proceso emprendedor incluye la exploración del entorno, la generación de ideas, y la materialización de una iniciativa emprendedora, y que necesariamente debe 
medirse de acuerdo a Atienza, Lufín, \& Romaní (2016), la calidad del emprendimiento surge al considerar las diferencias espaciales que se encuentran dentro de un país, a pesar que desde el punto de vista de Salas Salazar, Martínez Mesías, \& Chamba Bastidas (2017), los pequeños emprendimientos que en la actualidad se encuentran posicionadas en este mercado gracias a una administración que se va perfeccionando a medida de su crecimiento tecnológico, la transferencia de conocimiento, capacitación de empleados, crecimiento del mercado nacional que ha permitido una inversión superior en cuanto a maquinaria y capacidad instalada, incrementando el valor productivo en el producto o servicio.

Para Suarez (2018), la ciudad de Loja se ha caracterizado por ser una ciudad comercial con pocos emprendimientos, empresas e industrias, generando con ello, consumismo y dependencia de la cadena de comercialización de los negocios de auge, se limitan las fuentes de trabajo y se multiplican las necesidades de ingresos para mantener el estatus social correspondiente.

Figura 2. Características de evolución de los emprendimientos familiares.

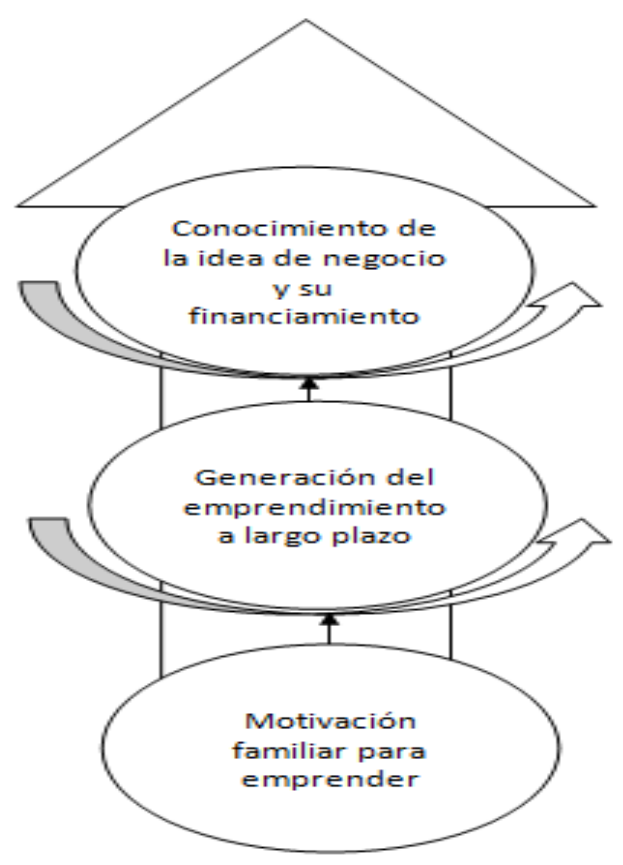

Si bien es cierto que las familias emprendedoras en la provincia de Loja tienen un denominador común, que es el de no haber contado con capital propio al momento de montar su empresa, también es cierto que dichas familias participan de manera activa, ya sea en al ámbito de la gestión como en la parte operativa, de la misma forma las familias tienen la firme convicción de darle continuidad a sus negocios, lo que hace que se diferencie del resto de emprendimiento establecidos en la localidad. La motivación existente dentro del mismo entorno es un factor clave que afirma 
el compromiso organizacional. Para la conformación de la empresa, se aseguraron tener el conocimiento necesario que les permita mantenerse en el mercado.

La satisfacción de necesidades familiares se basa en los ingresos generados por los mismos, el mejoramiento económico y de ingresos familiares, lo que hace que sus miembros mejoren su calidad de vida.

Basados en la información suministrada por los informantes claves se pudieron establecer una relación entre los ingresos necesarios para satisfacer las necesidades, según la pirámide de necesidades de Maslow, en función de los ingresos promedios devengados por las familias emprendedoras en la ciudad de Loja y los ingresos promedios denotados por las familias emprendedoras en la ciudad de Loja, pudieron establecer fluctuaciones de ingresos que les permita suplir las necesidades básicas e intrínsecas dentro de su entorno familiar, tomando en cuenta que las familias se encuentran compuestas por 5 miembros.

Tabla 4. Jerarquías de necesidades humanas.

\begin{tabular}{|c|c|}
\hline Jerarquía de necesidades humanas & $\begin{array}{c}\text { Ingreso promedio de familias en Loja } \\
\text { para cubrir sus necesidades \$ }\end{array}$ \\
\hline Autorrealización & 2900 \\
\hline Reconocimiento & 2300 \\
\hline Afiliación & 1096 \\
\hline Seguridad & 645 \\
\hline Fisiología & 394 \\
\hline
\end{tabular}

Según datos publicados por Global Entrepreneurship Monitor (GEM), Ecuador es uno de los países más emprendedores de Latinoamérica, posicionándose como la cuarta economía más emprendedora a nivel mundial, con una Tasa de Actividad Emprendedora (TEA) del 32,6\%, "la tercera parte de la población adulta está compuesta de emprendedores tempranos”.

Loja no es la excepción, a pesar de ser una ciudad chica. En 1973 vio la luz una pequeña y artesanal fábrica de condimentos ILE (Industria Lojana de Especerías), propiedad de la familia Godoy Ruíz, que desde el año 2006 exporta sus productos a España y Norteamérica de acuerdo a la Superintendencia de Compañías 2018.

Loja como tal es considerada la ciudad con el mayor número de emprendedores, los mismos que se han destacado a nivel nacional e internacional. De acuerdo a datos registrados por la Universidad Técnica Particular de Loja, Cristian Ramírez, ingeniero graduado en la misma Universidad creó “HAND OF HOPE” el nombre del proyecto que ganó el primer lugar representando a Ecuador en el concurso Internacional de Infomatrix, realizado en Bucarest, la capital de Rumanía.

Así mismo, Conéctate al aire, KEA Electronics, impulsado por los estudiantes de la UTPL Augusto Abendaño, Juan Diego Palacios, José Antonio Córdova y Mateo 
Sánchez. Los que participaron en el concurso que realiza la SENESCYT (Secretaría Nacional de Educación Superior, Ciencia, Tecnología e Innovación), por medio del banco de ideas y fueron condecorados como idea innovadora.

En Loja existen varias instituciones que promueven el impulso al emprendimiento, orientando al nuevo emprendedor a canalizar su idea de negocio y puesta en marcha del mismo: el Ministerio de Industrias y Productividad (Mipro); Agencia Nacional de Regulación, Control y Vigilancia Sanitaria (Arcsa), BanEcuador, las superintendencias de Control de Poder del Mercado, y Economía Popular y Solidaria, la Universidad Técnica Particular de Loja con su proyecto Phrendo, el Municipio de Loja bajo Bolsa Global de emprendimiento y trabajo, son las entidades públicas que ayudan a consolidar una idea para lanzarla al mercado, brindando asesoría, acompañamiento y apoyo en la obtención de registros sanitarios, entre otros. El principal requisito para emprender y recibir apoyo de estas organizaciones es presentar una idea innovadora.

Así mismo capacitan en diversas áreas: motivación para acceder a nuevos mercados, a través de ferias y negociaciones, diseño de logotipos, marcas, en caso de que el emprendedor llegue con una o varias ideas.

Los emprendimientos que llegan a estas instituciones pasan por un proceso de clasificación o categorización, con el fin de establecer la calidad en los productos. Esta clasificación se divide desde artesanos hasta directivos. La consecución de mercado se realiza mediante el proceso de diseño, imagen, fortalecimiento, desarrollo del emprendimiento, hasta llegar al posicionamiento del producto en el mercado.

Los emprendimientos establecidos en la ciudad de Loja cuentan con características especificas acorde a la realidad local y demanda del mercado.

Tabla 5. Características comunes y no comunes de los emprendimientos.

\begin{tabular}{|l|l|}
\hline \multicolumn{2}{|c|}{ Características de los emprendimientos en la ciudad de Loja } \\
\hline Comunes & No comunes \\
\hline Motivación de superación económica en la familia & Manejo y desarrollo productivo \\
\hline Innovación & Creación de sistemas de entrega de bienes y servicios \\
\hline Trabajo en equipo y negociación & $\begin{array}{l}\text { Estructura organizativa, acorde a la constitución de cada em- } \\
\text { presa }\end{array}$ \\
\hline Perseverancia en el tiempo & Mercados diferenciados \\
\hline Fluidez en los procesos productivos y de servicios & Objetivos planteados a corto mediano y largo plazo \\
\hline
\end{tabular}




\section{Conclusiones}

Las empresas familiares en el mundo se constituyen en los motores del desarrollo regional y local, ya que cuentan con un mejor desempeño y un notable crecimiento en sus ventas y retornos de las utilidades para los accionistas de las empresas. De acuerdo al Banco Mundial se estima que las empresas familiares representan más del 70 \% del PIB mundial. Por tanto, la capacidad del sector empresarial basado en la familia, es vital para la prosperidad de los pueblos y la consecución de un crecimiento a largo plazo de la economía mundial. Con el objetivo de crecer a corto plazo y ser sostenibles para las futuras generaciones, las empresas familiares deben enfrentar de manera efectiva varios desafíos, lo que incluye una escasa noción sobre la innovación, la propiedad que puede estar compartida entre varios sectores de una familia, la necesidad de realizar una transición eficiente a las nuevas generaciones de líderes de la empresa y un vínculo emocional potencialmente obstaculizador con el legado del fundador.

En la actualidad este tipo de organizaciones son objeto de estudio e investigación, ya que las mismas se están abriendo campo para considerarse áreas independientes, debido a su connotación. Sin embargo se encuentran aún en un proceso embrionario. Los resultados y discusiones generados en la presente propuesta han tenido la intencionalidad de mostrar las consideraciones explicativas y el entorno en el ámbito de la investigación de los emprendimientos familiares.

El proceso evolutivo del emprendimiento permite conocer la multidisciplinariedad sobre la que se está construyendo un nuevo concepto del emprendimiento familiar, basado en experiencias emprendedoras y fundamentación científica. La demostración de la perspectiva actual empresarial y su evolución permite reformular las condiciones en las cuales se pretende generar una nueva organización familiar, basada en la motivación de un grupo familiar y sus estrategias a aplicar en el tiempo.

Las posturas investigativas dentro del ámbito del emprendimiento familiar son diversas, por lo que sus autores tienen la tarea de integrar conocimientos, que les permita construir un cuerpo teórico propio, ya que, con una definición mucho más centrada, el abordaje del tema se facilita. De momento la creación y el manejo de las empresas familiares pueden ser considerada en el ámbito de la aplicación del emprendimiento. Los componentes intrínsecos son los que realmente importan en el horizonte temporal, así como la elaboración de una empresa basada en características propias del medio.

La ciudad de Loja acoge un numero considerable de emprendedores, producto de la sinergia existente entre las entidades público-privadas para formar emprendedores, la coyuntura existente entre ellos hace que las ideas de negocio permanezcan en el tiempo. 


\section{Referencias}

Aira, M. R. (2016). La suceción exitosa en las empresas familiares . Revista Científica Electrónica de Ciencias Humanas, 4.

Amorós, J. E. (2013). Familia y dinámica emprendedora en Chile: una mirada desde el Global Entrepreneurship Monitor. El emprendimiento familiar (pág. 12). Santiago de Chile: RIL ${ }^{\circledR}$ editores.

Arrubla Franco, M. (2016). Finanzas y educación financiera en las empresas familiares Pymes. Sinapsis, 4.

Atienza, M., Lufín, M., \& Romaní, G. (2016). Un análisis espacial del emprendimiento en Chile. Más no siempre es mejor. EURE, 4.

Basco, R. (2006). La Investigación en la empresa familiar: "Un debate sobre la existencia de un campo independiente". Investigaciones Europeas de Dirección y Economia de la Empresa , 35.

Bedoya Villa, M. A., Toro Jaramillo, I. d., \& Arango Alzate, B. (2017). Emprendimiento Corporativo e Innovación: Una Revisión y Futuras Líneas de Investigación. Espacios, 1.

Cortés, D., Betancourt, J., \& Gonzalo, G. (2016). imlementación de prácticas de gobierno corporativo en Colombia: Un análisis desde el isomorfismo Institucional en Empresas familiares y no familiares . Revista Facultad de Ciencias Economicas , 4.

Cortés, E., García, L., \& Quer, D. (2008). Factores familiares y compromiso internacional: Evidencia emprírica en las empresas españolas. Cuadernos de Economia y Dirección de Empresa, 5.

Díaz Valbuena, N. J., Guerra, M. L., \& Urdaneta Montiel, A. J. (2018). ADN organizacional y productividad en las empresas familiares. Desarrollo Gerencial, 2.

Giomar, M. (2015). Las “Finanzas Saludables” en las Empresas Familiares. Neumann Business Review, 2.

Gutierres, S. (2015). Emprendimiento en las empresas familiares. Revista Iberoamericana de Contaduría, Economía y Administración , 4.

Gutiérrez Montoya, G. A. (2013). Evolución del emprendimiento en el Salvador . Cientifica, 5.

Jara Nivelo, J. J., Contreras Caicedo, B. J., \& Barba López, R. (2016). Las empresas familiares. Tendencias investigativas. Revista Publicando, 4.

Llanos Contreras, O., \& Álvarez de Eulate, Y. (2019). Evolución percibida de la competencia para emprender a partir de la implementación de un programa de formación de competencias en emprendimiento e innovación. REOP, 12. 
Maiane de Sousa Tavares, I., \& Vasconcelos Rodrigues, L. (2018). A Percepção dos Trabalhadores Formais sobre a Gestão de Pessoas em Empresas Familiares. Revista Multidiciplinar y de Psicologia, 2.

Manterola, C. (2013). Porqué Investigar y Cómo Conducir una Investigación. International Journal of Morphology, 4.

Mite Alban, M., Lovato Torres, S., Franco, L., \& Melvin. (2017). Emprendimiento en el Morro, empresas familiares y sus necesidades de capacitación. Dominio en Ciencias, 5.

Moreno Gavilánes, K. A., Miranda López, R. F., \& Vásconez Fuentes, J. L. ( 2017). La obsolescencia programada y la pirámide de las necesidades: un estudio exploratorioa partir de la percepción del consumidor. Revista Publicando, 10.

Núñez Ladeveze, L., \& Núñez Canal, M. (2016). Noción de emprendimiento para| una formación escolar en competencia emprendedora. Revista Latina de Comunicación Social, 2.

Omaña Guerrero, L. M., \& Briceño Barrios, M. A. (2013). Gerencia de las empresas familiares y no familiares: análisis comparativo. Estudios Gerenciales, 5.

Parra, J., \& La Madriz, J. (2017). Presupuesto como instrumento de control financiero en pequelas empresas de estructura familiar . Negotium, 3.

Quejada Pérez, R. F., \& Ávila Gutiérrez, J. N. (2018). Empresas familiares:Conceptos, teorias y estructuras. Revista EAN, 3.

Salas Salazar, M. d., Martínez Mesías, R. F., \& Chamba Bastidas, L. A. (2017). Evolución de las pymes en la ciudad de riobamba, crecimiento y aporte económico. Eumed, 5.

Salazar, F., Gonzalez, J., Paola, S., \& Jhonnathan, S. (2019). Emprendimiento e Innovación: Agentes potencionadores de la Empresa Familiar . SAPIENTIAE: Ciências sociais, Humanas e Engenharias , 3.

Sanabria Navarro, J. R., Pérez, Y., \& Digna, P. (2019). Emprendimientos deportivos: Caso Subregión Sabana, Departamento de Sucre, Colombia. Retos, 4.

Suarez Vinueza, E. (2018). Incubación de emprendimientos sustentables en el grupo social "San Juan Bosco" Loja. INNOVA, 3.

Suarez, E. (2018). Incubación de emprendimientos sustentables en el grupo social "San Juan Bosco" Loja. Innova, 4.

Sukier, H., Neira, H., Rafael, P., \& Hernandez, L. (2017). Dirección estratégica en las empresas familiares. Espacios , 3.

Valencia Maldonado, G., \& Erazo, M. A. (2017). Indicadores de Emprendimiento. Caso Ecuador. Revista Publicando, 3. 
Zachary, R. (2013). El emprendimiento familiar, desde adentro hacia fuera. El empremdimiento familiar (pág. 1). Santiago de Chile : RIL editores.

Zambrano, S., Vazquez, A., \& Urbiola, A. (2019). Empresas familiares, emprendimiento y género. Cinco problemáticas para el análisis regional. Espacios, 4.

Zúñiga Jara, S., Soza Amigo, S., \& Soria Barreto, K. (2015). Dinámica del emprendimiento y el desempleo en la Patagonia chilena. Magallania, 2. 



\section{Capítulo}

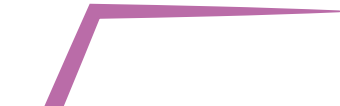 \\ Capitu}

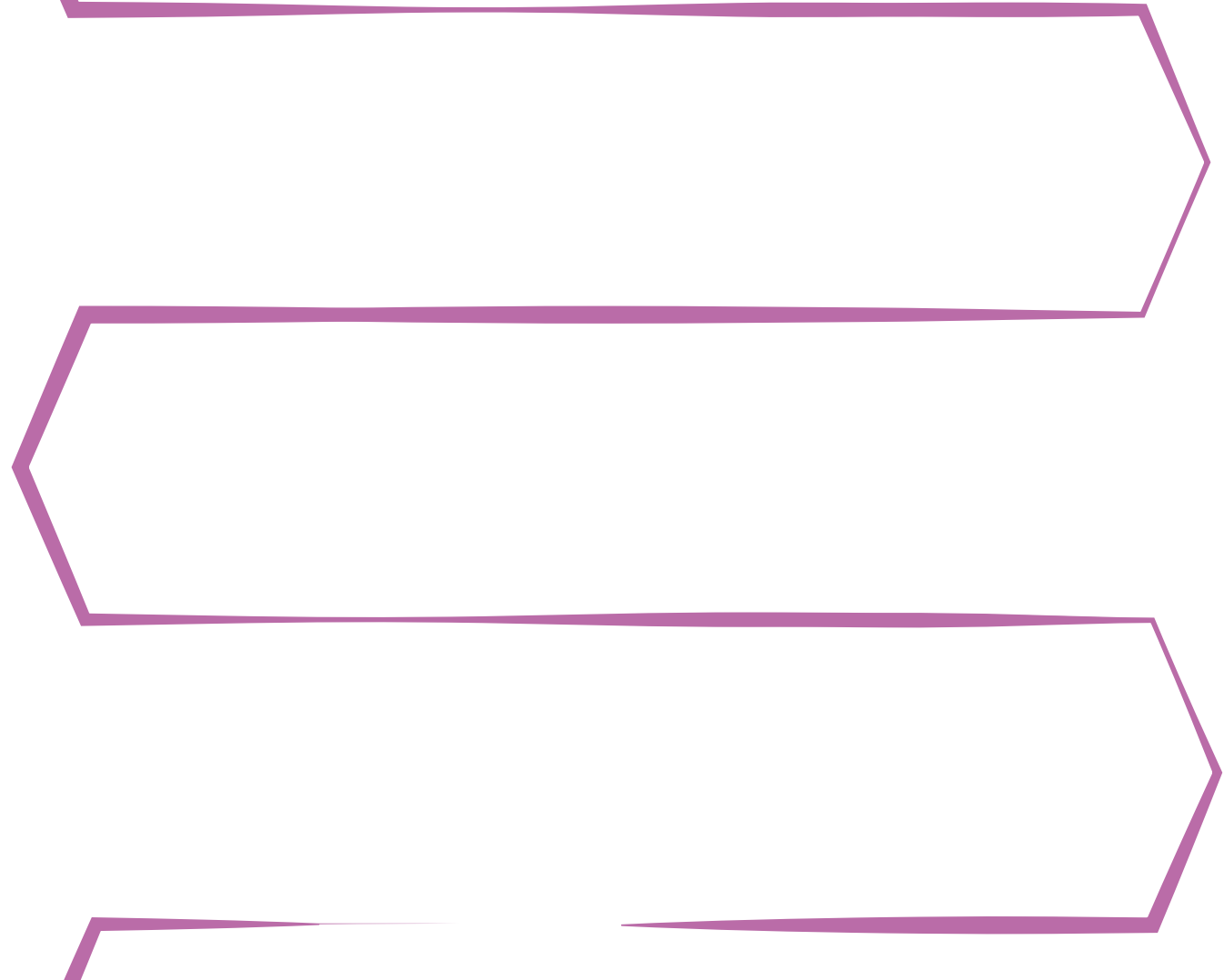

Responsabilidad Social Empresarial y el emprendimiento comunitario femenino en el sector turístico de Santa Elena - Ecuador

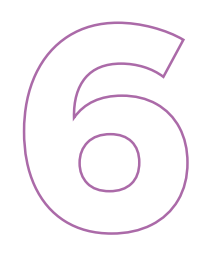




\title{
Responsabilidad Social Empresarial y el emprendimiento comunitario femenino en el sector turístico de Santa Elena - Ecuador
}

\author{
Linda Núñez Guale \\ Roberto Lucas Saltos \\ Manuel Serrano Luyo
}

Autores 


\section{Responsabilidad Social Empresarial y el emprendimiento comunitario femenino en el sector turístico de Santa Elena - Ecuador}

\section{Linda Núñez Guale}

Ingeniera Comercial, mención Gestión Empresarial; con Maestrías en Gerencia Educativa y Administración de Empresas, mención Recursos Humanos. Cursando estudios doctorales en Ciencias de la Administración. Diplomados en el área educativa y administrativa. Ejercicio profesional en calidad de Presidenta de Compañía, Decana de Facultad, Directora de Carrera, Coordinadora de Áreas Administrativas.

\section{Roberto Lucas Saltos}

Ingeniero Agrónomo, con Maestrías en Educación Superior y Administración de Empresas. Cursando estudios doctorales en Ciencias de la Administración. Especialista en Proyectos de Consultoría. Diplomados en Educación. Ejercicio profesional como Gerente de Compañía, Director de Transporte terrestre, tránsito y seguridad vial Municipal. Coordinador Zonal del Programa Buen Vivir Rural.

\section{Manuel Serrano Luyo}

Ingeniero Comercial y Empresarial; con Maestría en Marketing y Comercio Internacional. Especialista en Marketing y Comercio Exterior. Ejercicio profesional en calidad de Gerente de Provepronto S.A.; Statecorp S.A., Manser S.A. Gerente de Santa Elena EP. Asesor en Gestión de Marcas. Docente en Marketing, Operaciones y Gerencia (UPSE).

DOI: http://doi.org/10.48190/9789942241405.6 


\section{Resumen}

El presente trabajo de investigación cuyo objetivo fue determinar la aplicabilidad de la responsabilidad social empresarial y la participación del género femenino en el desarrollo de los emprendimientos comunitarios turísticos de Santa Elena - Ecuador, se delimitó con una metodología de investigación básica de nivel descriptivo, fundamentando los lineamientos teóricos de las variables en la identificación de características, tendencias internacionales y nacionales, limitantes en los sectores comunitarios, participación activa de la mujer y su inserción en el campo laboral, de manera particular en el sector turístico; aspectos enmarcados bajo un diseño de estudio transversal con una recogida de información en el año 2019 en la comuna Libertador Bolívar de la provincia de Santa Elena. Se trabajó con una población de 13 emprendimientos y una muestra de 383 turistas locales e internacionales, estadounidenses, de acuerdo a datos proporcionados por el Ministerio de Turismo. Se consideró información primaria y secundaria obteniendo insumos relevantes con la utilización de técnicas de observación, encuestas, sondeos de opinión y revisión documental. Los principales resultados del estudio determinan que los emprendimientos comunitarios mantienen en sus gestiones los 3 elementos de la responsabilidad social; también que el género femenino lidera los emprendimientos creando recursos desde sus propios domicilios. Entre las conclusiones se logró establecer las teorías y contextos de las dos variables, la aplicabilidad de los elementos de la responsabilidad social empresarial en los emprendimientos comunitarios turísticos, validación de la intervención de la mujer en estas actividades de negocios e inferir en posibles acciones adaptables a los productos y recursos existentes.

Palabras claves: emprendimientos comunitarios, emprendimiento femenino, responsabilidad social empresarial, movilidad turística extranjera, ambientes ecológicos.

\section{Introducción}

La Responsabilidad Social Empresarial - RSE empieza desde el individuo, ser consciente de su accionar y pensamientos dirigido al bienestar de un colectivo humano. Las personas pueden gobernar o administrar pensando en generar las buenas acciones o las denominadas "buenas prácticas" no sólo de la organización hacia fuera, hacia la sociedad que se beneficia consumiendo los productos o servicios; sino también, al interior de la misma, observar desde la percepción del trabajador, cómo su líder se preocupa por su bienestar y por supuesto, por los clientes externos.

La RSE es un eje transversal en toda actividad empresarial, sea de menor o mayor dimensión, en el caso específico de los emprendimientos comunitarios y parti- 
cularmente impulsados por el género femenino, han contribuido en las economías reprimidas de diversas comunidades, con mayor tendencia, en América Latina.

El presente trabajo realiza un análisis de las variables: Responsabilidad Social Empresarial y Emprendimientos Comunitarios cuyo objeto de estudio es la provincia de Santa Elena ubicada en Ecuador, que se caracteriza por la generación de fuentes de empleo derivado de emprendimientos principalmente del género femenino. Para el 2017 este tipo de emprendimiento alcanzó el 57\% de acuerdo a datos del Global Entrepreneurship Monitor-GEM 2017.

$\mathrm{Al}$ referirse sobre la variable Emprendimientos Comunitarios, se examinan las definiciones de los emprendimientos desde contextos europeos y americano principalmente de América Central y América del Sur. Luego focaliza el análisis del sector turístico de Ecuador destacándose por los valiosos recursos naturales que posee, los esfuerzos que desde el gobierno se practican para atraer al turista nacional y extranjero, las alianzas del sector público y privado para ambientar entornos y recursos atrayentes a clientes, comunidades rurales asociándose para brindar buena hospitalidad a usuarios. Se identifican adicionalmente, algunos sectores del Ecuador donde existen marcados emprendimientos que aportan a la producción nacional. Además, el estudio analiza la participación de la mujer en los emprendimientos comunitarios del sector turístico, cómo su ímpetu, constancia, perseverancia logran concretar posibilidades laborales con todo lo que implica, ser amas de casa, madres y esposas, canalizando finalmente los esfuerzos a toda una comunidad.

Con los lineamientos esenciales de las dos variables, se establece como parámetros para la evaluación de la actividad comunitaria los siguientes elementos que componen la responsabilidad social empresarial:

a) Alcances: Colaboradores, accionistas, proveedores, clientes, competidores, consumidores, sociedad.

b) Indicadores: Respeto al medio ambiente, desarrollo del potencial humano, compromisos con la comunidad, innovación social, calidad de la administración, producto/servicio ecológico, responsabilidad con cliente interno/externo, políticas y comportamientos de prevención, medición de satisfacción de clientes, medición de percepción de proveedores, creatividad.

c) Impacto: Dimensión económica, dimensión ambiental, dimensión social.

\section{Antecedentes:}

En los actuales momentos, las grandes empresas dependen de las más pequeñas, de su producto final; y, a pesar que las micro, pequeñas y medianas empresas - MIPYMES tienen dificultades para mantenerse en los mercados, se convierte en una ventaja su propia naturaleza, dándoles libertad para transitar por las diversas instancias de los negocios, despojándose de mucha burocracia, mantienen un manejo 
adecuado del talento humano por organizaciones mucho más horizontales, exenciones diversas amparadas en las normativas estatales y otras más.

La globalización de mercados, la facilidad de información, la identificación de oportunidades donde otros solo observan limitaciones, a partir de ello, surgen emprendimientos factibles con relevancias como:

- No implica grandes inversiones, infraestructuras ni recursos para concretar o poner en ejecución un negocio.

- Las tendencias actualmente buscan el consumo de productos naturales, sanos y saludables.

- Se busca que los ambientes sean más reales, más naturales, ecológicos, autóctonos y ambientales.

- Las adecuaciones de esos ambientes, sean elementos con mayor tendencia naturales, inclusive de reciclaje; lo que se conoce actualmente como "concepto de negocio".

- Aprovechamiento de los recursos naturales que ofrece un entorno para la venta sin procesamiento o más bien, la identidad de una comunidad a través del producto a ofrecer o incorporar en los insumos del producto.

- En el caso particular del turismo, uno de los aspectos analizados en esta investigación, se aprovecha en primer lugar, la tendencia del usuario que es el contacto de la naturaleza; y en segundo lugar, las bondades que un entorno brinda y mientras más ecológico se presente, más atractivo será.

Con la revolución industrial, las empresas e industrias fueron mayormente posicionadas y la responsabilidad social empresarial fue tomando protagonismo, no solo considerada como una filantropía, dejando de ser un compromiso para pasar a una obligación a través de normativas, regulaciones o reglamentaciones desde cada país y a nivel internacional alrededor del año 1930. Para Latinoamérica empieza su auge por los años 1968-69 (Canessa \& García, 2005). A continuación en la figura 1, puede observarse una síntesis histórica de la evolución conceptual de la Responsabilidad Social Empresarial:

Figua 1: Evolución Conceptual de la Responsabilidad Social Empresarial

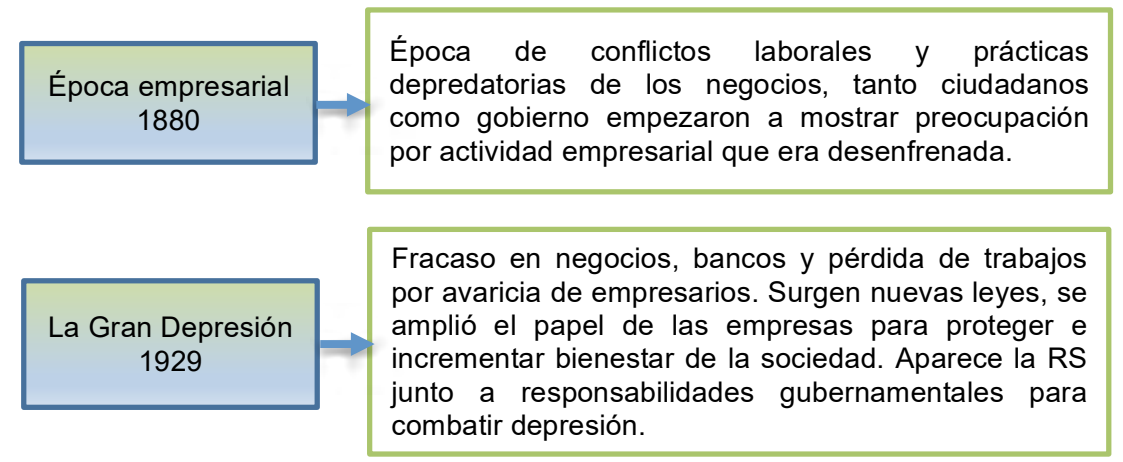




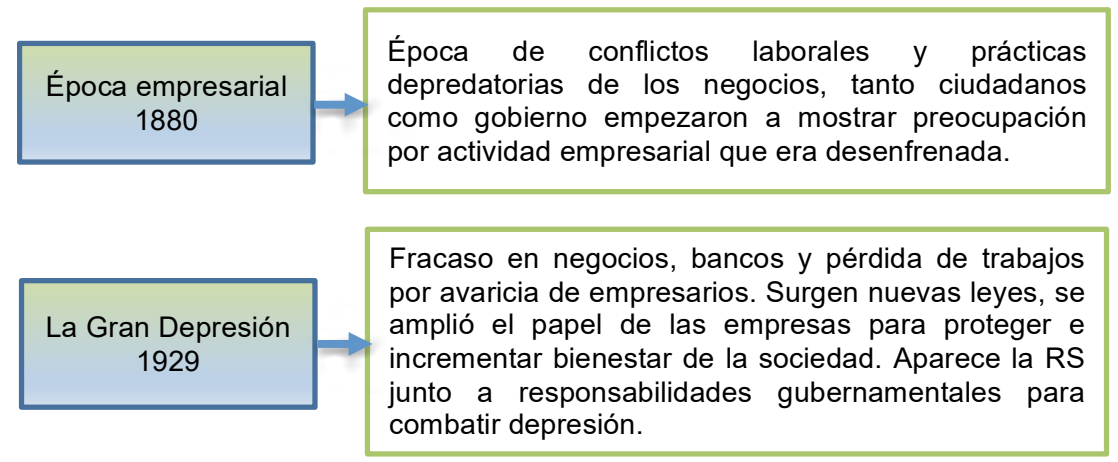

Nota: Canessa y García (2005). El ABC de la Responsabilidad Social Empresarial en el Perú y en el Mundo.

Según Canessa y García (2005), en su obra publicada El ABC de la Responsabilidad Social Empresarial en el Perú y en el Mundo, expresan:

En lo que se refiere a Latinoamérica, las primeras manifestaciones del movimiento de responsabilidad social se presentaron en la década de los sesenta. Así, en 1965 aparece la Asociación de Reguladores Cristianos de las Compañías del Brasil - ADCE, que para 1977 mutaría a la ADCE UNIAPAC Brasil, institución que se preocupa por difundir el concepto de Responsabilidad Social no solo en el Brasil, sino en toda la región. (...) (p. 23)

Para Herrera Meza (2014), Decana Nacional de la Facultad de Ciencias Económicas y Administrativas de la Universidad Cooperativa de Colombia, expresó en el marco del II Encuentro de Investigación en Ciencias Económicas, Administrativas y Contables que "La Responsabilidad Social Empresarial ha existido desde siempre, considerada como la forma ética en que los hombres de negocios y empresarios asumían sus responsabilidades frente a la sociedad en la cual desarrollaban sus actividades económicas”.

Vives, Corral e Isusi (2005), en su obra Tendencias de la Responsabilidad Social en Argentina, indican que:

Este proceso se inicia a través de prácticas responsables en programas de asistencia social, fundamentalmente como obras de caridad efectuadas por la iglesia católica y financiadas a través de donaciones privadas y a requerimientos de orden fundamentalmente ético o religioso, de corte absolutamente individual. A partir de la primera década del siglo XX, el tema de la RS se interpreta como acciones de tipo filantrópico realizadas por empresarios, en algunos casos de forma puntual, pudiéndose encontrar casos importantes muy vinculados a la visión que existe actualmente de desarrollar programas relacionados con la dimensión interna de la RS, orientados al bienestar del trabajador, como sucede en Venezuela y Colombia. (p. 18)

Las condiciones sociales para América Latina no han cambiado mucho desde el año que se hace referencia para la aparición de la responsabilidad social; es decir el año 1980, pues revisando las principales dificultades en el año 2007, indicado 
por Puterman Szomstein (2010), en su obra Implicaciones de ISO 26000 para los países en desarrollo, se puede mencionar entre otras cosas: la falta de conciencia empresarial respecto a la dimensión real de los problemas ambientales y sociales, escepticismo de muchos empresarios latinoamericanos sobre los beneficios para el negocio de las prácticas responsables, pobreza extrema (población que vive con menos de $\$ 1$,oo diario), cumplimiento parcial de derechos humanos y condiciones laborales en algunos países, altos índices de corrupción y falta de transparencia en actos públicos y privados, alta inestabilidad social a causa de índices de pobreza y desempleo, entre otras.

Respecto a la variable emprendimientos comunitarios, es importante reconocer primero sobre la conceptualización del emprendimiento para lo cual se toma el criterio de Vinueza (2010) que indica:

El emprendimiento suele ser un proyecto que se desarrolla con esfuerzo y haciendo frente a diversas dificultades, con la resolución de llegar a un determinado punto, el uso más habitual del concepto aparece en el ámbito de la economía y los negocios. En este caso un emprendimiento es una iniciativa de un individuo que asume un riesgo económico o que invierte recursos con el objetivo de aprovechar una oportunidad que brinda el mercado. (p. 34)

Para Núñez Guale (2012) "El emprendimiento se convierte en una necesidad imperiosa de muchas familias, profesionales y personas en general, pues permite emprender proyectos productivos, generando recursos propios, mejorando la calidad de vida y contribuyendo al progreso de la sociedad" (p.8)

Muchos países han logrado desarrollarse a partir del impulso que generan los emprendimientos, para Rodríguez (1996) ha encontrado que, en España, su crecimiento y progreso se deben al desarrollo permanente de microempresas, apoyo de organismos estatales y participación activa de sus habitantes. Estados Unidos donde, para apoyar la creación de empresas, surgieron las incubadoras hace ya cerca de 50 años y continúan desarrollándose, aplicando políticas de apoyo a la creación y fortalecimiento; y, hoy se dan en todo el mundo, ocurriendo de manera simultánea al estímulo, a la innovación y a la formación de emprendedores en las universidades.

En los países latinoamericanos como: México, Costa Rica, Venezuela, Colombia, Perú, Ecuador, y otros; sus economías encuentran plena justificación para estimular el espíritu emprendedor, por la evidente incapacidad del sistema económico y social para generar empleo en la cantidad y calidad requeridas que superen la exclusión, marginalidad y atraso de sectores (Arce, 2010).

De acuerdo con Fxtrader (2010), un emprendimiento comunitario o social incluye tres elementos claves: Un objetivo social, una innovación transformadora y un modelo de negocios sostenible. El emprendimiento suele darse y tener éxito, en los sectores de la economía donde el mercado ha fallado y la acción del Estado es inexistente o ineficaz. Un emprendimiento, cuando resulta exitoso, puede no 
sólo transformar la vida de los beneficiarios, sino también la forma de abordar un problema en general.

Para la Fundación Beterlsmann (2007), el emprendimiento comunitario está integrado en áreas sociales y culturales, en cualquier índole ya sea público o privado. En la actualidad es aplicado por parte del Estado, gobiernos provinciales, cantonales, parroquiales y comunales; también se han realizado este tipo de emprendimientos en sectores barriales, organizaciones y asociaciones, con la finalidad de lograr el mejoramiento o desarrollo de las comunidades.

Ecuador es un país con una gran diversidad cultural y ecosistemas muy atractivos para turistas nacionales e internacionales. Entre los sectores productivos, el turismo permite el crecimiento económico en muchas partes del país y es muy relevante por la diversidad de flora y fauna.

De acuerdo con datos del Ministerio de Turismo - MITUR del 2017, en los últimos 3 años, las visitas de turistas extranjeros se registran aproximadamente en 1'617.914 personas. Pero la Edición LATAM (2018), indica que Ecuador registró un aumento de $57 \%$ en la llegada de turistas extranjeros entre enero y mayo del 2018, arribando al país 952.488 personas en los primeros cinco meses del mismo año. Junto a Diario "El Comercio" (2018) menciona la misma cifra de ingreso de extranjeros, ampliando además que el MINTUR admite que el crecimiento del turismo receptivo se debe a la nueva estrategia de promoción que han implementado a partir de agosto de 2017, con el ingreso al sistema de Agencias de Viajes Internacionales Online-OTA (por su definición en inglés).

Este sistema facilita a los viajeros de varios países del mundo, donde se desarrolla la campaña de promoción, la posibilidad de conocer de manera inmediata los diversos servicios que tiene el país en materia turística. La promoción se realiza en tres de las principales OTAs en el mundo, como son: Despegar, TripAdvisor y Expedia, y está cambiando la estructura del comportamiento en las búsquedas, así como en las compras online del destino Ecuador. A eso se suma la llegada a Ecuador de la aerolínea estadounidense Spirit que cubre la ruta Fort Lauderdale - Guayaquil - Fort Lauderdale, que ha permitido que los arribos estadounidenses crezcan significativamente.

Analizando un poco más la variable de los emprendimientos comunitarios que se encuentran liderados por mujeres en gran porcentaje, se hace también una visión desde un contexto macro. Para la Asociación Las Kellys (2016), grupo de féminas organizadas de España, dedicadas a la labor del turismo, consideran que en la actualidad, el género femenino desempeña un papel fundamental en el mercado laboral; sin embargo, algunos estudios relacionados con la perspectiva de género concluyen que la mujer inmersa en la empresa desempeña un papel secundario, mientras que el hombre sigue jugando un papel más relevante en la gestión de las empresas.

Sparrer (2003) contrapone con sus argumentos lo antes mencionado e indica que el turismo ha incorporado a la mujer a través del trabajo remunerado, los cam- 
bios afrontados por el desarrollo acelerado del entorno, la conllevan a ser partícipe y a ocupar el papel protagonista en la mayor parte de las actividades desarrolladas por este tipo de empresas.

Para la Organización de Naciones Unidas - ONU Mujeres (2011), con sede en México consideran que:

Los derechos fundamentales de las mujeres han sido un tema central para el desarrollo global y para la política internacional, empoderar a las mujeres para que participen plenamente en todos los sectores y a todos los niveles de la actividad económica resulta fundamental para: construir economías fuertes; construir sociedades más estables y justas; alcanzar los objetivos de desarrollo, sostenibilidad y derechos humanos acordados internacionalmente; mejorar la calidad de vida de las mujeres, de los hombres, de las familias y de las comunidades; y promover las prácticas y objetivos empresariales. (p.4)

Desde el año 1995 al 2000, época que estuvo marcada por las campañas masivas referente a la participación de la mujer en distintos sectores sociales, según el Centro de Documentación Turística - CEDOC de México (1996) que analiza los diversos sectores de la economía a fin de impulsar el sector turístico, indica que a partir de dicho período se estableció un plan internacional de parte de la ONU buscando promover la participación plena y efectiva de la mujer en la vida económica, social, política y cultural a nivel mundial, que ayude a consolidar su intervención en decisiones, responsabilidades y beneficios del desarrollo, en igualdad de condiciones que los hombres.

En Ecuador la realidad de la participación de la mujer en el sector turístico es: $7 \%$ laborando en agencias de viajes, $27 \%$ en establecimientos de alojamiento, $60 \%$ en restaurantes, $4 \%$ en centros de recreación y el $2 \%$ en transportes turísticos, sumando un total de 50.572 mujeres insertadas en el mercado laboral. (Viteri, Peñaherrera, \& Vinueza, 2017).

Santa Elena, una de las 24 provincias del Ecuador, ofrece hermosas playas, gastronomía, ambientes de descanso, naturaleza acogedora, alojamiento, entretenimiento, espacios recreativos, etc. Tiene una población de 308.693 habitantes (INEC, 2010), ubicada en la zona costera de Ecuador. Posee condiciones climáticas, ambientales y sociales que dan paso a pequeños emprendimientos a través del aprovechamiento de sectores productivos como pesca, agricultura, turismo y artesanía.

Las comunas que se asientan en la provincia de Santa Elena han tenido un crecimiento pausado por años, producto de la poca atención de los gobiernos de turno, sus habitantes buscan la forma de generar ingresos a partir de los recursos naturales existentes en cada sector. La comuna Libertador Bolívar tiene una extensión de 1.476 hectáreas, ubicada en el Km. 50 al norte de la provincia con una población de 4.000 habitantes. Está situada a $131 \mathrm{~km}$. de Guayaquil. Tiene una dimensión de $3.100 \mathrm{~m}$. de longitud de playa. Posee flora y fauna. Sitio donde se encuentran 
alojamientos de choza con hojas de palmeras como techo o construcción mixta. En la playa existen 3 bares cada uno con su autenticidad; hamacas, construcciones con caña guadua, música. Lugar propio para un fin de semana de relajación (Opturmo, 2018)

La comuna Libertador Bolívar es una comuna muy colorida, hamacas y lámparas multicolores decoran el panorama y captan la atención de los conductores; mujeres tejen, hombres atienden. Las artesanías son hechas en concha, madera y caña. El sombrero de paja toquilla es infaltable (Diario El Telégrafo, 2017)

Figura 2: Artesanías en comuna Libertador Bolívar (Molina, 2017)

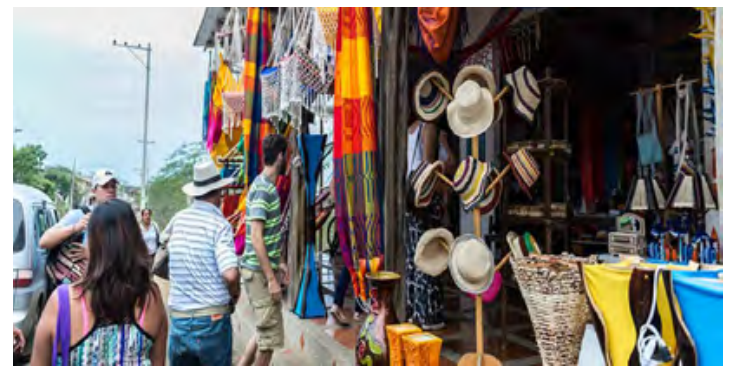

Haciendo un diagnóstico en la comuna Libertador Bolívar con la finalidad de identificar fortalezas y debilidades que direccionen hacia un mejor análisis del objeto de estudio se aplicó una ficha de observación obteniendo lo siguiente:

Tabla 1: Análisis FODA de la comuna Libertador Bolívar, año 2019

\begin{tabular}{|c|c|}
\hline \multicolumn{2}{|c|}{ SITUACIONES INTERNAS } \\
\hline FORTALEZAS & DEBILIDADES \\
\hline $\begin{array}{l}\text { Comuna con recursos naturales atractivos al turista extran- } \\
\text { jero } \\
\text { Recursos naturales suficientes que permiten adecuar entor- } \\
\text { nos ecológicos } \\
\text { Habitantes dispuestos a mejorar sus servicios. }\end{array}$ & $\begin{array}{l}\text { - Nativos sin conocimientos del idioma inglés } \\
\text { - Nativos con limitaciones en herramientas } \\
\text { tecnológicas } \\
\text { - Poco conocimiento de ambientación de lu- } \\
\text { gares }\end{array}$ \\
\hline \multicolumn{2}{|c|}{ SITUACIONES EXTERNAS } \\
\hline OPORTUNIDADES & AMENAZAS \\
\hline $\begin{array}{l}\text { - } \\
\text { Alta movilidad de turistas extranjeros hacia el país y comu- } \\
\text { na durante todo el año. } \\
\text { - } \quad \text { Clima favorable durante todo el año } \\
\text { - } \quad \text { Anstituciones estatales impulsando el desarrollo turístico } \\
\end{array}$ & $\begin{array}{l}\text { - Competencia del entorno con administrado- } \\
\text { res de experiencia } \\
\text { Dueños de negocios de nacionalidad extran- } \\
\text { jera con recursos económicos y conocimien- } \\
\text { tos de otros entornos. }\end{array}$ \\
\hline
\end{tabular}


Figura 3. Fortalezas de Libertador Bolivar. (a) Playa Bruja (Pesantes, 2016). (b) Restaurante Caída del Sol (Sanchez, 2016)

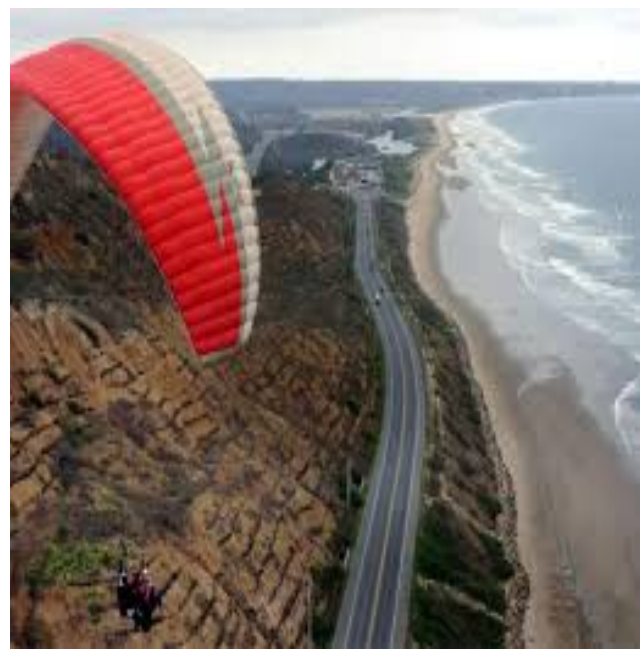

(a)

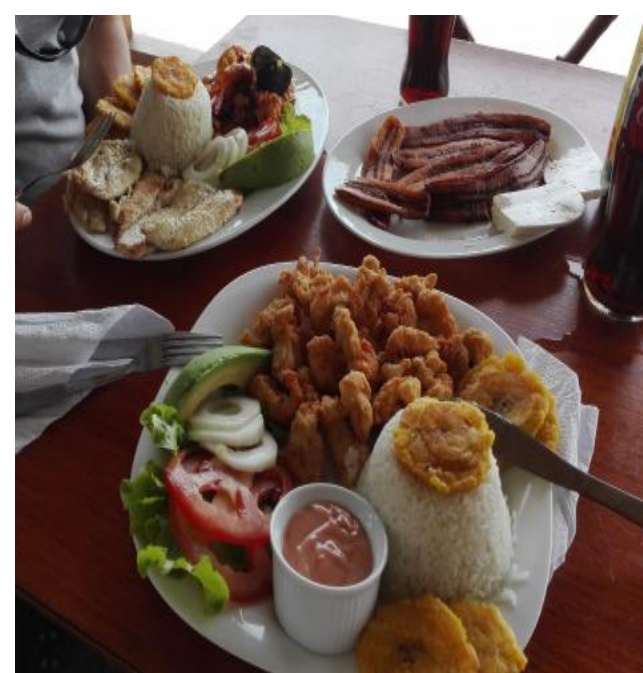

(b)

Según datos del Ministerio de Turismo (2019), se determina que la mayor afluencia de turistas extranjeros que llegan a Ecuador corresponde a visitantes de Estados Unidos; de acuerdo a ello, la participación de turistas estadounidenses correspondiente al $46 \%$, tal como se presenta a continuación:

Figura 4. Ranking de llegadas de turistas internacionales, año 2019

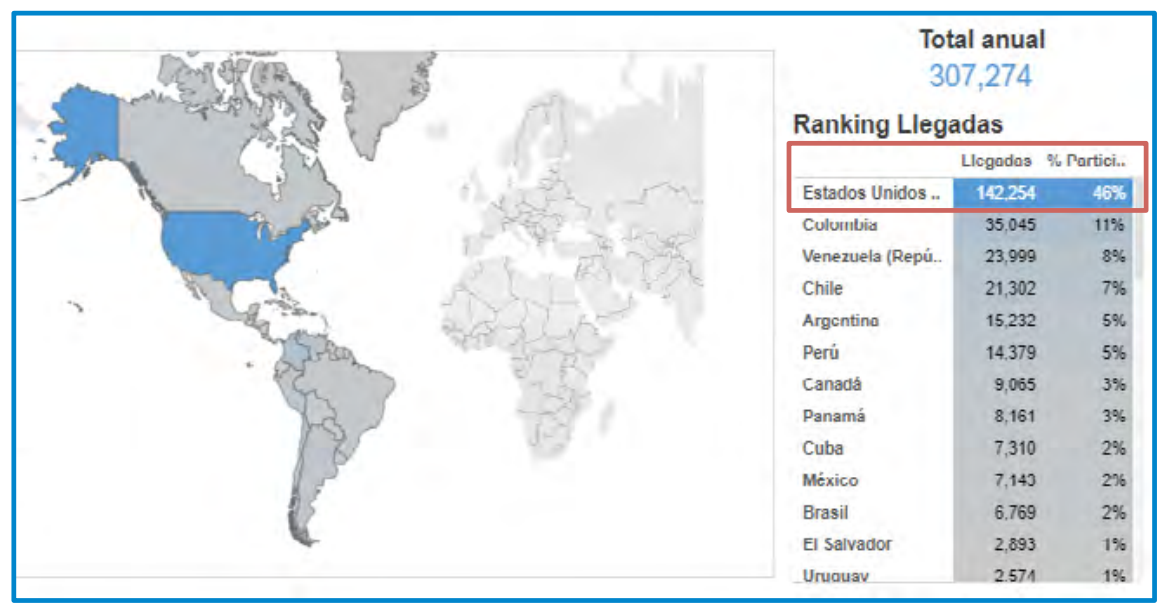

Nota: Ministerio de Turismo (2019)

Al referirse particularmente en la provincia de Santa Elena, la cantidad de estadounidenses que visitan las comunidades peninsulares corresponde a un $25 \%$ del total de ingreso de personas extranjeras, tal como muestra la gráfica: 


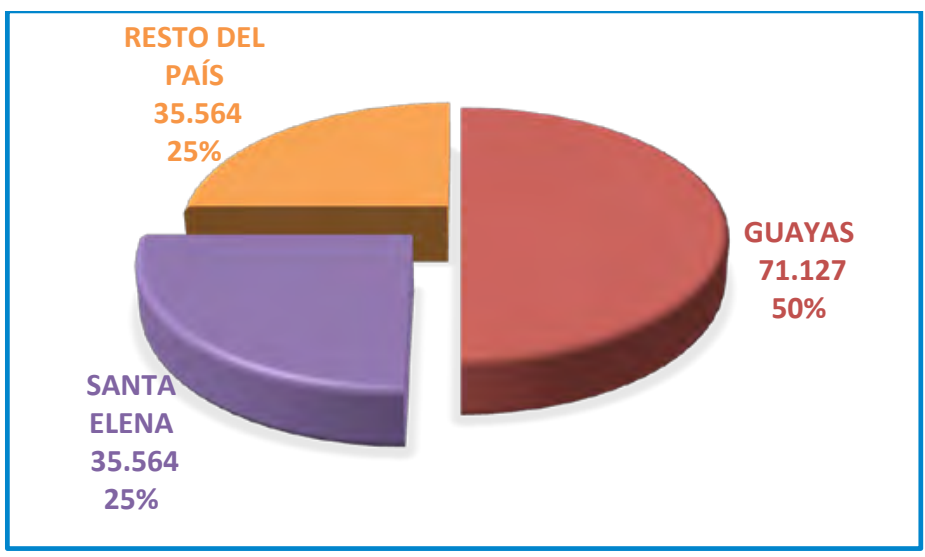

Nota: Elaboración propia a partir de información del Ministerio de Turismo, 2019

\section{Justificación:}

Teórica, los emprendimientos de base comunitario son un mecanismo para generar oportunidades laborales en sectores poco favorecidos, sobre todo en América Latina donde las condiciones de pobreza y las escasas plazas de empleo hacen que los habitantes impulsen emprendimientos por necesidad. En cuanto a la responsabilidad social empresarial es el conjunto de acciones o toma de decisiones que repercuten positivamente en una sociedad determinada. Se indagó sobre teorías, características, elementos, condiciones, situaciones y otros detalles que permitan conocer cómo estas variables han impactado y evolucionado la práctica empresarial.

Metodológica, en la búsqueda de información relevante que permita sustentar el presente trabajo, se definieron los aspectos metodológicos para una investigación descriptiva con la utilización de un estudio de campo a través de fuentes primarias y conocer características de la población estudiada, identificar realidades de las variables planteadas, tanto de responsabilidad social empresarial como de emprendimientos comunitarios. Las fuentes primarias fueron los propietarios de emprendimientos turísticos de la comuna Libertador Bolívar de Ecuador, como también turistas locales y extranjeros que llegan al sitio. Para la recopilación de información fue necesario acudir a encuestas y sondeos de opinión, herramientas valiosas en la cualificación de variables. Se buscó identificar qué elementos de la responsabilidad social son más aplicados en estos negocios, las oportunidades de innovación y creatividad a partir de productos existentes o de recursos naturales del medio, condiciones demográficos de los emprendedores y sus negocios, conductas, comportamientos, preferencias del servicio turístico, experiencias de los turistas respecto al hospedaje, razones de alojamiento y nivel de satisfacción del turista. De igual 
forma, se acudió a fuentes secundarias para el sustento científico en libros, autores, metodologías, prensa, organismos competentes, revistas académicas, sitios web, entre otras. Los métodos que se aplicaron fueron inductivo, deductivo y analítico cuya finalidad no sólo era el cumplimiento del objetivo propuesto sino también el planteamiento de acciones u oportunidades en los emprendimientos comunitarios.

Práctica, Con el diagnóstico levantado en el presente estudio deja abierta posibilidades de otras investigaciones más profundas y propuestas productivas que beneficien no solo a la comunidad de emprendedores sino a una sociedad en general. Las mujeres emprendedoras reflexionan su actuación en la actividad productiva que generan a diario, valoran el compromiso que tienen con sus familiares, con las comunidades y sobre todo con sus clientes; están conscientes que existen posibilidades de prosperidades en sus actividades turísticas, por ende, sus ingresos y condiciones de vida. A partir de los resultados se pueden presentar no solo acciones de mejoras sino nuevos proyectos, principalmente ecológicos, auspiciados por aliados estratégicos como gobiernos locales para impulsar el turismo y mejorar los ingresos económicos en la provincia. Los turistas consultados se sienten atraídos por estos sectores peninsulares y estarían gustosos de encontrar mejoras en cada visita para demandar más servicios.

\section{Objetivo general}

Determinar la aplicabilidad de la responsabilidad social empresarial y la participación del género femenino en el desarrollo de los emprendimientos comunitarios turístico de Santa Elena - Ecuador.

\section{Objetivos específicos}

a) Establecer las diversas teorías que inciden en la responsabilidad social empresarial y los emprendimientos comunitarios femeninos, delimitando el diagnóstico situacional.

b) Identificar la aplicabilidad de los elementos de la responsabilidad social empresarial en los emprendimientos comunitarios femeninos.

c) Validar mediante los instrumentos de investigación, la relevancia de la participación de la mujer en los emprendimientos comunitarios turísticos.

d) Inferir entre los resultados del levantamiento de información, posibles acciones aplicables en los emprendimientos comunitarios femeninos. 


\section{Metodología}

\section{Materiales y métodos}

Para conocer respecto a las variables estudiadas en esta investigación se procedió a la revisión bibliográfica sobre Responsabilidad Social Empresarial, destacando aspectos como la evolución histórica conceptual, tendencias internacionales y limitantes en América Latina para su aplicación, elementos (alcances, indicadores e impacto). En cuanto a los Emprendimientos Comunitarios se indagó sobre definiciones generales, desarrollo en otros ambientes, participación activa de la mujer y respaldo desde varios organismos internacionales, realidades en otros entornos latinos, condición del turismo comunitario, nuevas tendencias para la atención turística comunitaria, criterios del turista extranjero en visitar al país, condiciones y características de la comuna Libertador Bolívar en Ecuador.

De acuerdo al enunciado planteado, el trabajo corresponde a una investigación básica de nivel descriptivo cuyo propósito fue determinar los lineamientos teóricos de la responsabilidad social empresarial y los emprendimientos comunitarios femeninos que respalden al diagnóstico situacional en la provincia de Santa Elena - Ecuador.

Mediante el estudio de campo que abordó el levantamiento de información de las fuentes primarias, se demostró la realidad sobre el objeto de estudio; es decir, los emprendimientos comunitarios de la comuna Libertador Bolívar de Santa Elena, actividad netamente turística y donde el liderazgo los ejerce mayoritariamente el género femenino. Otra fuente de información fueron los turistas locales y extranjeros, en este caso estadounidenses, por ser los visitantes con mayor ingreso al país tal como se refleja en el marco teórico.

Para el cumplimiento de las técnicas de investigación fue necesario recurrir a encuestas y sondeos de opinión que facilitaron datos sobre las características demográficas, conductas, comportamientos, condiciones de los negocios, aplicación de responsabilidad social empresarial, preferencias del servicio turístico, experiencias previas de hospedajes, razones de alojamientos y nivel de satisfacción del turista. También se hizo un trabajo de observación para tener un diagnóstico de la comuna Libertador Bolívar y su actividad turística.

A través de las técnicas retrospectivas, se pudo obtener información de libros sobre responsabilidad social, talento humano, metodología de investigación, administración y emprendimiento. Se tomó datos estadísticos de organismos como el Ministerio de Turismo ecuatoriano, Banco Central, aerolíneas, prensa escrita, fundaciones o asociaciones. Se revisaron también informes como el Global Entrepreneurship Monitor - GEM, revistas académicas, sitios web, normativas vigentes y demás documentos. Los métodos inductivos, deductivos y analíticos concibieron teorías, modelos, componentes y otros aspectos que permitieron no solo cumplir 
con el objetivo de la investigación sino también, incorporar propuestas que impactan en el campo laboral de la zona norte de la península de Santa Elena.

La población y muestra en el presente trabajo está conformada de la siguiente manera, no sin antes aclarar que el direccionamiento hacia el turista extranjero, el estadounidense, se debe a la información suministrada por el Ministerio de Turismo ecuatoriano en el "ranking de llegadas de turistas internacionales-2019":

Tabla 3. Población

\begin{tabular}{|l|l|l|}
\hline $\mathrm{N}^{\circ}$ & DETALLE & CANTIDAD \\
\hline 1 & Emprendedoras comunitarias & 13 \\
\hline 2 & Turistas locales & 77.173 \\
\hline 3 & Turistas estadounidenses & 35.564 \\
\hline & TOTAL & 112.750 \\
\hline
\end{tabular}

Para la obtención de la muestra se procedió a la aplicación de fórmulas, quedando de la siguiente manera:

$$
\mathrm{n}=\frac{Z^{2} N * p * q}{e^{2}(N-1)+Z^{2} * p * q}
$$

A través de la fórmula estadística se obtuvo el siguiente resultado:

$$
\begin{gathered}
\mathrm{n}=\frac{(1,96)^{2} 112.737 * 0,5 * 0,5}{(0,05)^{2}(112.737-1)+(1,96)^{2} * 0,5 * 0,5} \\
\mathrm{n}=\frac{3,8416 * 112.737 * 0,25}{0,0025 * 112.736+3,8416 * 0,25} \\
\mathrm{n}=\frac{108.272,62}{282,8004}
\end{gathered}
$$

\begin{tabular}{|c|c|c|}
\hline $\mathrm{N}^{\circ}$ & DETALLE & CANTIDAD \\
\hline 1 & Turistas locales & 190 \\
\hline \multirow[t]{2}{*}{2} & Turistas estadounidenses & 193 \\
\hline & TOTAL & 383 \\
\hline
\end{tabular}$$
382,86=\mathbf{3 8 3}
$$

Tabla 4. Muestra 


\section{Rersultados y discusión}

a) Encuestas aplicadas a propietarios de emprendimientos comunitarios Para efectos de una mejor interpretación se realizaron algunas relaciones que se presenta a continuación:

Figura 6. Relación edad - género

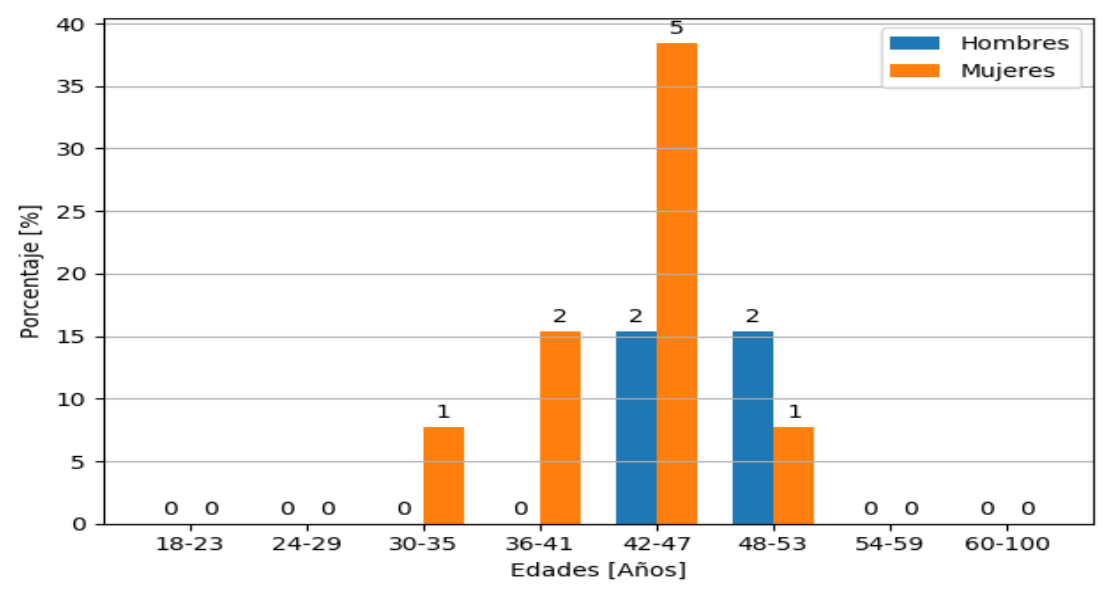

Los propietarios de los emprendimientos comunitarios de la comuna Libertador Bolívar mantienen las siguientes características respecto a sus edades. La mayor tendencia se encuentra en edades de 42 a 47 años. En menor rango están aquellos entre 48 y 53 años; y, entre 30 a 41 años. Su género está inclinado mayoritariamente a las féminas con un total de 9 mujeres lo que representa al $70 \%$ de la población investigada. Se deduce que esta representación es propia de la actividad turística ya que utilizan sus domicilios para brindar hospedaje.

Figura 7. Estado civil de propietarios de emprendimientos comunitarios

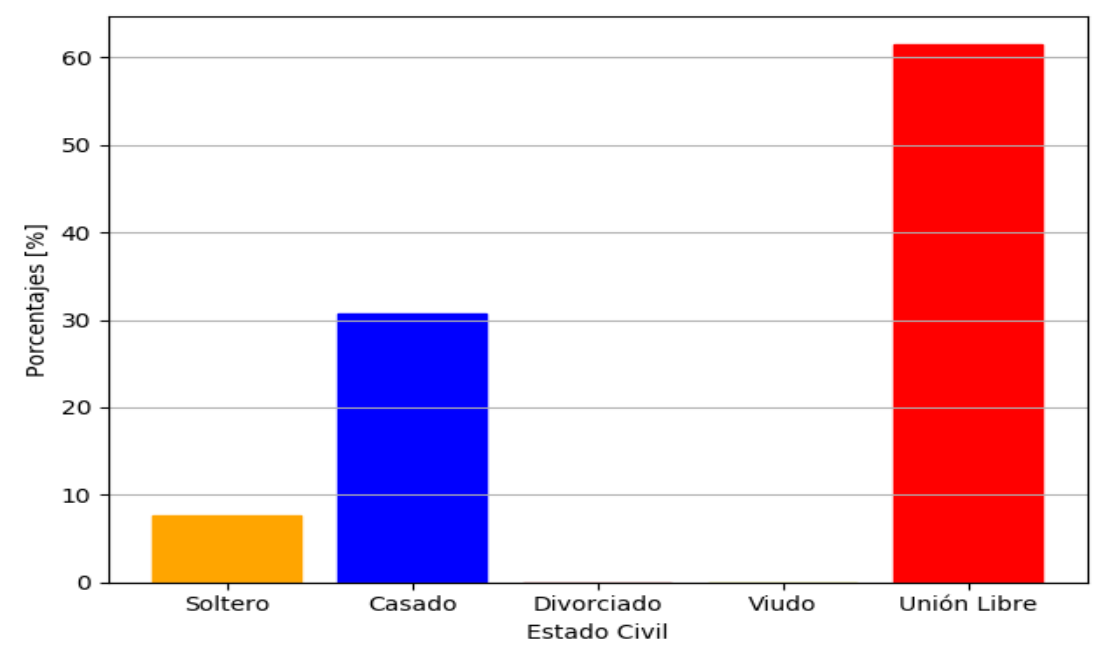


El estado civil que sobresale de la población encuestada está reflejada en la condición de unión libre con más del 60\%. Superando el 30\% se encuentran las personas casadas y en un porcentaje menor están las personas solteras. Manifestando por tanto que el mayor interés por generar emprendimientos se debe a la conformación y responsabilidad de un núcleo familiar, evitando la ausencia de la mujer por horas prolongadas y cubrir esos espacios labores en sus propios domicilios.

Figura 8. Nivel de educación de los propietarios de emprendimientos comunitarios

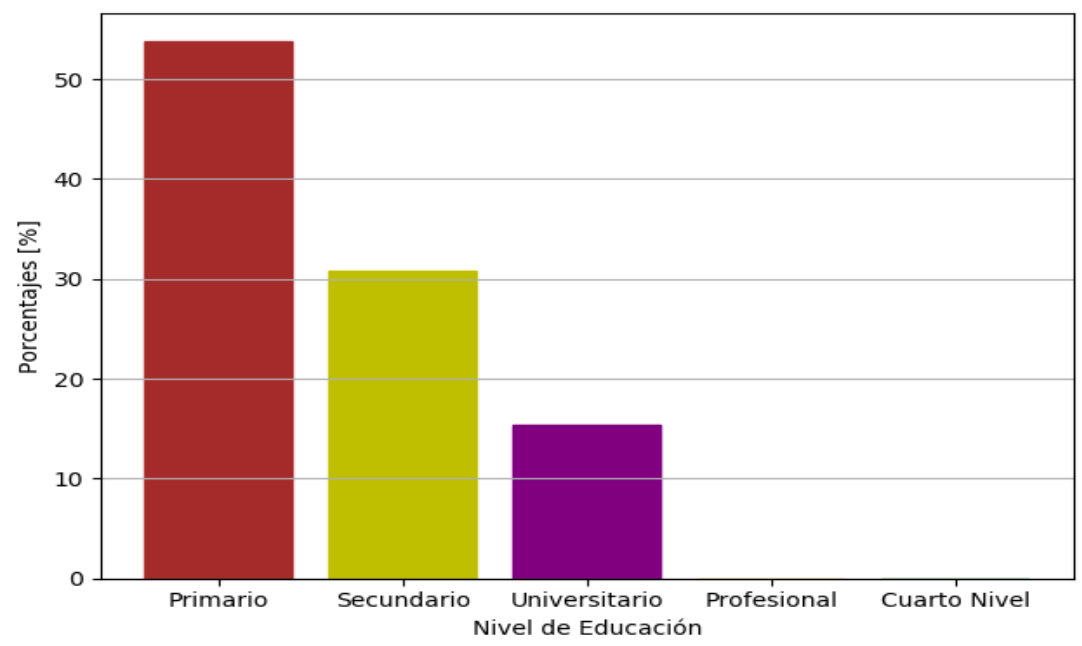

Los encuestados expresaron que su nivel de educación está dado mayoritariamente por estudios culminados de primaria. En menor proporción con estudios secundarios o universitarios. Se infiere de igual manera que por la particularidad de la actividad turística, los propietarios alcanzan esos niveles de educación ya que han vivido en sectores comunitarios desde su nacimiento donde el acceso a la educación se limita al nivel primario.

Figura 9. Características de los emprendimientos: Condiciones, tipos de clientes y años de vigencia

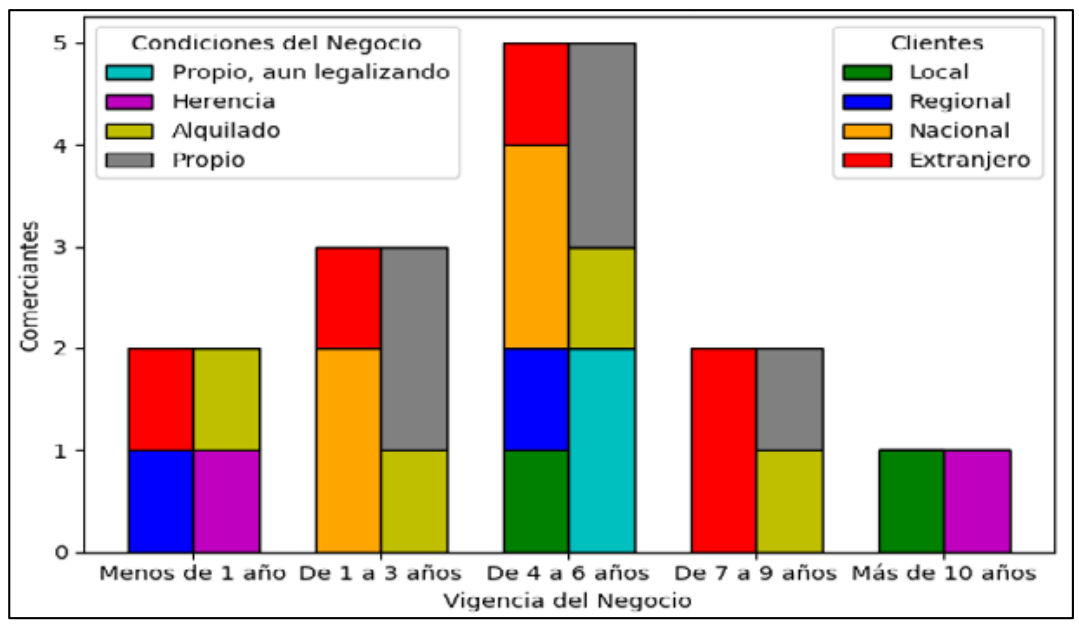


De acuerdo a la estructura de la encuesta, uno de los elementos a indagar es la característica de los emprendimientos compuesto por: condiciones de los negocios, años de vigencia y tipos de clientes. Se observa que existe un fenómeno contradictorio, mientras para algunos emprendedores los negocios son propios, para otros son alquilados coincidiendo esta condición en los rangos de vigencia entre 1 a 9 años. A pesar de ello, existen negocios con tiempos de vigencia mayores a 4 años, cuyas propiedades se encuentran en proceso de legalización.

El criterio de los emprendedores comunitarios respecto a decisión de estadía de los turistas no está ligado a la vigencia que tenga el negocio, pues se puede observar que el extranjero se hospeda en sitios recién establecidos o en aquellos con varios años. El turista nacional, acude con mayor frecuencia a lugares que tengan de 1 a 6 años de vigencia. Estos resultados reflejan de manera particular, los tipos de clientes que visitan los emprendimientos comunitarios en el sector Libertador Bolívar de Ecuador, sin ser una limitante los años de experiencia brindando el servicio de hospedaje.

Figura 10. Aplicación de la Responsabilidad Social Empresarial (alcance e impacto) en los emprendimientos comunitarios.

impacto) en los emprendimientos comunitarios.
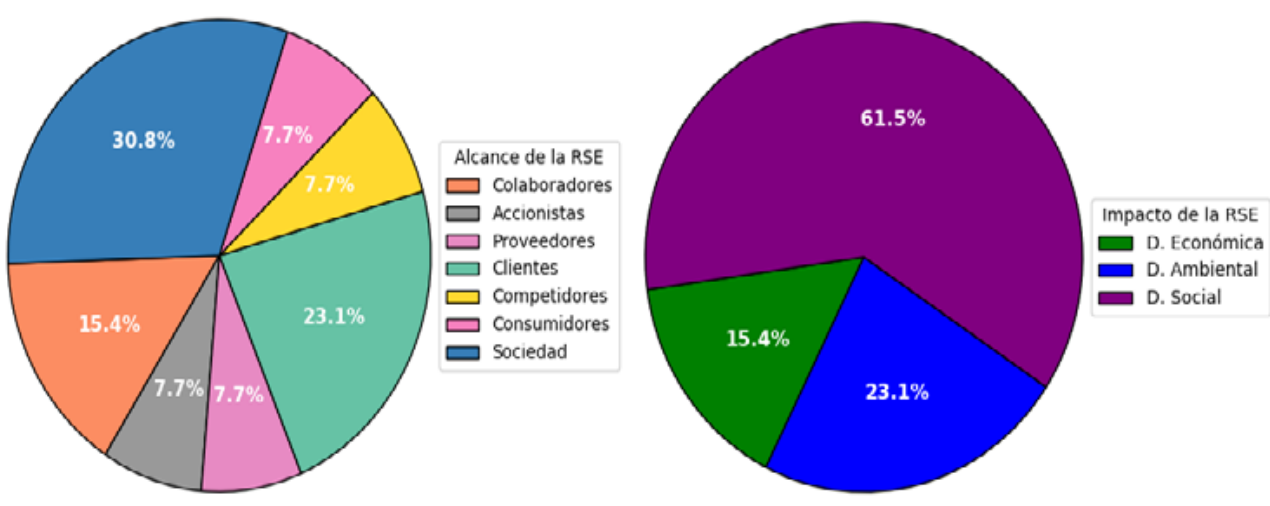

Respecto al abordaje de la responsabilidad social empresarial aplicada por los emprendedores comunitarios se obtienen los siguientes resultados, tomando en cuenta los elementos de Alcance e Impacto:

De acuerdo a los resultados sobre Alcance, se expresa que los emprendedores de la comuna Libertador Bolívar en Ecuador, priorizan 3 de los 7 componentes cuyo orden de prelación es: Sociedad, Clientes y Colaboradores, evidenciando que sus propietarios reconocen la labor que cumplen y a medida que ellos mejoran sus servicios, la sociedad en general es beneficiada de forma directa o indirecta. 
$\mathrm{Al}$ observar el elemento Impacto, los resultados reflejan que, de igual forma la Dimensión Social es la que prevalece, seguido de la dimensión ambiental y económica; por tanto, tiene coherencia con el elemento Alcance, respaldando, la convicción de negocio que tienen las emprendedoras.

Figura 11. Aplicación de la Responsabilidad Social Empresarial (Indicadores) en los emprendimientos comunitarios.

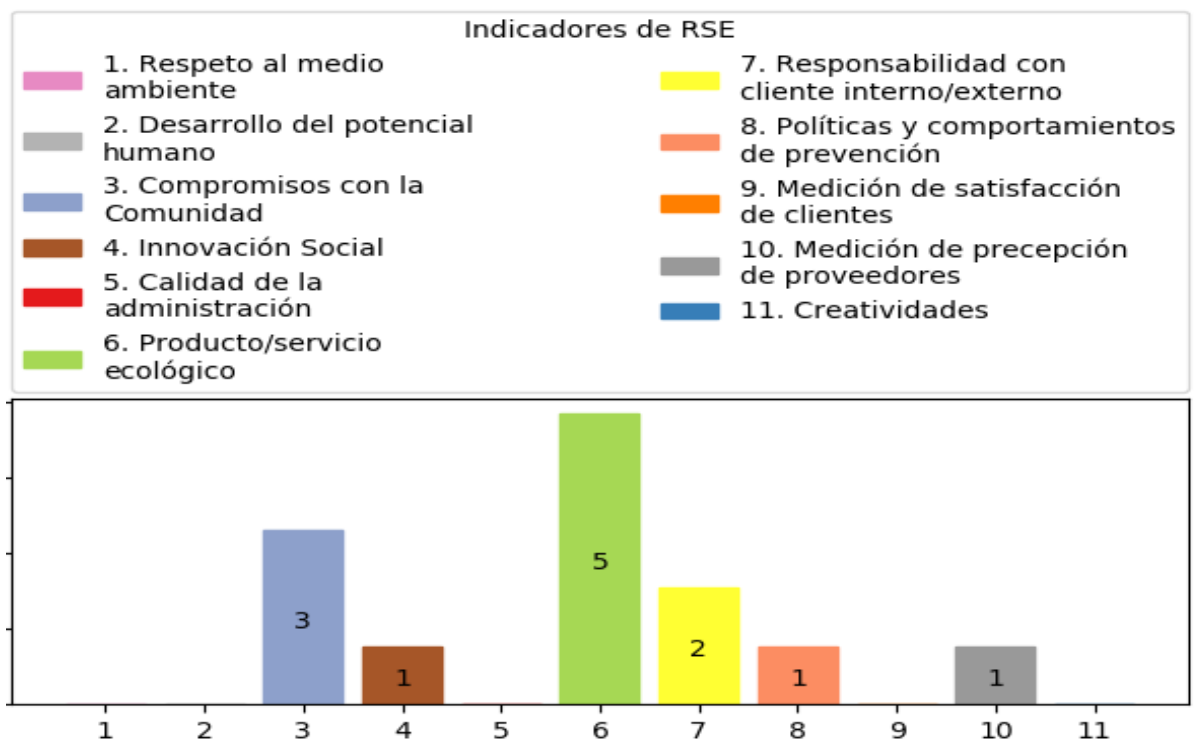

Cuando se analiza el elemento Indicador, los criterios sobre la aplicación de la responsabilidad social empresarial en los emprendimientos comunitarios es el siguiente:

- De los 11 indicadores, los emprendedores practican 6 de ellos.

- El indicador Producto/Servicio ecológico sobresale entre los practicados por los emprendedores, teniendo coherencia con la actividad turística que ejercen.

- De manera casi paralela, el indicador Compromisos con la Comunidad y Responsabilidad con cliente interno/externo, es una práctica en menor escala de los emprendedores.

- Muy escasamente los emprendedores se concentran con la Innovación Social, Medición de satisfacción del cliente y Desarrollo del potencial humano.

Estos resultados sobre la aplicación de la responsabilidad social empresarial, tanto en Alcance, Indicadores e Impacto reflejan la realidad de la actividad emprendedora estudiada, por ser servicios comunitarios su enfoque se concentra hacia la sociedad y la cobertura de los indicadores está dado por aquellos elementos propios del servicio que ofrecen. 


\section{b) Sondeos de opinión a Turistas locales y extranjeros (estadounidenses)}

Como parte integrante de la investigación, se indagó también a los turistas locales y extranjeros sobre la percepción de los servicios brindados en los hospedajes comunitarios de la comuna Libertador Bolívar, obteniendo lo siguiente:

Figura 12. Edades de los turistas

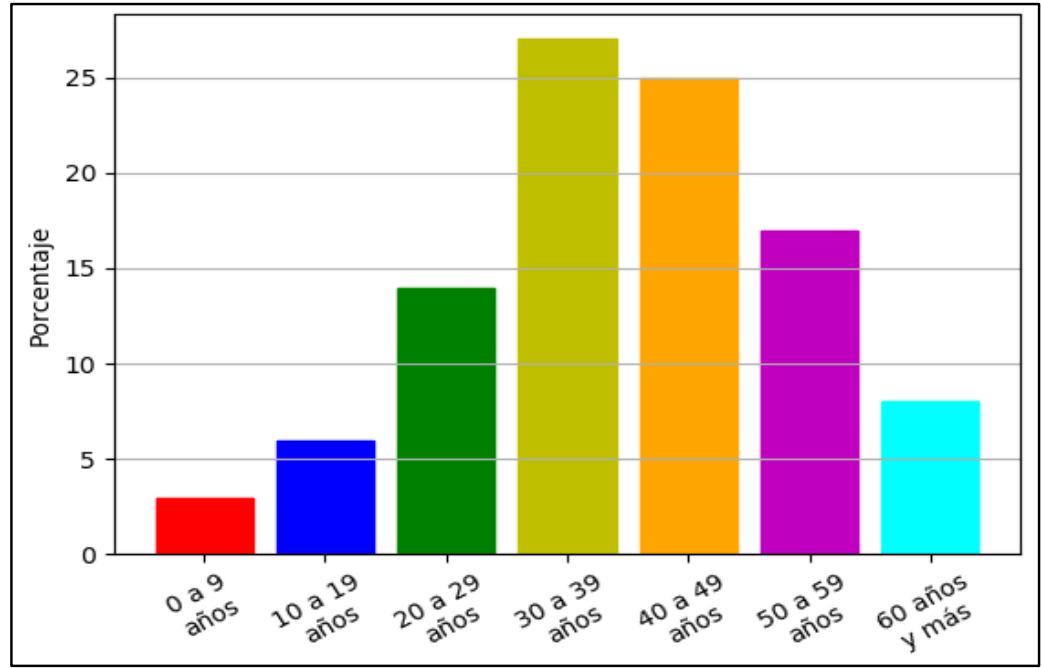

Entre los sondeos de opinión aplicados, se determina que los rangos de edades de los visitantes, con mayor tendencia se dan a partir de los 30 años. Encontrando también un $14 \%$, con edades de 20 a 29 años. Esto indica que los usuarios de los servicios comunitarios tienen una solvencia o estabilidad económica para convertirse en un visitante frecuente, siendo importante brindar un buen servicio.

Figura 13. Experiencia anterior en un hospedaje comunitario

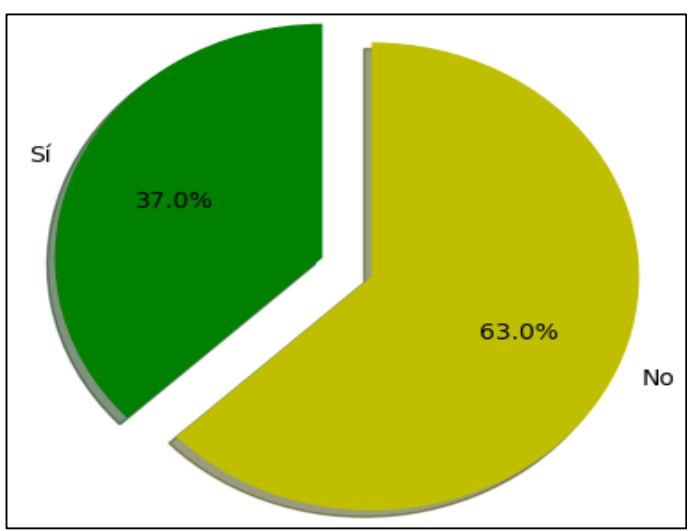

Del total de encuestados se identifica que al visitar el país, muchos de ellos no hacen uso del hospedaje comunitario. Indagando algo más con este grupo, varios expresaron que debido a referencias negativas no han decidido utilizar estos servicios pero les encantaría disfrutarlos. 
Figura 14. Razones para alojarse en hospedaje comunitario

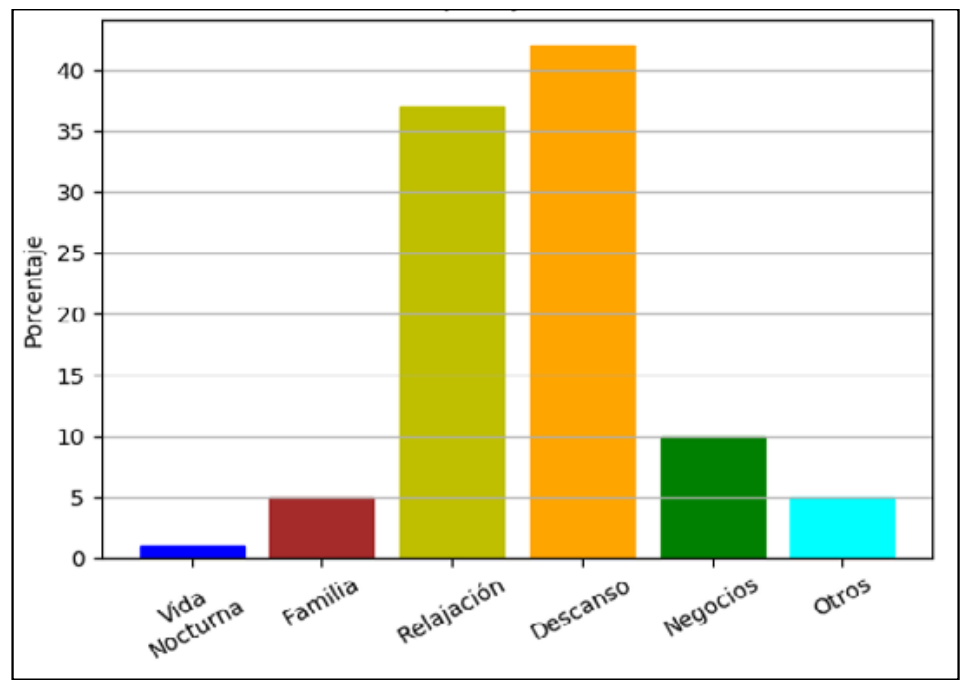

Con mucha relación a la pregunta anterior, los encuestados aseguran su preferencia en un hospedaje comunitario porque buscan de relajación y descanso. Si estos usuarios tienen una estabilidad económica, es necesario hacer los esfuerzos para que estos emprendimientos sean una fuente atractiva de ingresos para los núcleos familiares de la comuna Libertador Bolívar.

Figura 15. Nivel de satisfacción por servicios brindados en comuna Libertador Bolívar

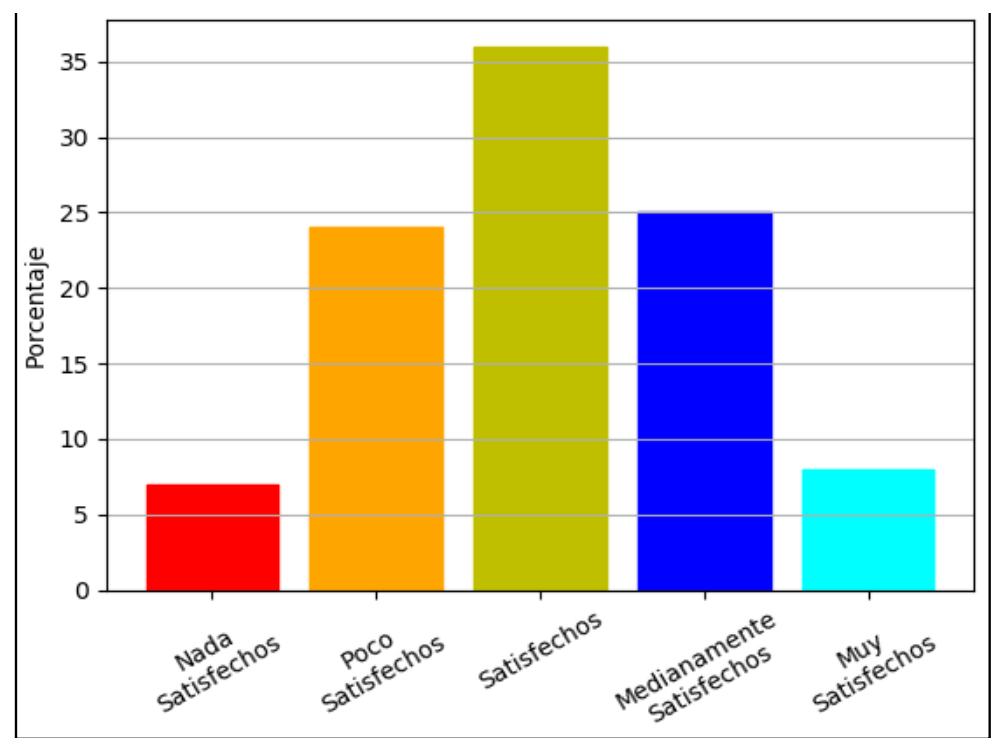

El criterio de los encuestados refleja que los habitantes de la comuna Libertador Bolívar deben preocuparse por mejorar los servicios brindados al turística y potenciar este segmento de mercado, armar paquetes turísticos con el aprovechamiento de los recursos que tiene el sector; además de servicios adicionales para lograr una fidelidad en el usuario. 
Figura 16. Días promedios de permanencia

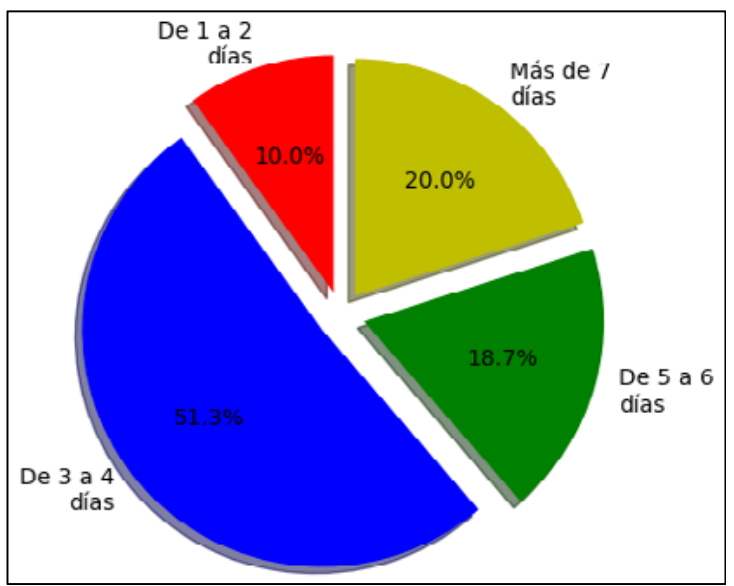

El tiempo de permanencia para un turista que gusta de relajación y descanso, está determinado entre 3 y 4 días; planteando por tanto, la necesidad de armar propuestas que incluyan paquetes turísticos con estas referencias y dar una mejor cobertura, ofreciendo tiempos de calidad y plenitud al visitante nacional y extranjero.

\section{Conclusiones}

- La investigación permite identificar con mayor claridad el contexto de las dos variables estudiadas: Responsabilidad Social Empresarial y Emprendimientos Comunitarios, saber el itinerario marcado desde que surgen estas tendencias hasta los actuales momentos y cómo interfieren en los resultados sociales y económicos de una comunidad nacional o extranjera. En el caso particular de Ecuador y específicamente la provincia de Santa Elena, los emprendimientos comunitarios liderados por mujeres ganan preferencia de turistas extranjeros en relación a otros sectores del país. Para la comuna Libertador Bolívar, las bondades naturales como playa, mar, clima, flora, fauna, geografía idónea; y, los recursos generados por los propios habitantes, cultivos diversos, artesanías, museos, actividades recreativas, culturales y otras contribuyen a generar ingresos sustentables.

- El compromiso o deber que tienen las empresas con la sociedad que los acoge cuando deciden ofertar sus bienes o servicios, no culmina con una labor social o filantropía, incluso no solo es esforzarse por el cliente externo, sino que a partir del ejercicio cotidiano de la Responsabilidad Social, sus elementos deben visibilizarse también con los clientes internos. Los resultados de esta investigación en los emprendimientos comunitarios, llevan a identificar que la tendencia de los 3 elementos de la responsabilidad social empresarial (alcance, impacto e indicadores) las mantienen en sus gestiones, tomando en cuenta siempre a la sociedad o sector donde habitan. Separando el elemento 
Indicadores, se resalta que las acciones están siempre alineadas al Producto/ Servicio ecológico; seguido de Compromisos con la comunidad y de Responsabilidad con cliente interno/externo.

- El género femenino paulatinamente ha ganado espacios en el campo empresarial y en los negocios, dejando de lado creencias, ideologías, tendencias y más estereotipos que limitan en otros contextos. La participación de la mujer, por ser parte integrante de los sectores vulnerables contribuye en mejorar sus condiciones de vida y de sus familias, consiguiendo además resultados favorables para las economías, particularmente en nuestra región, provincia de Santa Elena - Ecuador a pesar de las restricciones como el nivel de educación y estado civil. La realidad social hace que las mujeres busquen las formas de dar sustento a sus hogares sin tener que movilizarse, realizando adecuaciones en sus hogares a fin de ofrecer servicios de alojamiento comunitario a los turistas. Muy probablemente sus domicilios han sido producto de herencias familiares en relación al rango de edades en las que prevalece la actividad emprendedora. Los clientes que hacen uso de los servicios de hospedaje son con mayor frecuencia los extranjeros de nacionalidad estadounidense.

- Los resultados obtenidos en el trabajo de campo detectan algunas necesidades de los turistas y emprendedoras comunitarias para mejorar los servicios de alojamiento, proponiendo por ello, algunas acciones o estrategias como: nuevas adecuaciones ecológicas según los recursos disponibles en el sitio y sectores aledaños; ampliación de servicios brindados a través de itinerarios de paquetes turísticos con recorridos a sitios cercanos para mejorar las economías de otros pobladores; establecer alianzas estratégicas para incorporar servicios de transporte interno y externo con choferes que dominen el idioma inglés; adicionalmente, la implementación de herramientas o plataformas tecnológicas, vital por el segmento de mercado al que pertenecen. 


\section{Referencias}

Arce Castro, B. (2010). Características que distinguen a las Pequeñas y Medianas Empresas. México: Pearson

Canessa, G. y García, E. (2005). El ABC de la Responsabilidad Social Empresarial en el Perú y en el Mundo. Perú: Biblioteca Nacional.

Centro de Documentación Turística - CEDOC (1996). Las mujeres y el mercado laboral del sector turismo. Recuperado de https://cedocvirtual.sectur.gob.mx/ janium/Documentos/003414Pri0000.pdf. Consultado en: 20 de Octubre del 2019.

Grupo Viajar (13 de Junio de 2018). "Cerca de un millón de extranjeros arribaron al país”. Diario El Comercio. Recuperado de: https://www.elcomercio.com/viajar/ cerca-millon-extranjeros-arribaron-ecuador.html

Edición LATAM (2018). "Ecuador registra cifras récord de turismo internacional en 2018". Recuperado de: https://www.hosteltur.com/lat/114060_ecuador-registra-cifras-record-turismo-internacional-2018.html

España, Fundación Bertelsmann (2007). Emprendimiento Social Juvenil, 18 Buenas Prácticas. Recuperado de https://www.observatoritercersector.org/Portals/13/Publicacions/Llibres/16.\%20Emprendimiento_Social_Juvenil.pdf?ver $=2018-01-10-120346-680$

Fxtrader. (2010). ¿Qué es el emprendimiento social?. Emprendices. [Blog en línea] Recuperado de www.emprendices.co/que-es-el-emprendimiento-social/

Global Entrepreheurship Monitor - GEM, capítulo Ecuador (2017)

Herrera Meza, B. (Agosto de 2014), Participación de la Mujer y la innovación en los negocios. Desarrollo Humano y Responsabilidad Social. Simposio llevado a cabo en el II Encuentro de Investigación en Ciencias Económicas, Administrativas y Contables, Bogotá, Colombia.

Las Kellys. (2016). Trabajo Turístico y Mujeres. Obtenido de Asociación Las Kellys: https://laskellys.org/2016/07/26/trabajo-turistico-y-mujeres/

Ministerio de Turismo de Ecuador (2017). Industria turística del país se familiariza con la herramienta turismo en cifras. Recuperado de https:/www.turismo.gob.ec/ industria-turistica-del-pais-se-familiariza-con-la-herramienta-turismo-en-cifras/

Ministerio de Turismo de Ecuador (2019). Movimientos Internacionales, Cifras de llegadas y salidas de viajeros internacionales en el Ecuador. Recuperado de https:// servicios.turismo.gob.ec/index.php/turismo-cifras/2018-09-19-17-01-51/movimientos-internacionales 
Molina, W. (2 de Septiembre, 2017). "El turismo familiar motiva a comuna Libertador Bolívar". Diario El Telégrafo. Recuperado de: https://www.eltelegrafo.com. $\overline{\mathrm{ec} / \text { noticias/guayas/1/el-turismo-familiar-motiva-a-comuna-libertador-bolivar }}$

Núñez Guale, L. (2012), La Unidad de Emprendimiento y el fortalecimiento de la Cultura Emprendedora, en los estudiantes de la Escuela de Ingeniería Comercial, de la Universidad Estatal Península de Santa Elena, en el año 2010, (Tesis de postgrado inédita) Universidad Estatal de Bolívar, Guaranda, Ecuador.

Opeturmo. (20 de julio del 2018). Comuna Libertador Bolivar - Santa Elena Ecuador [Mensaje en un Blog]. Recuperado de: https://opeturmo.com/blog/ es/2018/07/20/566/. Consultado en: 16 de Octubre del 2019.

Organización de Naciones Unidas - ONU MUJERES. (2011). Principios para el empoderamiento de las mujeres. Compact, United Nations Global.

Pesantes, E. (19 de Noviembre, 2016). “UUn gran sábado amigos! En el \#AmanecerEC de hoy llegamos a Playa Bruja, en Santa Elena. Como ven, un gran lugar para vivir aventuras." Diario El Comercio. [Publicación en Twitter]. Recuperado de: https://twitter.com/elcomerciocom/status/799975525112496132

Puterman Szomstein, P. (Noviembre de 2010). Implicaciones de ISO 26000. Otro Mundo es posible. Recuperado de http://www.otromundoesposible.net/habemus-norma-iso-26000/

Rodríguez Valencia, J. (1996). Cómo Administrar Pequeñas y Medianas Empresas. $4^{\circ}$ Edición. México: Thomson Editores.

Sanchez, M. (Abril, 2016). “Fresco y delicioso...”. Re: La Caída del Sol. [Comentario en TripAdvisor]. Recuperado de: https://www.tripadvisor.co/Restaurant_Review-g635730-d8503850-Reviews-La_Caida_Del_Sol-Puerto_Lopez_Manabi_Province.html\#photos;aggregationId=\&albumid=\&filter=2\&ff=180845540

Sparrer, M. (2003). Género y Turismo Rural. El ejemplo de la Costa Coruñesa. Revistas Científicas Españolas FECYT.

Valle, C. (2018). INEC, Atlas de Género. Recuperado de http://www.ecuadorencifras.gob.ec/documentos/web-inec/Bibliotecas/Libros/Atlas_de_Genero_Final. pdf

Vinueza, G. (2010). Definiciones de Emprendimiento. Recuperado de http://es.scribd. com/doc/44363666/Deber-Defeniciones-de-Emprendimiento

Viteri, D., Peñaherrera, P., \& Vinueza, J. (2017). La equidad de Género como parte de la Responsabilidad Social en el Mercado Laboral de la Industria Turística del Ecuador. Revista Iberoamericana de Estratégia, 23 - 36. Obtenido de http://www.redalyc. org/pdf/3312/331253804003.pdf

Vives A., Corral, A. e Isusi, I. (2005). Tendencias de la Responsabilidad Social en Argentina. Argentina: Universidad Católica de Córdoba. 
Universidad Técnica de Machala

Ediciones UTMACH

Primera edición en español 2020

PDF interactivo 



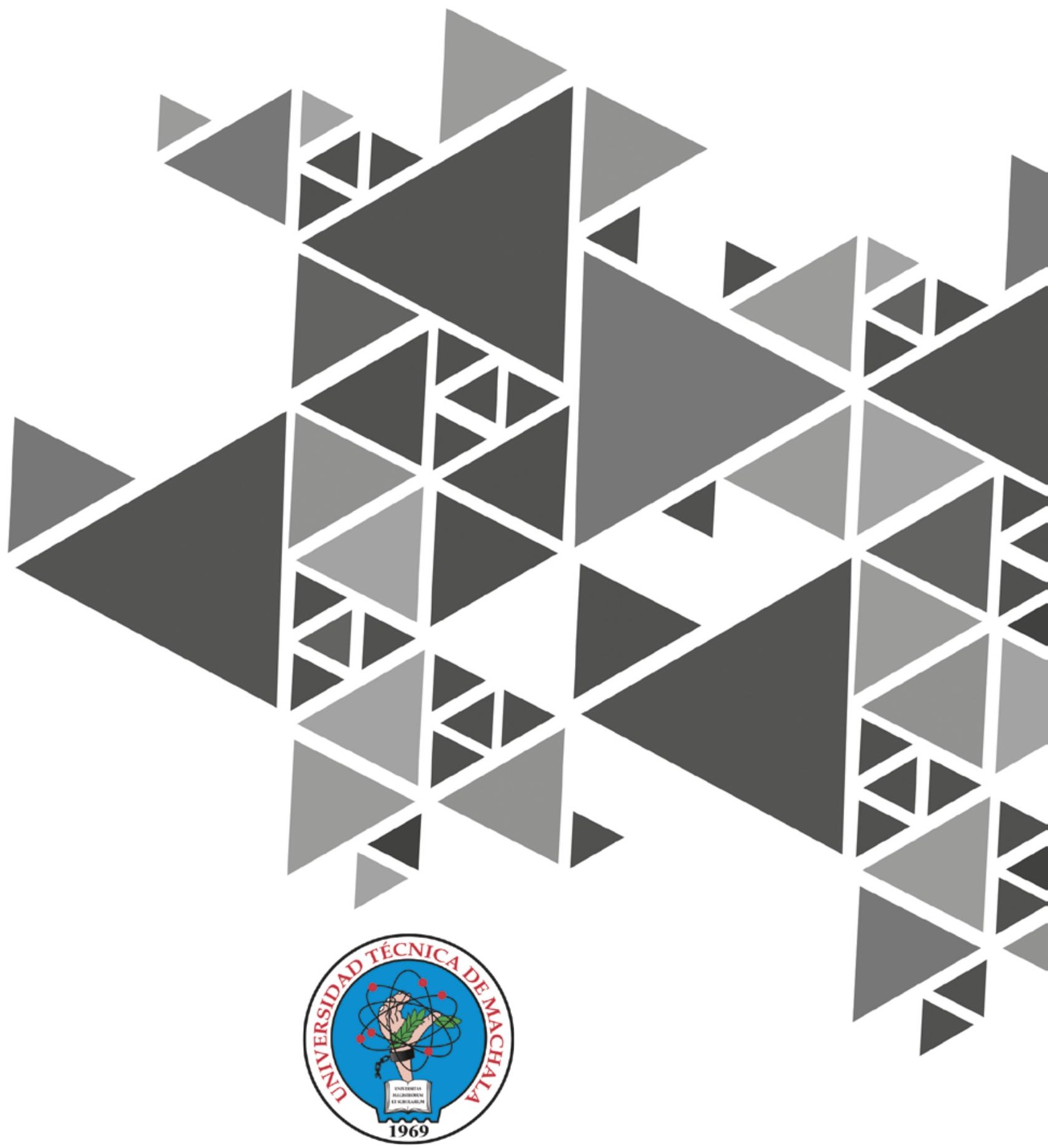

Universidad Técnica de Machala

Dirección de Investigación 